

\section{NOTICE}

This unit was prepared as an account of work sponsored by the United States Government. Neither the United States nor the United States Department of Energy, inor any of their employees, nor any of their contractors, subcontractors, or their employees, makes any warranty, express or implied, or assumes any legal liability or responsibility for the accuracy, completeness, or usefulness of any information, apparatus, product, or process disclosed, or represents that its use would not infringe privately owned rights. Reference herein to any specific commercial product, process, or service by trade name, mark, manufacturer, or otherwilse, does not necessarily constitute or imply its endorsement, recommendation, or favoring by the United States Government or any agency thereof. The views and opinions of authors expressed herein do not necessarily state or reflect those of the United States Government or any agency thereof.

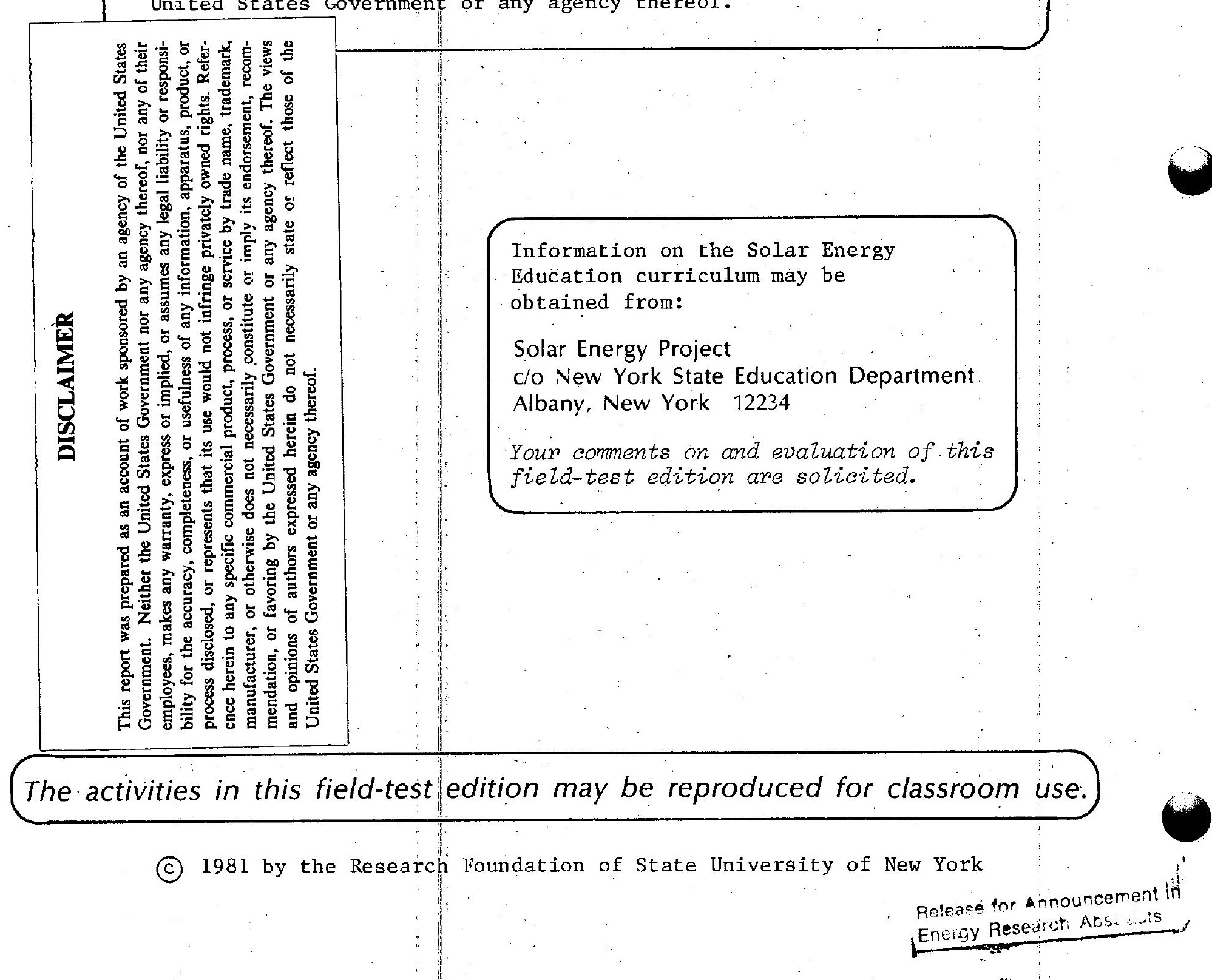




\section{The Solar Energy Education Curriculum}

The booklet in your hands is just one part of a series.

The Solar Energy Education materials include

S Solar Energy Text,

a Solar Energy Reader in four parts:

Energy, Society, and the Sun (general),

Sun Story (history and literature),

Solar Solutions (practical applications), and

Sun Schooling (classroom-oriented readings),

Solar Energy Education Activities for

Science,

Industrial Arts,

Home Economics,

Social Studies, and

Humanities (Art, Music, and English), and

Solar Energy Education Teacher's Guides

to accompany the above activity booklets.

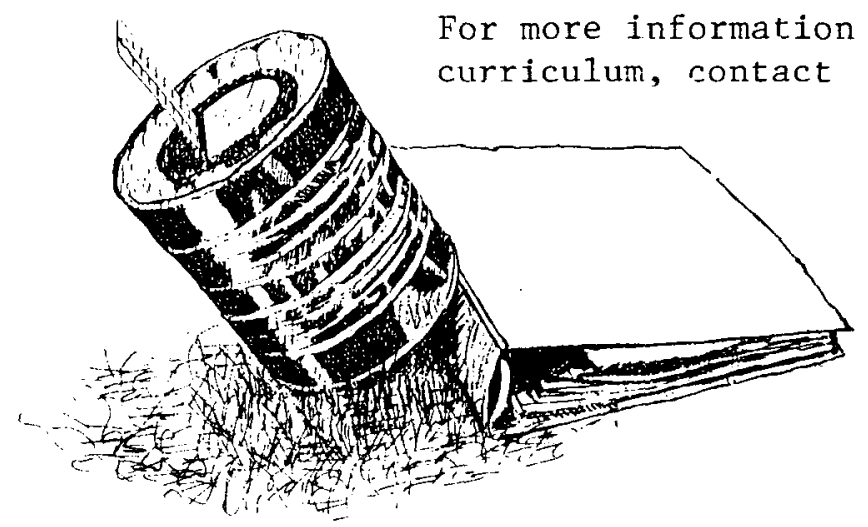

Solar Energy Project c/o Curriculum Services New York State Education Department Albany, New York 12234 
Staff

Thomas Boehm

Project Director

RoseAnne Fogarty

Publications Coordinator

Carolyn Graham

Field-test Coordinator

David Colon

Graphic Artist

Karen Blaustein

Administrative Assistant

Lisa Rice

Administrative Assistant

Lesa Schissler

Secretary/Layout

EZzen Altschuler

Typist/Proofing

Margaret Hasselwander

Typist/Proofing

Ecward T. Lalor

Douglas S. Reynolds

John V. Favitta

Project Advisers

\section{Acknowledgements}

While many individuals and organizations have contributed to this home economics solar curriculum, we would like to acknowledge especially the following:

The New York State Education Department's Division of Curriculum Services, Bureau of Science Education, and Bureau of Home Economics

The SUNY Atmospheric Sciences Research Center Volker Mohnen, Director, and Ronald Stewart, Associate Director

The participating teachers

Jeanne Ortiz

Nanoy Marks

Betty Buezz

Cynthia Theiss

Marilyn Stevens

Consultant - Lil Clirard

Reader - Al Sholtes 


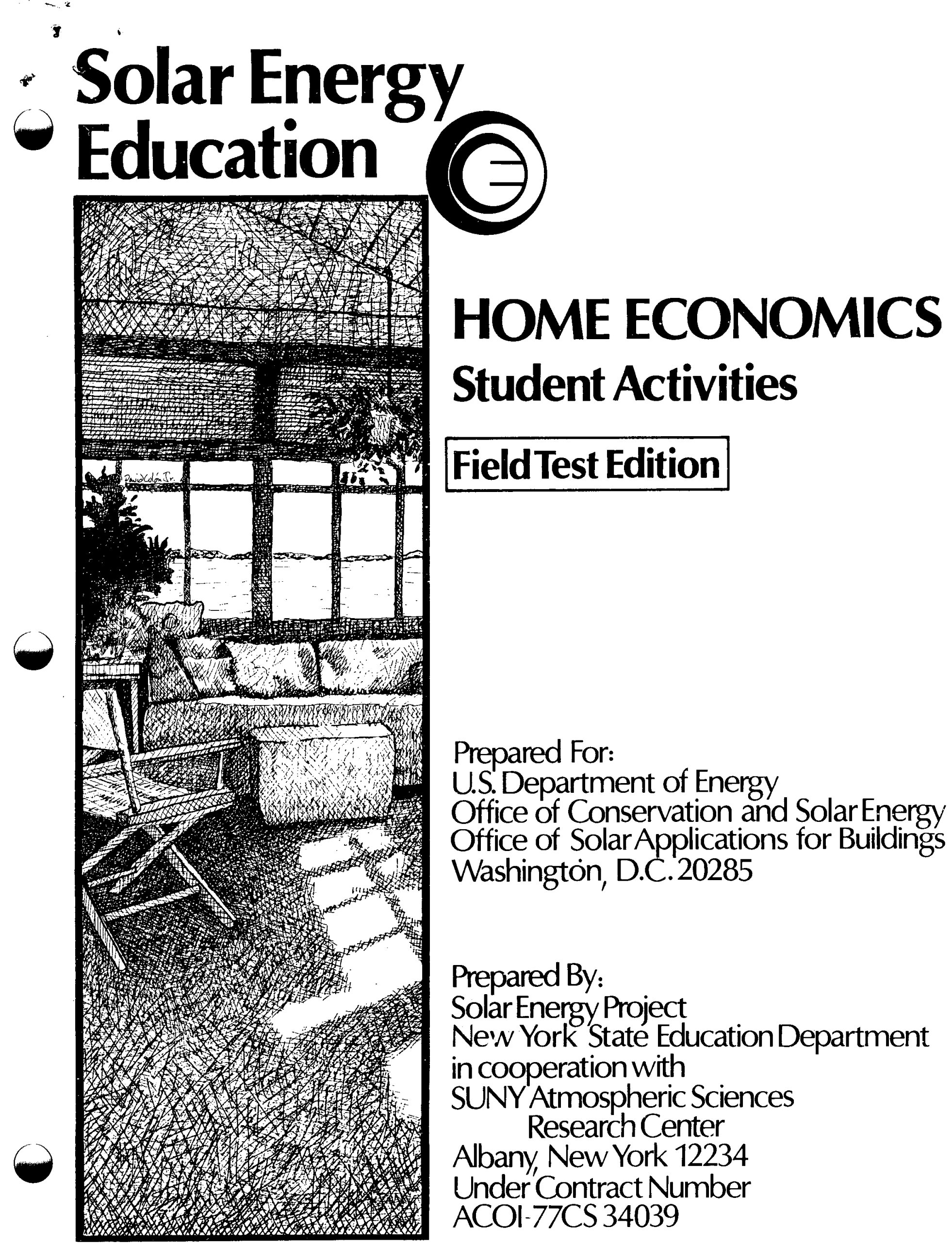




\section{To the Teacher}

\section{Using the Activities}

The activities in this booklet are written for student use. Worksheets and other pages requiring duplication in large numbers are placed separately at the end of each activity and are marked with a gray square for ease in locating them.

A teacher information section follows each activity and contains suggestions for implementing the activity in the classroom. This section is identified by a gray strip along the sides of the pages.

Additional information on using the activities is provided in the accompanying Home Economics Teacher's Guide.

\section{Field-Test Evaluation}

The Solar Energy Project actively seeks your comments on and evaluation of this field-test edition, as well as the comments and evaluations of your students. We invite you to send us any original activities you may have written. Any activities received will be considered for inclusion in the revised edition.

Suggestions and inquiries may be sent to

Solar Energy Project

c/o New York State Education Department

Albany, New York 12234 


\section{TABLE OF CONTENTS}

Page

Activity 1

The Appliance Explosion 1-1

Teacher Information 1-11

Activity 2

A Short Solar History $2-1$

Teacher Information 2-9

Activity 3

Drying Foods with Solar Energy 3-1

Teacher Information 3-9

Activity 4

Preparing Foods Sunny-side Up 4-1

Teacher Information 4-11

Activity 5

Catch a Sunbeam

A Game for Young Children 5-1

Teacher Information 5-7

Activity 6

Sunny the Solar Snake 6-1

Teacher Information 6-7

Activity 7

Living with Alternative Energy $7-1$

Teacher Information 7-9

Activity 8

Buying Solar Without Getting Burned 8-1

Teacher Information 8-9

Activity 9

Living with Solar Energy:

Clothing's Role 9-1

Teacher Information 9-7

Activity $\quad 10$

Window Coverings for Solar Energy $10-1$

Teacher Information 10-13 


\section{The Appliance Explosion}

\section{Introduction}

Approximately twenty percent of the energy used in the United States is consumed in the home. Energy is used in many ways: to heat, cool, and

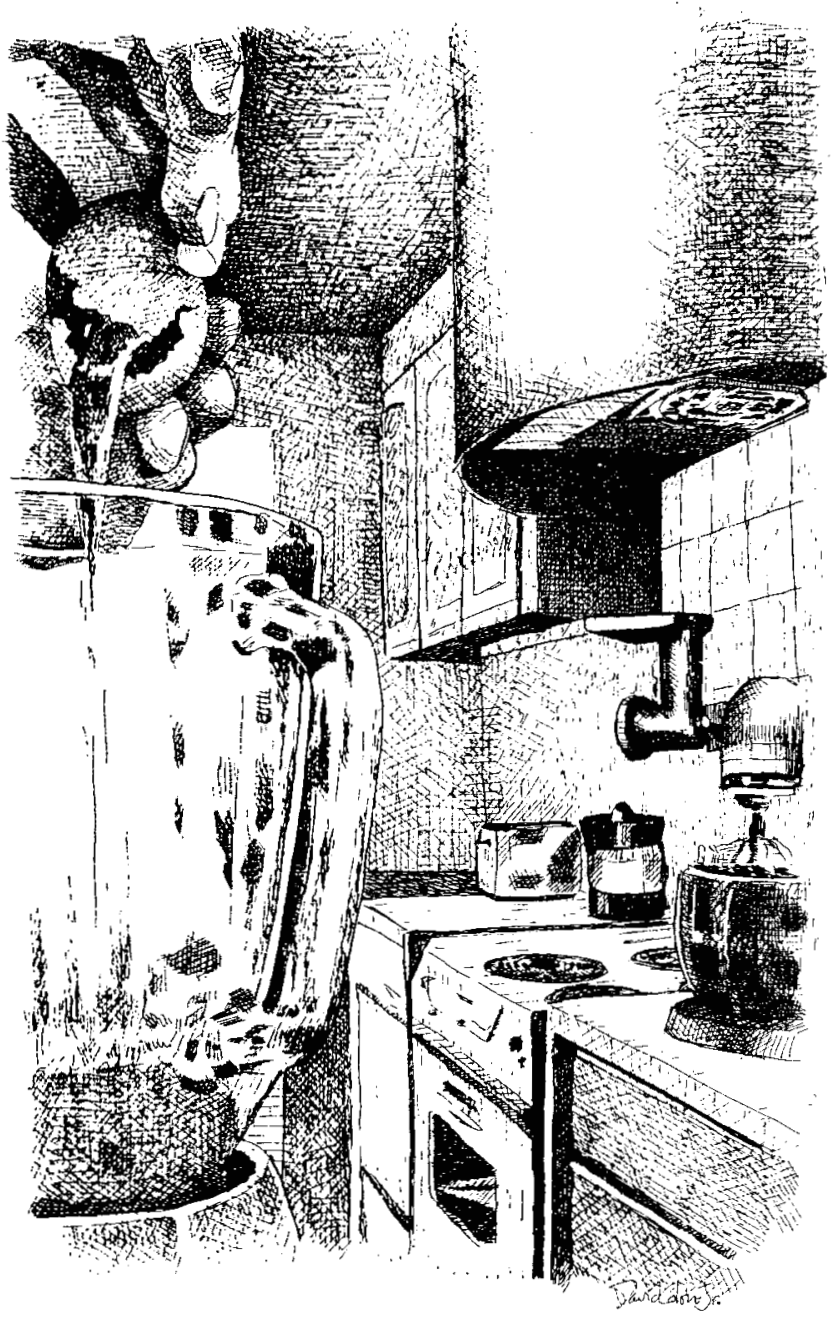
light your rooms; to heat water; to refrigerate and cook your food; to wash and dry your clothes; to entertain you; and to aid in personal care.

How many appliances do you have in your home? Can you even guess at the number? Do you know where the energy that runs these appliances originates?

Most of this energy comes from fossil fuels, either oil or natural gas, burned in your home by your furnace or hot water heater. The energy consumed in the home may also be produced from oil or coal burned at a power plant to produce electricity. In a few locations, energy may originate from hydropower or nuclear power plants that also produce electricity.

In this activity, you will discover the number and kinds of appliances you have in your home. You will compare this information with the appliances an adult had in his/her home a generation ago. Your results should help you understand the important role that energy plays in your life, and why energy demand has increased so much in the last twenty years. 


\section{Objectives}

At the completion of this activity, you should be able to

- conduct a survey of appliance use,

- identify the appliances used in the home today and one generation ago,

- explain why the number of appliances used today differs greatly from the number used by adults when they were children,

o Iist appliances that could be eliminated from the home in an attempt to conserve energy, and

o construct a bar graph to show changes in appliance use over a period of time.

\section{Skills and Knowledge You Need}

How to do basic arithmetic

How to construct a bar graph

How to set up a display

\section{Materials and Equipment}

Home Appliance Survey

Typical House Floor Plan sheet

Construction paper and materials for an appliance use display

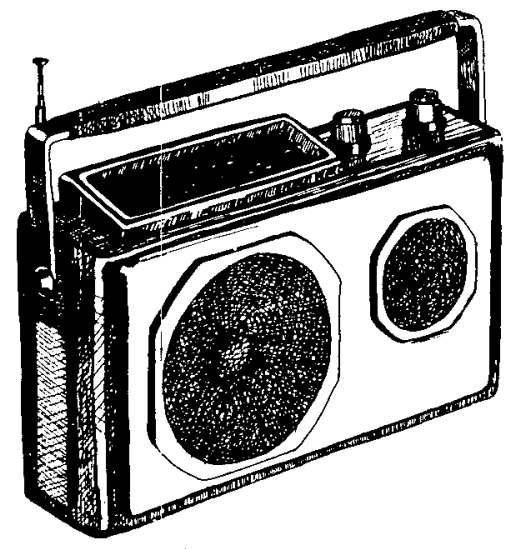

Home Appliance Use sheet

\section{Procedure}

1. Scan the list of appliances on the Home Appliance Survey. If you are not familiar with some of the appliances, consult your teacher or look them up in a store catalog. 
2. Take the survey home. Under Column 1 , record the number of each kind of appliance you have in your home.

a. For example:

Doughnut Maker Radio, Clock

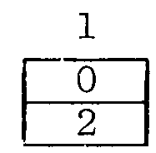

b. Be sure to check for appliances in each room, in closets, and even areas outside the home, such as the patio or carport.

c. Add any appliances not on the list to the blank space that is labeled "Other Appliances".

3. Now ask one of your parents or another adult to complete the survey.

a. The adult should complete the survey in Column 2 .

b. The adult should complete the survey by listing the appliances found in his/her home when he/ she was the age you are now.

c. Record the year that the adult was your age.

4. Total the number of appliances in Column 1 and then in Column 2 .

5. Using the Typical House Floor Plan sheet, place the name and number of each appliance you found in your home in the room where it was located. For example, on the floor plan of the kitchen area, write the words "refrigerator - 1 ".

6. Using a second floor plan sheet, ask the same adult to write the name and number of appliances he/she indicated on the survey in the room where the appliance would have been located.

7. Several students in the class should create a bulletin board for the classroom or display area. Some title suggestions are

Appliances of Yesterday and Today

Home Energy Use -- Past, Present, and Future?

Conserve or Accumulate? 
The bulletin board should have two large floor plans of a house like the smaller floor plans that students and adults have completed.

8. On one of the larger floor plans, students should record the kinds and numbers of appliances that were found in the students' homes during the survey. Each appliance should be listed in the room where it was located.

For example:

On the kitchen area of the large floor plan, students should write

Mixer, Electric 21

Diagram 1

Sample Bulletin Board

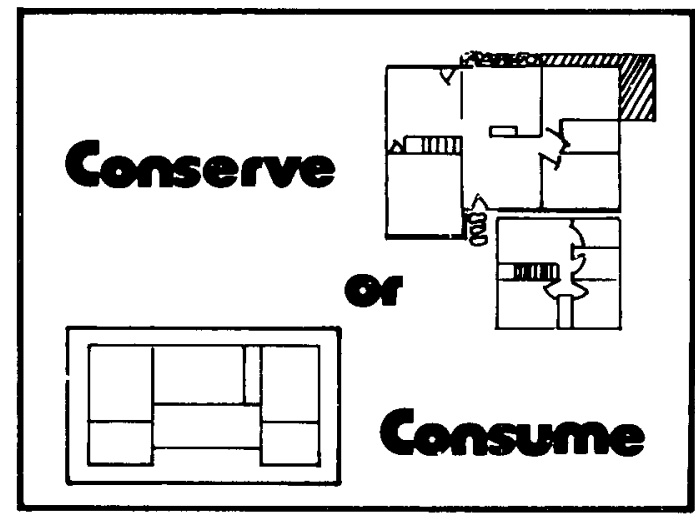

to indicate that 21 students found an electric mixer in their kitchens.

9. Using the second large floor plan, students should record the numbers and kinds of appliances listed by the adults who completed the appliance survey.

10. Using the results of Steps 8 and 9 , complete the sheet on graphing home appliance use. Select 10 kinds of appliances to graph.

11. Construct a bar graph which compares the numbers of appliances for class members with the numbers of appliances owned by the adults at a corresponding age. Your bar graph might resemble this.

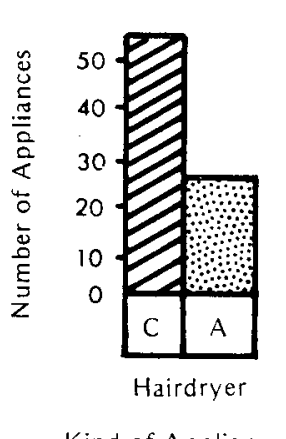

Diagram 2

Kind of Appliance

\section{Questions}

1. How does the total number of appliances you use today differ from the number of appliances used by an adult when he/she was the age you are now? 
2. Why do you think the numbers differ so greatly? What kinds of changes have taken place to make this possible?

3. Make a list of the appliances which you simply could not live without and another list of the ones which you feel you could eliminate from your home. Why did you decide the way you did?

4. Which appliances were found in the homes of today which were not in the homes of people one generation ago? How do you feel people managed without these appliances?

5. Solar energy is also a possible fuel source. Can you think of some ways solar energy could replace or reduce the fossil fuel energy used by appliances in your home?

\section{Looking Back}

Were you surprised by how many appliances your home has? When you compare this number with how many an adult had in his/ her home a generation ago, it should help you understand how much the demand for energy has grown.

But the United States now faces a continuing "energy shortage". Perhaps you can begin to think of ways to conserve energy at home by reducing or eliminating nonessential appliance use.

\section{Going Further}

Trace appliance use back one more generation. Have a grandparent or older adult fill out the survey. Find the total number of appliances used. Compare this to your totals for a younger adult and for your own home. Tabulate class frequencies if data are available.

With your family's agreement, plan ways to reduce both the number of appliances and the length of time appliances are used. Then implement this plan from one utility meter reading to the next. Was your family able to reduce the amount of energy consumed?

Keep a daily log of the number of ways you use energy from the time you get up until the time you go to class. Can you reduce this energy use? How? 
Research information on the new appliance labeling requirements for energy conservation. Visit an appliance store or invite a guest to speak on this topic.

Create a floor plan for the home of the future and in each room list the appliances you predict you will own twenty-five years from now. Do you notice any changes?

Invite other classes, parents, and friends to view the display and observe the types and numbers of appliances that were used in the homes of the students and adults who completed the survey. This display could be an FHA/HERO project for a local or district chapter. 
Directions: In Column 1, write the number of each kind of appliance you have in your home. Then have an adult fill in Column 2 for when he/she was your age. Total the number of appliances listed for each column.

Air Conditioner, Central. Air Conditioner, Home Unit(s) Automatic Bag Sealer, Electric Automatic Egg Cooker Automatic Timer, 24 hour Battery Charger, Electric Baby Bottle Waraer Beanpot, Electric Blanket, Electric Blender

Broiler, Electric, Portable Broom, Electric Bun Warmer, Electric Calculator with adaptor Can Opener, Electric Coffeemaker, Electric Comb, Electric

Cookie Maker, Electric Clock, Electric

Crepe Maker

Defroster for Refrigerator Dehumidifier

Dishwasher

Disposer, Food Waste

Door Bell, Electric

Doughnut Maker

Drill, Electric

Dryer, Clothes (Electric/Gas)

Fan, Electric

Fingernail Buffer, Electric

Floor Waxer

Fondue Pot, Electric

Food Dryer, Dehydrator

Food Processor

Food Slicer, Electric

Food Warmer Tray

Foot Whirlpool, Electric

Freezer, Independent Unit

Fryer, Deep Fat, Electric

Erypan, Electric

Furnace, (Electric/Oi1/Gas/Wood)

Garage Door, Electric

Griddle, Electric

Gril1, Outdoor (Electric/Gas)

Guitar, Electric

Hairbrush, Electric

Haircurlers, Electric

Hair Curling Iron, Electric

Hair Dryer, Standing/Portable/ Blower

Hamburger Maker, Electric

Heater, Room,Electric

Heating Pad

Hedge Trimmers, Electric

Hot Dog Cooker, Electric

Hot Pot, Electric

Humidifier

Ice Cream Maker, Electric

Ice Crusher, Electric

Intercom

Iron, Regular or Steam

Other

Subtotal

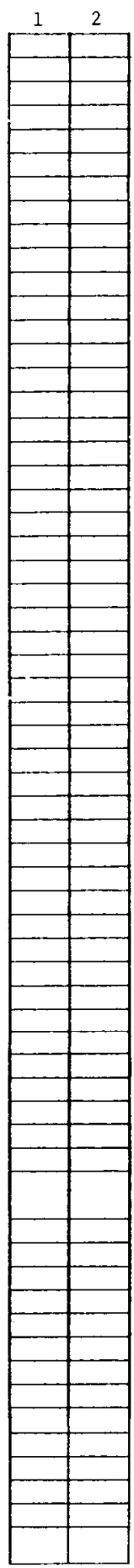

Kiln, Ceramic, Electric

Knife, Electric

Knife Sharpener, Electric

Lamps, Standard

Lamp, Heat

Lamp, Sun

Lawn Edger \& Trimmer, Electric

Lawnmower, Electric

Lights, Indoor Night or Ceiling

Lights, Outdoor Lawn

Manicure Set, Electric

Massager, Electric

Meat Grinder, Electric

Mirror, Lighted for Make-up

Nixer, Electric

Organ, Electric

Oven, Dutch, Electric

oven, Microwave

oven, Portable

Oven, Toaster

Peanut Butter Machine, Electric

Peeling Wand, Electric

Pencil Sharpener, Electric

Pizza Maker, Electric

Popcorn Popper, Electric

Portable Buffet Ranges, Electric

Projector, Movie

Projector, Slide

Radio, Clock

Radio, Standard

Range, Kitchen, Electric/Gas

Razor, Electric

Record Player

Refrigerator, Electric/Gas

Rotisserie

Router, Electric (Tool)

Rug Shampooer

Sander, Electric

Saw, Electric

Scissors, Electric

Sewing Machine

Shoe Polisher, Electric

Slow Cooker, Electric

Soldering Kit, Electric

Tape Recorder, Electric

Television

Thermostat (0i1/Gas)

Toaster

Toothbrush, Electric

Train Set, Electric

Typewriter, Electric

Vacuum Cleaner

Vaporizer

Waffle Iron

Washer, Clathes

Water Heater (Electric/Oi1/Gas)

Water Pik

Whirlpool, Electric

Wok, Electric

Woodburning Set, Electric

Yogurt Maker, Electric

Other

Subtotal

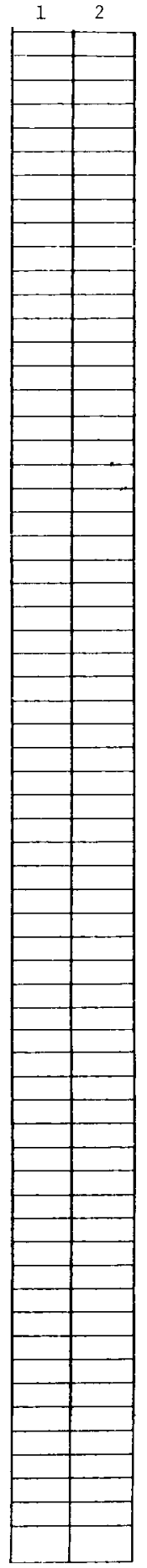

Total of Column

Total of Column 2 


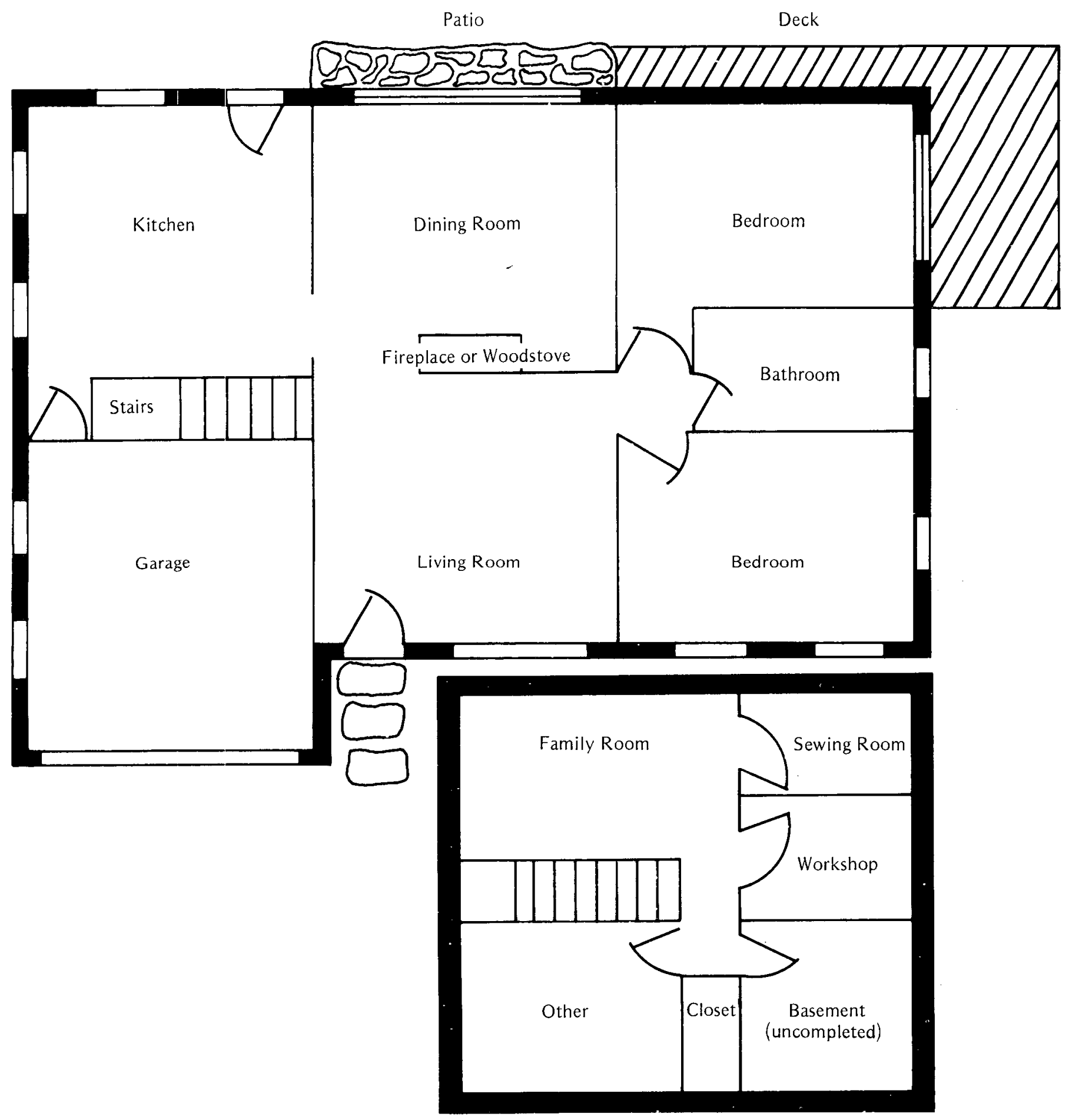




\section{DIRECTIONS :}

1. In the ten spaces at the bottom of the graph, write the names of ten different appliances.

2. Using the large floor plans on the class display, observe how many class members and adults owned each of the ten appliances.

3. Decide on what would be an appropriate number scale for "Number of Appliances" and fill in the numbers to make the scale.

4. Above each of the ten appliances, mark the number owned by class members and the number owned by adults. Draw bars to represent these numbers.

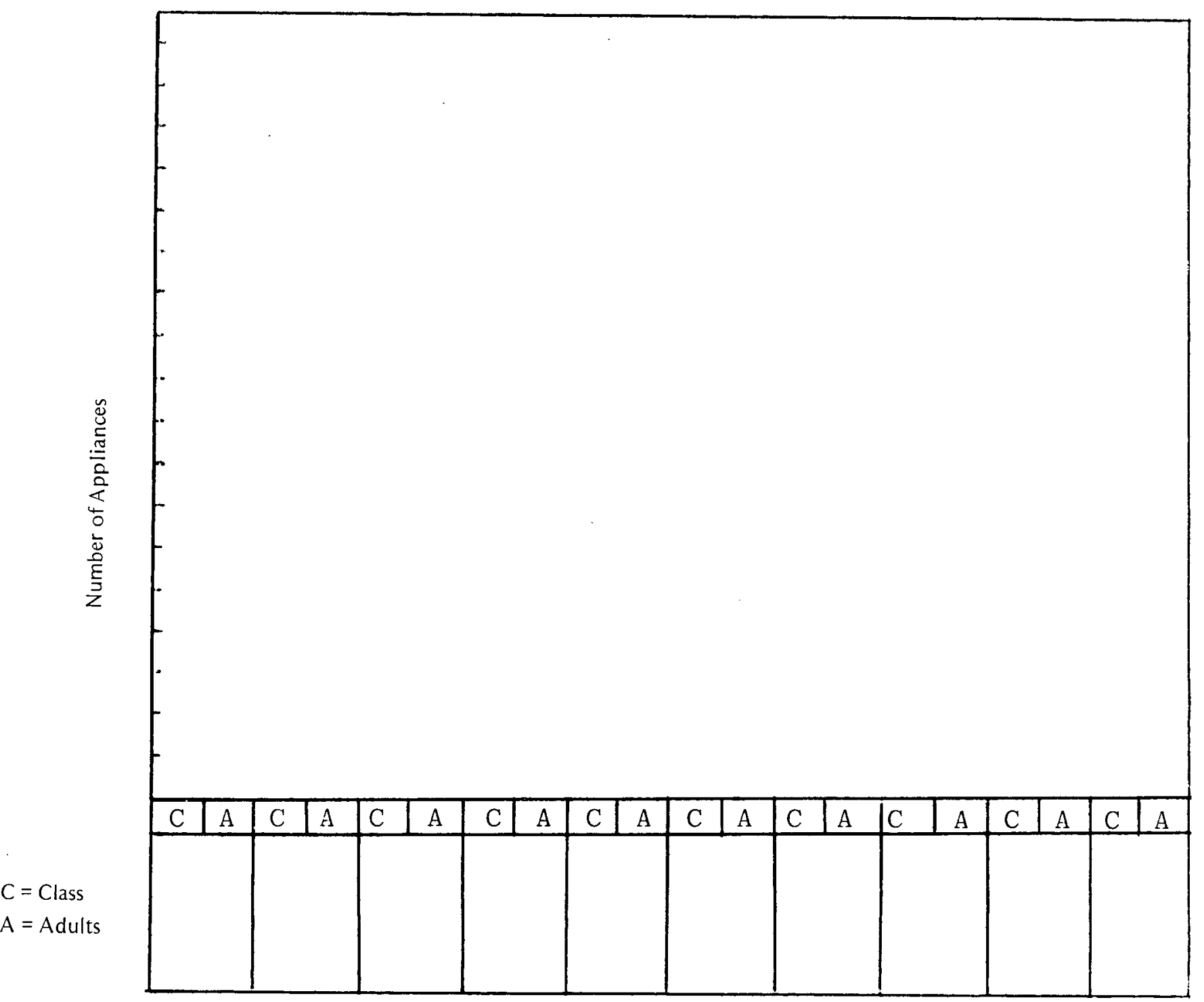




$$
1-10
$$




\section{Suggested Grade Level and Skill Area}

7-12 Home Economics

Future Homemakers of America

\section{Skill Objectives}

Conducting a survey

Collecting and recording data

Constructing a bar graph

Interpreting results

\section{Content Objectives}

Today's homes have many more appliances than the homes of a generation ago.

The kinds of appliances used today are different from the kinds used a generation ago.

One reason for this increase in appliance use was the ready availability of "cheap" energy between 1945 and the early 1970's.

There are appliances that are essential and others that are nonessential to the well-being of the family.

Increased use of solar energy can reduce reliance on fossil fuel and electrical energy in the home.

\section{Background}

Today the world faces an energy crisis. Ninety-five percent of the energy consumed in today's world comes from fossil fuels. But fossil fuel reserves are being used at a tremendous rate and new resources are not being discovered to keep pace. It is estimated that at current rates of use, our known reserves of petroleum will run out in thirty years and natural gas in twenty. Coal may last several hundred years more, but there are serious environmental problems associated with increased use of coal. Even uranium for nuclear fission is in short supply.

As a result, petroleum and natural gas have become much more expensive and people are recognizing the need to conserve, both to save money and to direct valuable resources to other needs. The United States, especially, has much room for conservation; six percent of the world's population consumes thirty percent of the world's resource production each year. 
Nineteen percent of United States energy is consumed in the home. of this, $11 \%$ is for space heating and $8 \%$ is for the operation of electrical appliances, including $3 \%$ for small appliances. When considered as a nation-wide total, residential energy consumption becomes a large factor, and conservation of home energy can lead to substantial reductions in energy use.

Table 1 shows the per capita increase in domestic energy consumption since 1950.

TABLE 1 - Domestic Consumption Per Capita

Year

Total energy consumed (barrels of oil equivalent)

\begin{tabular}{|l|c|}
\hline 1950 & 38.4 \\
1955 & 41.2 \\
1960 & 42.5 \\
1965 & 47.2 \\
1970 & 56.2 \\
1975 & 56.9 \\
\hline
\end{tabular}

Source: Bureau of Mines

Thirty percent of all electrical energy output is used in the home. Residential electrical energy use has been growing at an average rate of $2 \%$ per year over the last thirty years. It is easy to see that the rapid increase in home appliance use found in this activity has contributed substantialiy to this growth rate.

Over the past few years, much research has gone into finding and exploring alternative sources of energy. One of these is solar energy, which includes wind; water, and biomass conversion (for example, woodburning). The total amount of energy produced by the sun is tremendous, much more than we could possibly use. So the sun is being investigated as a potential source of unlimited, clean, and safe energy.

Table 2 indicates how energy use is distributed in the home. Replacement of the energy used in some of these functions by solar energy would result in substantial conservation of fossil fuel resources.

TABLE 2 - Residential Consumption of Energy

\begin{tabular}{|l|c|}
\hline Space Heating & $53 \%$ \\
Water Heating & 12 \\
Air Conditioning & 8 \\
Refrigeration & 7 \\
Lighting & 5 \\
Other Electrical & 5 \\
Cooking & 4 \\
Clothes Drying & 1 \\
Miscellaneous & 5 \\
\hline
\end{tabular}

Source: National Bureau of Standards 
The easiest and most obvious areas in which to utilize solar energy are space heating, water heating, and air conditioning, which make up a substantial proportion of the total. Solar water heating has been shown to be cost effective even in the northern states. Wood-burning stoves can provide an auxiliary means of space heating that is also cost effective at today's oil prices.

Replacement by solar energy of the fuels used to power electrical appliances and lights is not now an alternative, since photovoltaic cells, which convert solar energy directly to electricity, remain very expensive to produce. However, it is expected that their cost will fall substantially in the next few years with new techniques for manufacturing and mass production.

\title{
Advance Planning
}

\author{
One week in advance \\ review background information to prepare for class discussion, \\ duplicate survey, floor plans, and Home Appliance Use \\ sheet for distribution to students (each student should \\ receive two floor plans), \\ collect store catalogs for students to use to look up \\ appliances with which they are unfamiliar, and \\ collect materials for the Appliarice Use Display.
}

\section{Suggested Time Allotment}

One class period to present background information and to give the assignment on the survey and floor plans.

Two class periods to complete the individual and class floor plans. One class period to tabulate class frequencies and construct bar graphs.

One class period to discuss results of survey and class frequencies.

\section{Suggested Approach}

Discuss the background information with the class.

Explain how the activity will be carried out.

Have students carry out activity and collect data as a homework assignment. Data will include numbers of appliances owned by students and adults. 
Have an individual student or committee of students create the Appliance Use Display.

If necessary, give students instruction in constructing bar graphs.

Discuss the results and implications of the activity as a class.

It will be least confusing if the entire class tabulates class frequencies for the same appliances. A blackboard can be used to compile results. An alternative approach could be to assign different groups to tabulate different appliances. If this method is used, it would lessen confusion if student surveys were collected, copied, cut into sections, and then the sections distributed to the various groups for tabulation and construction of graphs. These graphs could then be displayed in the room.

\section{Precautions}

Some parents may regard this activity as an invasion of privacy. A statement to parents of the activity's purpose, along with permission slips to be signed by parerits, is suggested.

It may be necessary to give students several days to complete the assignment. The survey is long.

\section{Points for Discussion}

Is there a difference between the results for the students' homes and the results for the adults' homes? What are the causes of the differences?

Which appliances are listed most frequently by both students and adults? Which ones are listed least frequently?

What will happen in the future to energy supplies if energy use continues to increase in this way?

Use a brainstorming technique to discuss how solar energy can help reduce fossil fuel and electrical energy consumption in the home.

Which appliances do students consider essential? Which appliances are nonessential?

What are some of the reasons for this rapid increase in the number of appliances used in the home?

Discuss ways in which energy can be saved by judicious appliance use. 


\section{Typical Results}

Most students will find that they have at least twice as many appliances in their homes as people did a generation ago.

Results for class frequencies will vary depending on the appliance chosen and the number of students in the class.

\section{Evaluation}

Observe students' skill in carrying out the assignment, completing the survey, recording data, compiling statistics, and graphing and interpreting data.

Check the quality of students' answers to questions.

Ask students to group appliances into essential and nonessential categories. Have them explain the reasons for their choices.

\section{Modifications}

Students could keep a daily log for one week on the ways they have used energy from the time they get up in the morning until the time they go to class.

Analyze the number of kilowatt-hours used by various electrical appliances.

Give students an energy budget of a certain number of kilowatthours they can use daily and discuss how they would allot their budget. Also give them a table of average $\mathrm{kWh} /$ day use for various electrical appliances. Cut the students' daily allotment. Now how would they spend their energy budget?

\section{References}

Energy Conservation in the Home, The University of Tennessee Environmental Center \& College of Home Economics.

(U.S. Department of Energy, Technical Information Center, P.0. Box 62, Oak Ridge, TN 37830, 1977, free.)

547 Easy Ways to Save Energy in Your Home, Roger Albright. (Garden Way Publishing, Charlotte, VT 05445, 1978, \$4.95.)

The Household Energy Game, Thomas W. Smith and John Jenkins. (The University of Wisconsin, Sea Grant College Program, 1800 University Avenue, Madison, WI 53706, 1974, contact the Sea Grant College Program for price.) 
Ideas \& Activities for Teaching Energy Conservation (Grades 7-12), The University of Tennessee Environment Center. (Educational Media Center, Smyrna, TN 37167, 非0412, 1977, contact the Educational Media Center for price.)

Sun Power: Facts About Solar Energy, Steve J. Gadler and Wendy Adamson. (Lerner Publishing Co., 241 First Avenue, Minneapolis, MN 55401, 1978, \$6.95.)

"Energy Questionnaire". (Journal of Home Economics, American Home Economics Association, 2010 Massachusetts Avenue, NW, Washington, DC 20036, December, 1973, pp. 34-35.) 


\section{DRAPT}

\section{A Short Solar History}

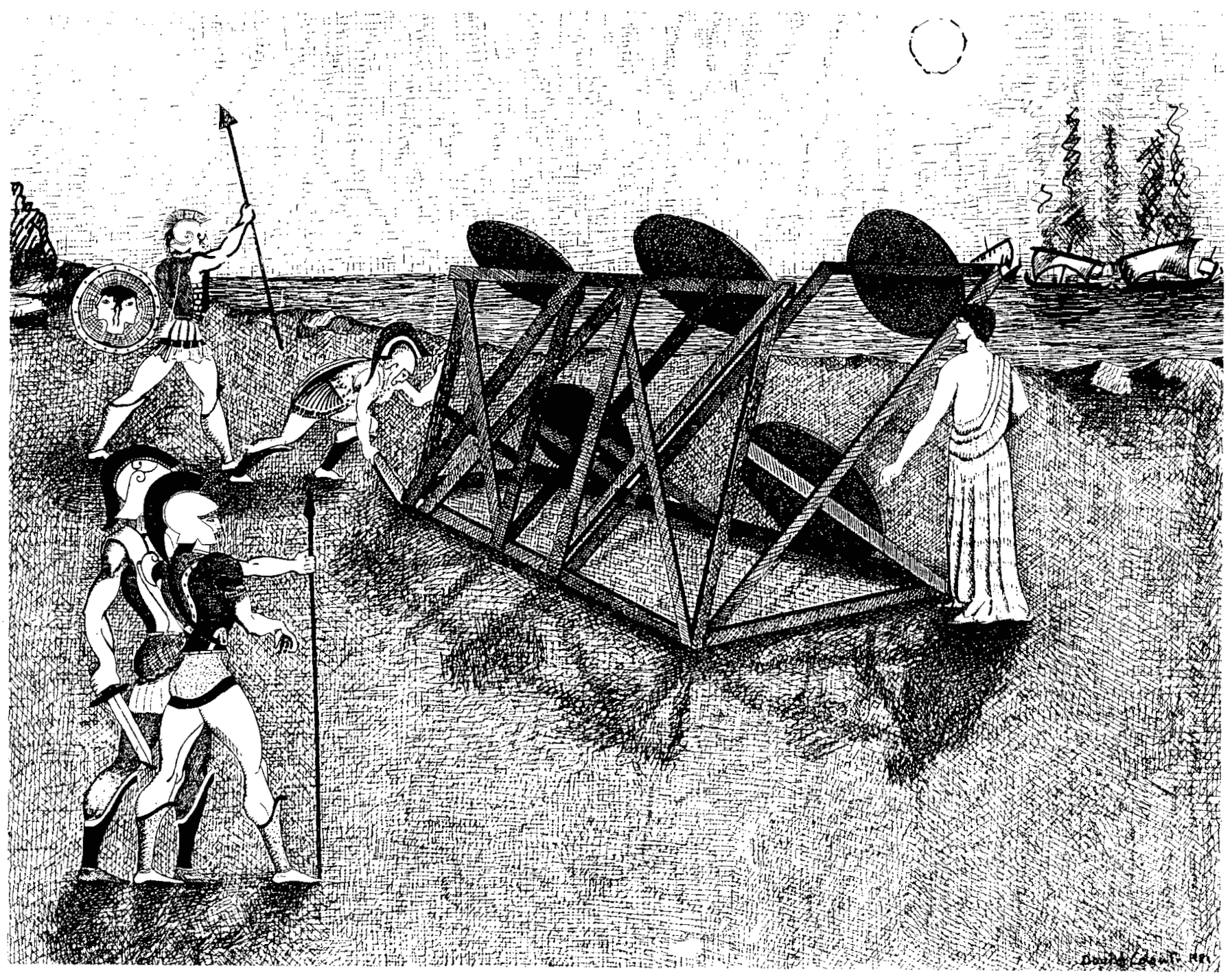

\section{Introduction}

Imagine yourself living a long time ago. If you had happened to discover a new way to use solar energy, how would it have changed the home you lived in, the foods you ate, or the clothing you wore?

This activity will give you a chance to look into the past to find out how solar energy affected the lives of people. You will also look at how solar energy is used today, as people again look to the sun as a source of energy. Future advances in solar energy will be very important; they may even determine the career you pursue or the home you live in. 


\section{Objectives}

At the completion of this activity, you should be able to

- construct a time line to express visually the advances in solar energy use throughout recorded history,

o recall examples of how solar energy was used to provide a more comfortable life for families,

o recall examples of how solar energy was used to do work, and

o determine ways solar energy is being used today.

\section{Skills and Knowledge You Need}

Constructing a time line

Understanding time in terms of centuries

\section{Materials and Equipment}
a roll of paper
markers or crayons
a meter stick

\section{Procedure}

1. Prepare a solar history time 1 ine in 100 year
intervals, from $500 \mathrm{BC}$ to $2000 \mathrm{AD}$, as follows.

a. Using a long roll of paper, brightly-colored markers, and a meter stick, mark off 26 equal divisions as shown. Leave enough space between each division to write information about solar energy .

\section{Diagram Time Line}

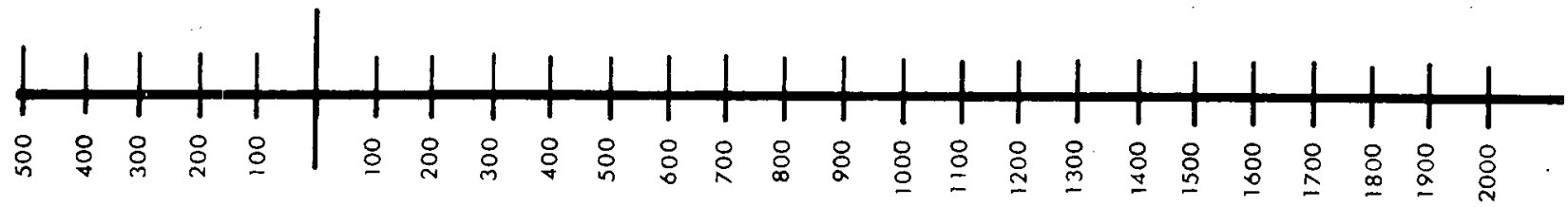

B.C.

b. Beside each division, write the year number as shown in the diagram.

c. Mark the present year with a brightly-colored star. 
2. Using the worksheet "A Brjef Look at Solar History", select advances in solar energy use and write them in the appropriate place on the time line.

3. Hang your time line in a visible location in your school, where many people will be able to learn about solar energy.

4. As you study solar energy, add new information to the time line. Be sure to include advances in solar energy use that are occurring this year and those which are planned for the future.

\section{Questions}

1. From the worksheet, select one advance in solar energy use. Think about the changes that occurred as a result of that advance. If you had been living then, how might the advance have affected your home or the way you lived?

2. In what ways has the sun's energy been used throughout human history to provide more comfortable shelter?

3. What forms of solar energy technology listed on the time line are still in use today?

4. During which 100-year interval was the largest number of advances in solar energy made?

5. Which of the solar energy advances do you think are the most important? Why?

\section{Looking Back}

Looking back through recorded history, we have found many ways in which people used solar energy. While some people used solar energy to make their work easier for them, others used it to provide more comfortable shelter.

If it were possible to look ahead 25 or 50 years, you would probably be surprised at the many new advances in solar technology. What effect do you think these advances will have on your life?

\section{Going Further}

Prepare a time line to be displayed in your community, for example, in a bank or post office lobby. 
On a wall chart, make two lists:

a. ways solar energy is already used in the school and at home, and

b. suggestions for utilizing solar energy in new ways at home and at school.

Using brightly-colored string and poster paper, make a large-scale time line for your school hallway. One meter, for example, could equal 100 years. Decorate your time line with photographs and/or drawings of solar energy use. 


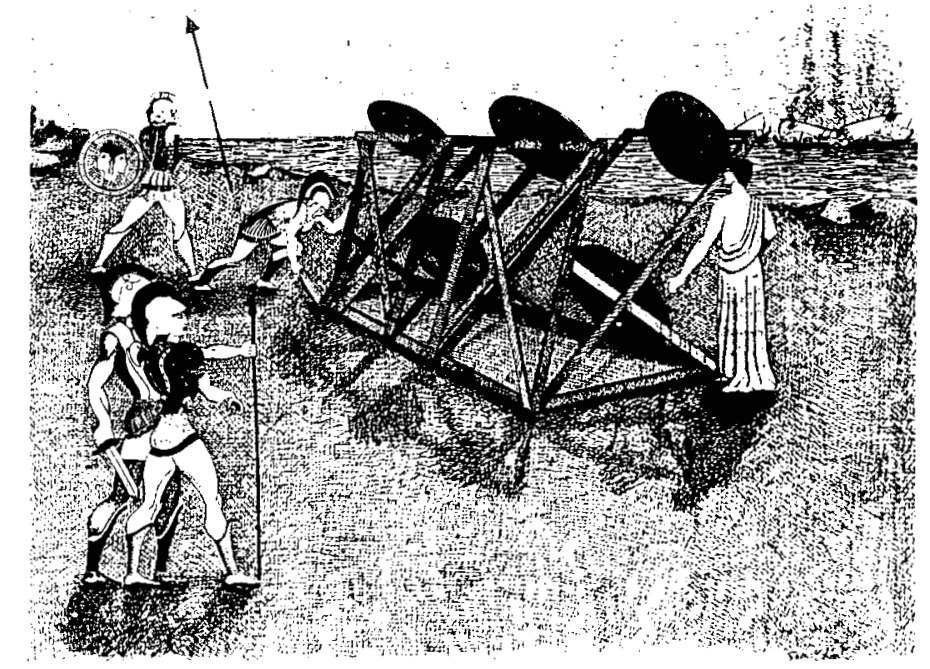

Archimedes' Legendary Burning of Enemy Ships
500 B.C.

The Greeks used sundials to chart the sun's daily and seasonal course. Homes were built to maximize the entrance of the winter sun into the main rooms and to shelter them from the cold north winds; overhanging roofs were used to shade homes from the summer sun.

$300-200$ B.C.

The Greeks described the use of "burning mirrors" -solar reflectors of curved, polished metal used to concentrate the sun's rays in order to ignite fires. According to legend, Archimedes used "burning mirrors" to set fire to enemy ships.

The Chinese used burning mirrors for religious purposes.

100 B.C.

The Romans invented the use of transparent (rather than colored) glass for windows. Transparent windows admit sunlight to a room and also trap heat inside. Solar greenhouses produced fruits and vegetables year-round. Solar energy helped heat public baths.

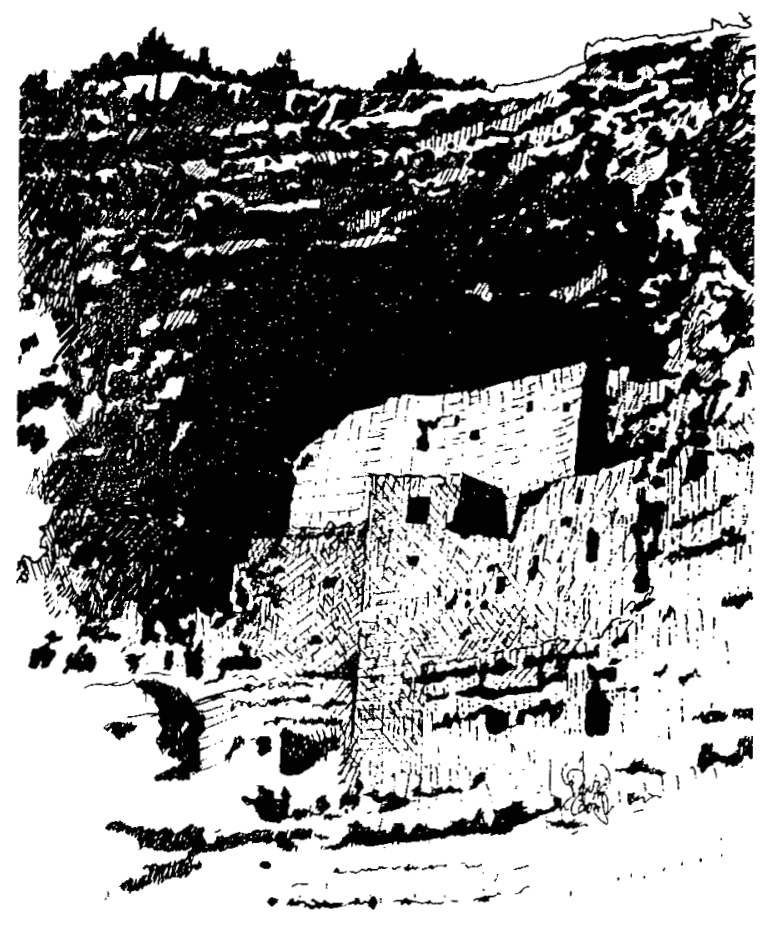

Early Cliff Dwellings From the American Southwest 1st - 6th Century A.D.

Wood became scarce in the Roman empire. The use of solar energy to heat residences and greenhouses was widespread. The first laws were written establishing the right of access to sunshine.

\section{$1100-1200$ A.D.}

The Pueblo Indians in southwestern North America built homes facing south, with thick adobe walls to absorb heat and to moderate temperature fluctuations.

\section{$1500^{\prime} \mathrm{s}$}

Alchemists used solar energy to make perfume by placing flowers in water-filled containers. The heat from a focused mirror caused the scent of the flowers to diffuse into the water. 
1515 A.D.

Leonardo Da Vinci planned and began work on a 4-mile wide mirror intended to generate heat and power for industrial use.

Early $1600^{\prime} \mathrm{s}$

Salomon de Caus, a French engineer, used the concentrated rays of the sun to operate a small water pump, one of the first

solar energy machines.

Athanasius Kircher, a German writer, described the first solar furnace, in which focused solar rays were used to purify water.

Late $1600^{\prime} \mathrm{s}$

Brick fruit walls were designed by the French and English.

Fruit ripened faster when fruit trees were grown against walls which retained the sun's heat.

$1700^{\prime} \mathrm{s}$

Colonial architects built "saltbox" homes in New England. "At the front, two stories faced south to admit the sun; only one story faced north at the rear. The sloped roof in the rear swept winter winds over the house.

1767 A.D.

Horace De Saussure built the first hot box, the forerunner of modern solar collectors. This box could reach temperatures above the boiling point of water.

1774 A.D.

Joseph Priestly discovered oxygen by heating mercury oxide with a burning glass.

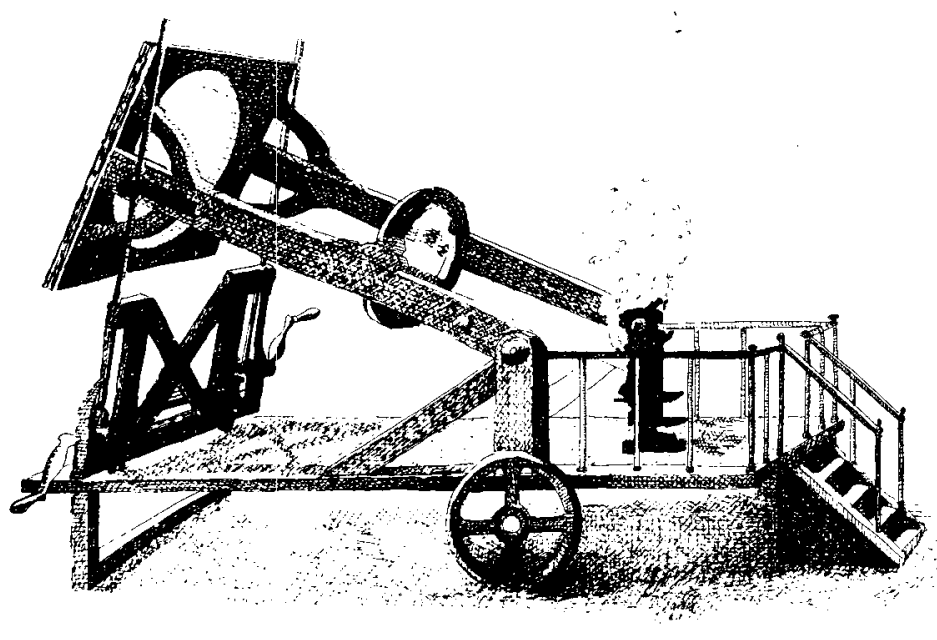

Lavoisier's Solar Furnace
Late 1700 's

Antoine Lavoisier, the "Father of Chemistry", built a large solar furnace which could reach temperatures of $1000^{\circ} \mathrm{C}$.

$1800^{\prime} \mathrm{s}$

Glass-walled conservatories for displaying plants became popular in the homes of wealthy Europeans; they also served to warm adjoining rooms. 
1839 A.D.

Edmund Becquerel, a French physicist, discovered that sunlight could produce electricity (photovoltaic effect).

Mid 1800's

Augustin Mouchot, a French solar pioneer, combined the concepts of solar reflectors and hot boxes and invented a solar oven, a solar still, and a solar pump. In 1866 he developed the first solar-driven steam engine.

$1870^{\prime} \mathrm{s}$

John Ericsson, an American engineer, deveioped a solar hot-air engine and an inexpensive way to make solar reflectors.

Charles Tellier, a French experimenter, invented what we now call the "flat-plate" collector.

1871 A.D.

A large solar water distilling plant was built in Chile by an American, Charles Wilson. The still produced 6000 gallons of fresh water a day and operated for 40 years.

1878 A.D.

A solar steam engine operated a printing press at the World Exposition in Paris. It was one of the hits of the show.

\section{$1880^{\prime} \mathrm{s}$}

Charles Fritts, an American inventor, made the first solar cells. Sunlight striking the cells produced electric current.

1891 A.D.

The first commercial solar water heater was developed. Called the "Climax", it combined a metal tank with a "hot box".

1904 A.D.

The first full-sized solar power plant was built in St. Louis.

1910 A.D.

William Atkinson, a Boston architect, used "sun boxes" oriented in different directions to prove his theory that the greatest benefit from the sun is gained through south-facing windows. He also convinced the Boston City Council to restrict the height of new buildings in order to guarantee access to the sun. 
1912 A.D.

Frank Shuman, an American, built a large-scale solar plant to produce irrigation water in Egypt.

1920 's and 30's

Solar water heaters were commonly used on homes in the southern and western United States.

1938 A.D.

Massachusetts Institute of Technology began building and doing research on solar homes. The principle factors affecting solar collector performance were investigated.

\section{$1940^{\prime} \mathrm{s}$}

Maria Telkes designed solar still "survival kits" used by the U.S. Navy in World War II.

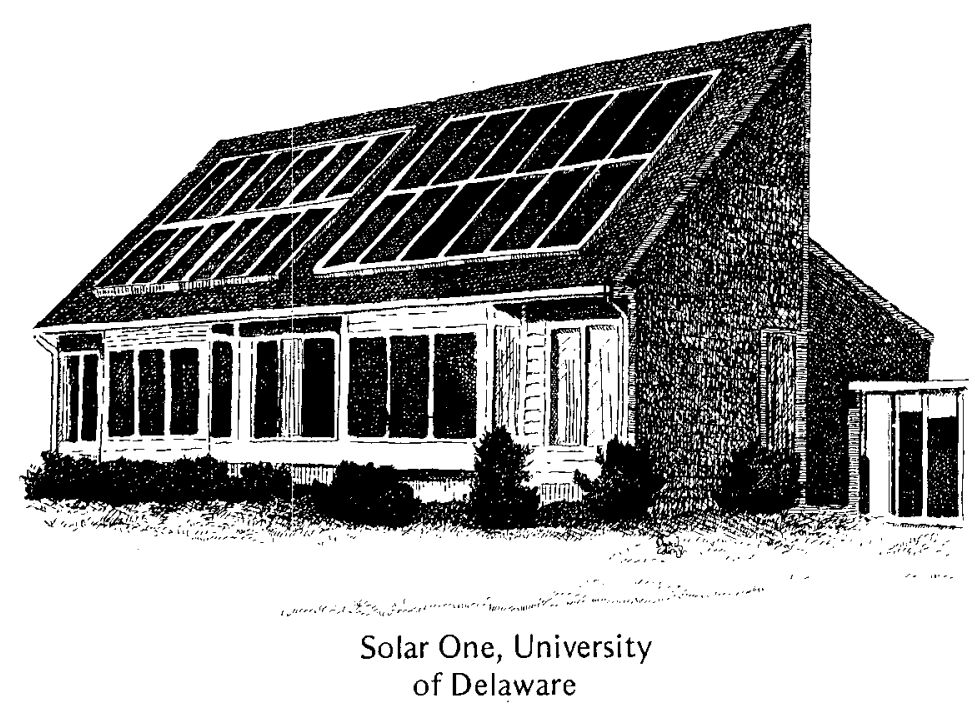
tinued on active and passive solar homes and many people were tinued on active and passive solar homes and many people were building them.

1954 A.D.

Silicon photovoltaic cells were developed by Bell Labs.

$1950^{\prime} \mathrm{s}$ and $1960^{\prime} \mathrm{s}$ NASA used solar cells, which are durable and lightweight, to power American space satellites.

$1970^{\prime} \mathrm{s}$

Because of fuel shortages and increasing costs here was renewed interest in solar dwellings. Research con- 
Teacher Information

A Short Solar History

\section{Suggested Grade Level and Skill Area}

7-12 Home Economics

Housing

Family Life

Future Homemakers of America

\section{Skill Objectives}

Using a meter stick to make a time line

Listing on the time line historical advances in solar energy uses

Observing forms of solar technology being used today

\section{Content Objectives}

Throughout human history, the sun has been used as a source of energy.

Many advances in the use of solar energy have been made since the beginning of recorded history.

Many of these advances have served to provide more comfortable she1ter.

Most of the advances in solar technology were forgotten during the "cheap energy" era. With today's inflation of fuel costs, there is renewed interest in solar energy.

\section{Background}

Solar energy has been used throughout human history to provide more comfortable shelter for families. Since the 1500's, solar energy has been a source of energy for doing work. It has been employed in many countries and by many cultures.

In this activity the student will become aware of a number of the varied ways solar energy has been used in the past. The time line will visually illustrate to the student the many advances made in solar energy use over time.

\section{Advance Planning}

Reproduce the worksheets before the class meets.

Collect materials needed to make the time line. 


\title{
Suggested Time Allotment
}

\author{
One to two class periods
}

\section{Suggested Approach}

This activity will fit well into units or courses in housing, consumer education, family life, and culture.

As an introduction to the activity, define solar energy and alternative energy. Provoke students into thinking about the effects of the sun's energy on them as individuals. How have they experienced the sun's energy? How have they used it? Examples can include acquiring a tan, using a beach umbrella for a sun shade, using glassed-in bus shelters, feeling the effects of the sun when walking in a protected area.

Students can be assigned to work individually on a particular period of one large time line or small groups of students may each develop a complete time line.

Discuss the "Going Further" suggestions. These may be done as an optional assignment or outside activity.

\section{Precautions}

obtain permission from your principal or from community officials before displaying the time line.

\section{Points for Discussion}

Where would you prefer to sit in the house or in the classroom when it is very cold or very hot outside?

In what ways could you use solar energy in your classroom or house?

In what ways have you used energy from the sun when hiking, skiing, or camping ?

The first public baths were cavelike, but later they were very open with large expanses of glass. What are the advantages of each kind of bath?

It has been predicted that solar energy will become the source of at least $20 \%$ of our energy by the year 2000 . Do you think this is a possibility? In what ways do you think solar energy will be used in the future?

\section{Typical Results}

The time line should emphasize the many forms of solar energy that have been utilized throughout the course of recorded history. It should stimulate discussion among observers. 


\section{Evaluation}

The time line should be neat and accurate.

Students should participate in discussion of the activity.

Students should be able to list examples of solar energy advances.

\section{References}

A Golden Thread, Ken Butti and John Perlin. (Cheshire Books, 514 Bryant Street, Palo A1to, CA 94301, $1980, \$ 15.95$.

Harnessing the Sun: The Story of Solar Energy, David C. Knight. (William Morrow \& Co., Inc., Wilmor Warehouse, 6 Henderson Drive, West Caldwe11, NJ 07006, 1976, \$7.44.)

Tips and Topics in Solar Energy.

(Texas Tech Journal of Education, Texas Tech University Library, Room 118, Texas Tech University, Lubbock, TX 79409, Volume 20, 护, Winter, 1980, contact Texas Tech University Library for price.)

"Historical Solar Energy Devices", Edison Shrum. (Hobbies, Lightner Publishing Corp., 1006 South Michigan Avenue, Chicago, IL 60605, August, 1977, pp. 118-120.) 


$$
\text { 2-12 }
$$

$\bullet$ 
DRAFT

\section{Drying Foods with}

\section{SolarEnergy}

\section{Introduction}

What is easy to use, produces no waste, can be used year round, requires no chemicals, and costs nothing to operate? This may sound like a riddle, but it's actually a description of a solar food dryer. In a society that emphasizes the importance of "fast foods", this household appliance can prepare foods efficiently at the same time it promotes good health and wise energy use.

In this activity, you will use low-cost household materials to build a solar food dryer. This dryer will preserve foods that are nutritious, delicious, and just right for a fast-paced, mobile lifestyle. 


\section{Objectives}

At the completion of this activity, you should be able to

- build a low cost, lightweight, portable solar food dryer from household materials,

- list the advantages and disadvantages of preserving food by solar drying,

o preserve fruits and vegetables according to solar food drying principles, and

o evaluate the dried food for taste and texture.

\section{Skills and Knowledge You Need}

Measuring ingredients in metric units.

Reading recipes

Selecting good quality fruits and vegetables

Following directions

\section{Materials and Equipment}

one dark-colored plastic dish pan

one roll of aluminum gutter mesh or window screening one large piece of clear plastic (a dry cleaner bag works well)

one roll of duct tape

one sharp knife

one centimeter ruler

one large rubber band

one thermometer (range $30^{\circ} \mathrm{C}$ to $50^{\circ} \mathrm{C}$ )

fruits and vegetables

Diagram 1

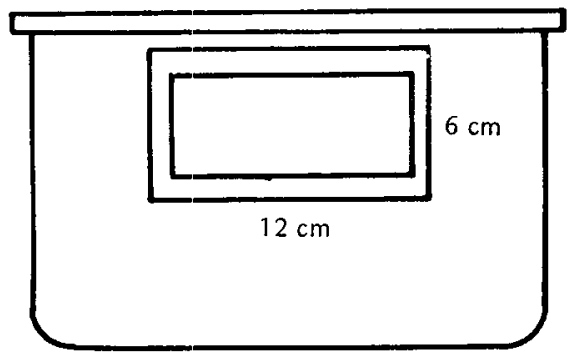

\section{Procedure}

1. Assemble the materials for the solar food dryer.

2. On each end of the dish pan, cut out a rectangle that measures $6 \mathrm{~cm} \times 12 \mathrm{~cm}$.) (See Diagram 1.)

3. Cut two pieces of gutter mesh that measure $10 \mathrm{~cm} \times 16 \mathrm{~cm}$. 
Diagram 2

4. Place a piece of the cut gutter mesh over each opening in the dish pan. Tape each piece of mesh in place with duct tape. (See Diagram 2.) The resulting vents will provide air circulation through the solar dryer.

5. On each long side of the dish pan, cut three slits, equal distances apart, to hold the dryer shelves. The slits should be $1 \mathrm{~cm}$ high and slightly wider than the width of the mesh. (See Diagram 3.)

6. Cut three pieces of mesh $4 \mathrm{~cm}$ longer than the width of the dish pan. These will serve as dryer shelves.

7. Stretch each mesh piece between each set of slits, pushing the ends of the mesh through the slits. Pull taut and fasten to the outside of the dish pan with duct tape. (See Diagram 4.) To keep out insects, make sure that the duct tape covers the slit completely.

8. From Worksheet A, choose one recipe for solar drying a fruit or vegetable. Prepare the food for drying according to the recipe.

9. Place the prepared food on the shelves of the dryer. Leave air spaces between the pieces of food.

10. Place the thermometer in the bottom of the dryer so that it faces the opening.

11. Cover the open side of the food dryer with a piece of plastic. Stretch the plastic tightly across the opening. Hold it in place by hooking a large rubber band over the rim of the dryer. (See Diagram 5.)

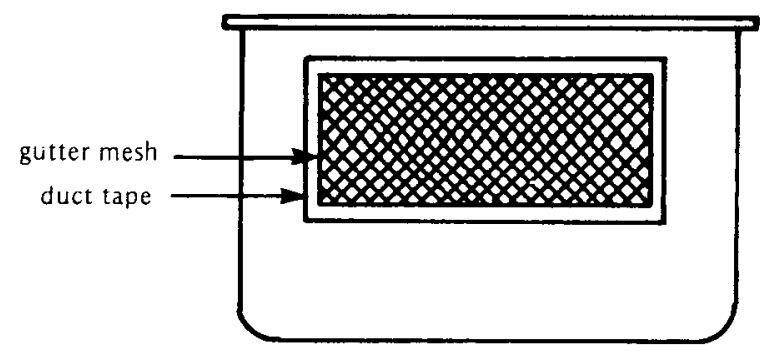

$\underline{\text { Diagram } 3}$
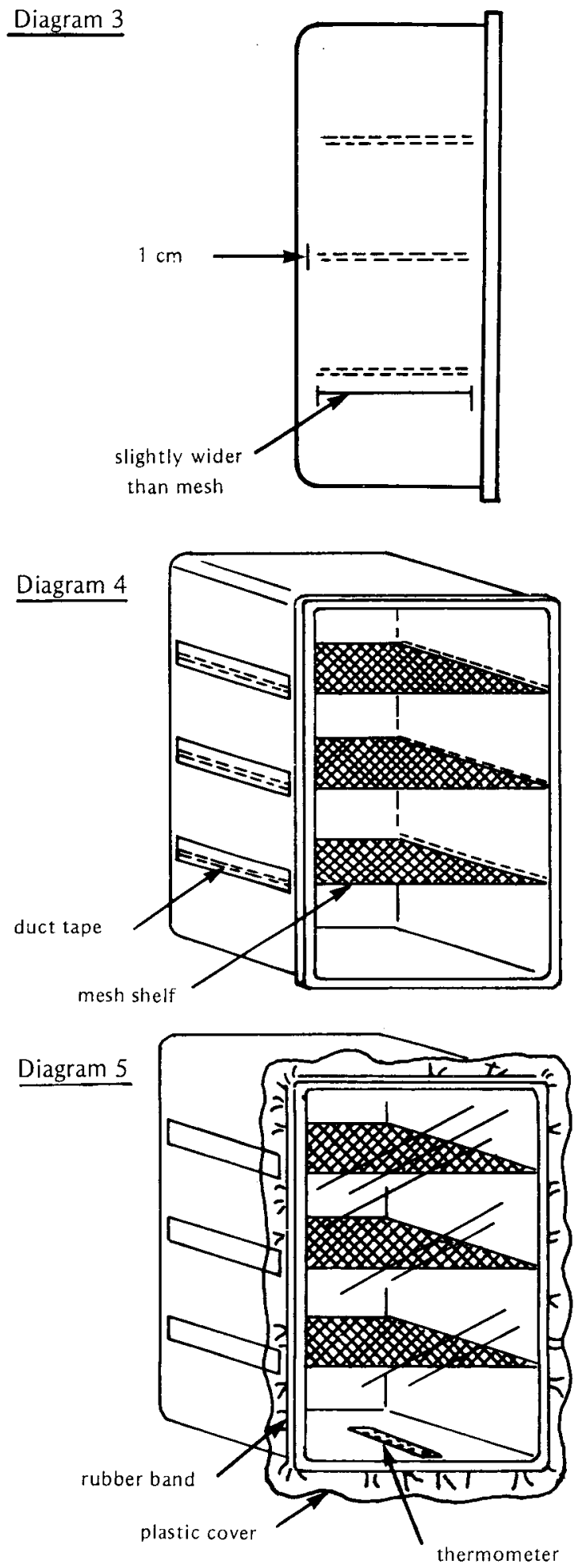
12. Place the dryer in direct sunlight, with the opening facing the sun. Turn the food two or three times each day. The idea is to remove moisture as quickly as possible to prevent spoiling.

13. Check the temperature inside the dryer often. If too high a temperature is maintained, the surface moisture evaporates from the food too quickly. This causes the outer shell to harden and prevents the escape of moisture from the interior of the food. If temperatures inside the dryer go above $60^{\circ} \mathrm{C}$, move the dryer out of the direct sunlight.

Caution: If you are drying the foods outside, bring the dryer inside at night and during periods of rain and high humidity. In the morning do not place the dryer outside until dew or rain has evaporated.

14. After several days continue the drying process in the shade. Your teacher will tell you when your food has reached the desired degree of dryness.

15. Use Worksheet $B$ to evaluate the results of your solar drying.

\section{Questions}

1. Which foods dried the best? The worst?

2. Which food tasted best dried? Worst?

3. What different kinds of textures did the dried foods have?

4. What are the advantages of using the sun to dry foods? The disadvantages?

5. Which advantage of solar dried food is most beneficial to the consumer? Why?

6. What qualities should foods have to be selected for solar drying?

\section{Looking Back}

Although solar food drying is an ancient method of preservation, it is still effective for keeping food from spoiling until you're ready to use it. For best results fruits and vegetables of high quality should be selected for drying. To quickly remove moisture, the prepared food is exposed to direct sunlight during daylight hours for several 
days. This is followed by several days in a shaded area, where evaporation is completed. The shelf life of solar dried food in air-tight packaging is greater than that of canned or frozen foods.

A solar food dryer can be constructed for a minimum cost, using available household materials. This portable appliance stores easily and costs nothing to operate.

\section{Going Further}

Use solar energy to dry fruit that requires sulfuring as a pretreatment process. Research the process and identify fruits which benefit from sulfuring in terms of preserving color, flavor, and nutrients.

Find and follow a recipe for producing fruit leather from pureed fruit. Solar dry the pureed fruit.

If you live in a very sunny, dry climate, prepare solar dried meat jerky from a tested recipe.

Prepare a meal using solar dried fruits and vegetables as substitutes for fresh, canned, or frozen products.

Solar dry herbs for classroom cooking use.

Use solar dried foods on a camping trip.

Research and make a chart comparing the shelf lives of solar dried foods to fresh, frozen, or canned foods. 
Recipes for Solar Dried Fruits and Vegetables

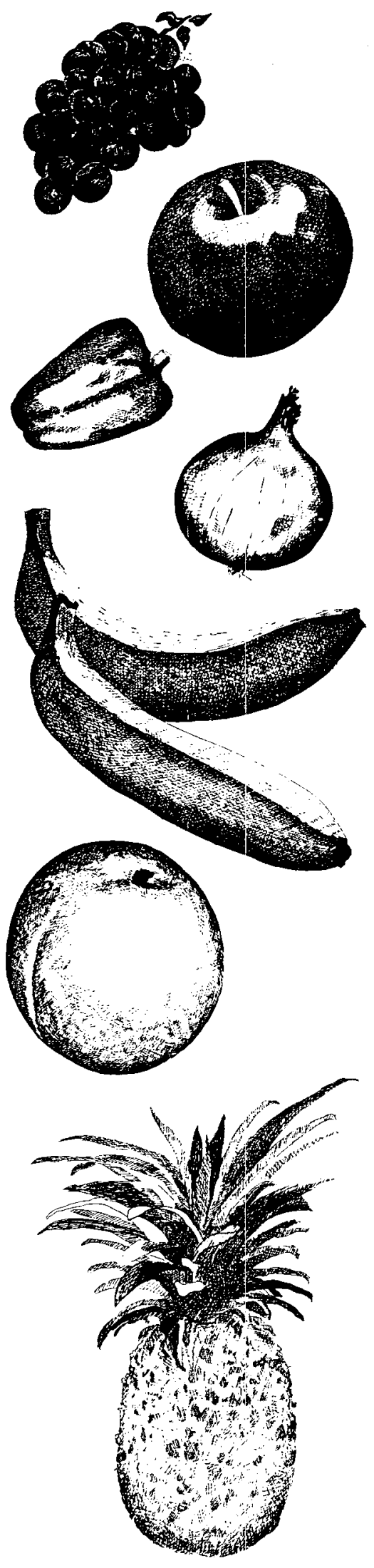

The highest quality food should be chosen for drying. Select fully ripe but not mushy fruit or vegetables.

Grapes: Thompson seedless grapes dry best but Sultanas can also be used. Four and a half pounds yield 1 pound of raisins. Leave the grapes on the stem; wash and dry them. Pretreat by steaming 30 seconds to 1 minute or until the skins crack. Protect the grapes from excess humidity, which causes crystallization. The grapes are dry when they are leathery, with no pockets of moisture.

Apples: Tart varieties such as Gravenstein, Granny Smith, Jonathan, Newton, and Rome Beauty are usually preferred for drying. The apples should be ripe but free from bruises or soft spots. Wash, peel if desired (skin tends to be tougher when dried), core, and slice into $5 \mathrm{~mm}$ pieces. The apples are dry when they feel pliable to crisp.

Onions: White varieties have the best dried flavor. Orions should be firm, heavy for their size, and aromatic. Trim the bulb ends and remove the paper shell. Slice $3 \mathrm{~mm}$ to $8 \mathrm{~mm}$ thick. The onions are dry when they feel like paper.

Peppers: Both green and red peppers can be dried. Choose fresh, firm, well-shaped peppers with thick walls. Chop or thinly slice the peppers. The peppers are dry when they feel tough to brittle.

Bananas: Purchase overripe, "reduced in price" bananas. Slice the bananas directly onto the drying shelf without overlapping the slices. The slices will not stick to the tray once they are dry.

Plums: To produce good quality prunes, cut the plums into small pieces to speed the drying process. Lay the plums skin-side down on the shelf and dry in strong, direct sunlight.

Pineapple: Select golden, slightly soft pineapples. Wash the outside thoroughly, to the point of scrubbing. Peel the pineapple, then slice crosswise into $1 \mathrm{~cm}$ portions. Remove the core. 
There are many ways to juage food, but two of the most important are the food's taste and texture. Without sharing your opinion with your teacher or any classmates, rate the fruits and vegetables that were solar dried.

\begin{tabular}{|c|c|c|c|c|c|}
\hline Food & & Tas & & & Texture \\
\hline $\begin{array}{l}\text { Grapes } \\
\text { (raisins) }\end{array}$ & $\begin{array}{l}\text { not very } \\
\text { tasty }\end{array}$ & average & tasty & delicious & \\
\hline Apples & $\begin{array}{l}\text { not very } \\
\text { tasty }\end{array}$ & average & tasty & delicious & \\
\hline Onions & $\begin{array}{c}\text { not very } \\
\text { tasty }\end{array}$ & average & tasty & delicious & \\
\hline Peppers & $\begin{array}{l}\text { not very } \\
\text { tasty }\end{array}$ & average & tasty & delicious & \\
\hline Bananas & $\begin{array}{c}\text { not very } \\
\text { tasty }\end{array}$ & average & tasty & delicious & \\
\hline Plums & $\begin{array}{c}\text { not very } \\
\text { tasty }\end{array}$ & average & tasty & delicious & \\
\hline Pineapple & $\begin{array}{c}\text { not very } \\
\text { tasty }\end{array}$ & average & tasty & delicious & \\
\hline
\end{tabular}

If you do not like the fruit or vegetable served plain, try using it in a recipe, such as cookies or spaghetti sauce. Then rate the dried food again.

Store any remaining food in one of the following ways.

1. Place the food in a jar and cover the top with plastic wrap. Screw the lid on tightly over the wrap. The wrap will make the jar even more airtight.

2. Place the food in zip-lock bags. Close the bag until only a soda straw can be inserted through the remaining opening. Suck out the remaining air without breathing into the bag. Remove the straw and finish sealing the bag.

To increase the length of time packaged foods can be stored, keep them in a dark, cool place. 
3-8

。

。 


\title{
Suggested Grade Level and Skill Area
}

\author{
7-12 Home Economics \\ Food and Nutrition \\ Outdoor Living \\ Future Homemakers of America
}

\section{Skill Objectives}

Building a low cost, efficient solar food dryer with available household supplies

Preserving fruits and vegetables with solar energy

Evaluating the taste and texture of solar dried foods

\section{Content Objectives}

Solar drying is one method of preserving foods.

The advantages of solar drying include retention of the food's nutrient value, economy, a long shelf life, minimum packaging, reduced weight and bulk, absence of artificial preservatives, and conservation of fossil fuel energy.

A low-cost solar food dryer may be constructed from a dish pan and wire mesh.

Many different fruits and vegetables can be dried by solar energy.

The disadvantages of solar drying include increased human effort and time in preparing the food for drying, variability of sunshine and humidity, and a product taste consumers may not be used to.

\section{Background}

Drying is both the most ancient method of food preservation and one that remains popular today. More recently developed preservation processes include canning, freezing, the use of preservatives, and irradiation.

Solar food drying is a highly effective way of preserving the energy plants store as nutrients through the process of photosynthesis. One thousand year old kernels of corn recently found in dry sand in a constantly cool New Mexico cave, for example, germinated when planted.

Food drying results in the loss of free water, which effectively protects the food from decay by microorganisms. The nutrients are preserved and the concentrated material has enduring quality. Food drying 
may be achieved by two processes: naturally by sun drying, or artificially by passing warm air over the product. In either process, as dehydration progresses, air circulation is needed to carry away moist air and to provide warm, dry air which can absorb additional moisture.

Dried foods will keep a minimum of one year if properly prepared. Foods must be dried to a $5 \%$ moisture content or lower for them to store we11. They should be stored in a cool, dark place. Many dried foods can be kept for as long as four years, which is double the recommended storage time for canned foods. Dried foods are reduced in weight and bulk, an advantage in packing provisions for hiking and camping.

Foods may be solar dried for many reasons. Solar drying is economical and conserves the fossil fuel energy that other forms of preservation require. Solar drying is especially energy conserving when you consider that the food processing industry consumes 12 times more energy in preparing focd for the table than the food contains. Also, with many people today worrying about the side effects of the preservatives used by the food processing industry, solar drying allows the individual to retain control over the food consumed. Solar dried foods are wholesome; no preservatives are required for a long shelf life and there is little nutrient loss from the food.

Many fruits are recommended for sun drying: apples, apricots, cherries, citrus peels, shredded coconut, currants, dates, figs, grapes, nectarines, peaches, pears, pineapple, and plums. Recommended vegetables include chili peppers, corn, lentils, peas, shell beans, and soybeans. Pretreatment by steaming may be required to kill microorganisms, stop certain chemical processes, preserve color, check the ripening process, preserve the vitamin and mineral content, or break down outer tissue so moisture escapes from inner cells more rapidly. The water content of fruits and vegetables may be very high. Apples and grapes, for example, have water contents of $84 \%$ and $81 \%$, respectively.

Vegetables are dry when they are leathery or brittle. Fruits are dry when they are leathery and pliable. If in doubt, it is better to overdry than underdry.

\section{Advance Planning}

Several warm, sunny days will be needed to accomplish the solar drying. Late spring and early fall days are especially good drying times, as humidity levels tend to be low while the sun's rays remain warm.

Select fully ripe, in-season fruits and vegetables for drying as these will yield the best results.

Collect the materials needed to construct the food dryer. 


\section{Suggested Time Allotment}

One class period to construct the solar dryer

At least 5 days to complete the drying (parts of class periods only)

One class period to evaluate and discuss results

\section{Suggested Approach}

Discuss with students the advantages and disadvantages of solar food drying. Brainstorming may be a useful technique or the background information can be reproduced for distribution to the class.

Appoint one or two students to tally the results of the taste and texture test. Share the findings with the class.

\section{Precautions}

Foods with a high protein content may spoil when exposed to warm temperatures for a period of time. THIS COULD RESULT IN FOOD POISONING.

This activity is most effective in climates with low humidity, frequent sunshine, and high temperatures. Dming temperatures should be over $47^{\circ} \mathrm{C}$ or spoilage may occur. Results may be unsatisfactory in the northeasterm United States.

High quality fmits and vegetables are most successfully solar dried.

Foods stored in air-tight containers wizl have a Ionger shelf life. Students should have clean hands when handling the drying foods. Make sure insects do not get into the dryers.

\section{Points for Discussion}

In what ways is solar energy for food drying "free" energy?

What are the human energy costs of solar food drying?

What are some of the potential dangers of solar drying foods if safety precautions aren't taken?

What safety precautions should be followed in solar drying foods? 


\section{Typical Results}

After drying, grapes and prunes will be leathery with no pockets of moisture, apples will feel pliable to crisp, onions will feel like paper, peppers will feel tough to brittle, bananas will be crisp, and pineapple will be pliable and perhaps somewhat sticky.

\section{Evaluation}

Observe students' ability to follow instructions, construct the dryer, prepare foods, and follow through on the drying process.

Have students list the advantages and disadvantages of solar food drying.

Ask students to discuss the results of the dried food evaluation.

\section{Modifications}

If the weather does not cooperate, you can finish drying foods in the oven. Preheating the oven to warm, then turning off the heat will speed the drying process. Microwave ovens can also be used.

Apples can be strung on a string and suspended from the ceiling to dry. This will produce a fragrant smell in the classroom.

Provide students with the opportunity to taste fruits and vegetables in cooked dishes. This will allow them to rate the taste more objectively, especially if you find they don't like the unfamiliar taste of dried foods. Two sample recipes follow.

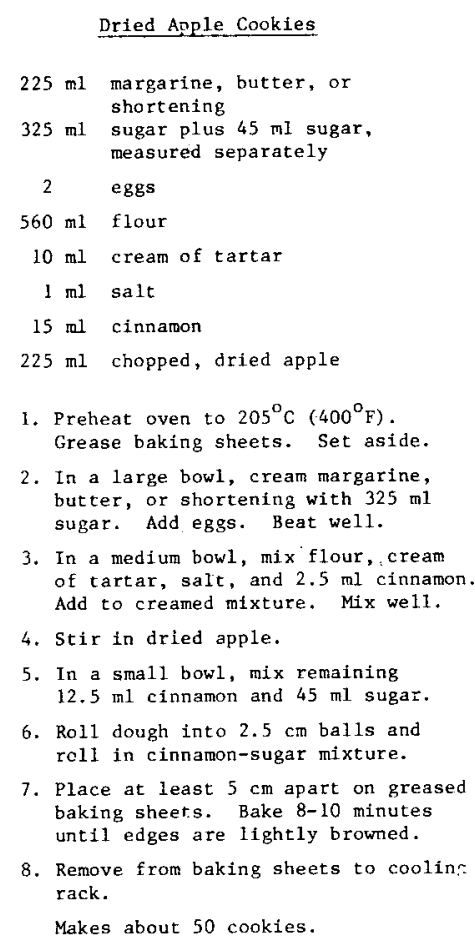

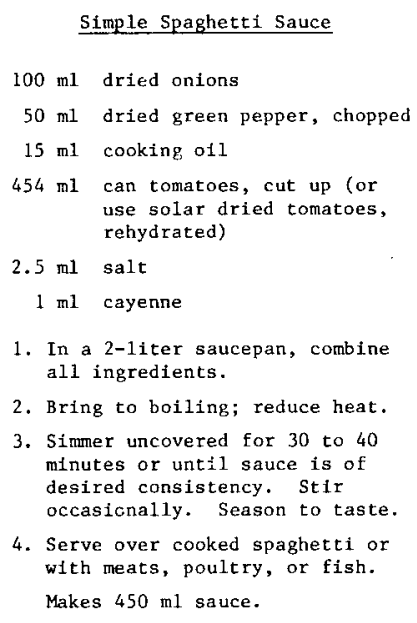




\section{References}

Don Holm's Book of Food Drying, Pickling, and Smoke Curing, Don and Myrtle Holm. (Caxton Printer, P.0. Box 700, Caldwe11, ID 83605, 1978, \$4.95/paper.)

The Home Workplace, from the editors of Organic Gardening \& Farming Magazine.

(Rodale Press, Inc., 33 East Minor Street, Emmaus, PA 18049, 1978, contact publisher for price.)

How to Dry Foods, Deanna Delong.

(H. P. Books, 341 Ponce de Leon Avenue, NE, Rm. 416, Tucson, AZ $85703,1979, \$ 5.95 /$ paper.)

The Solar Food Dryer Book, Stella Andrassy.

(Earth Books, Morgan \& Morgan, Inc., 145 Palisade Street, Dobbs Ferry, NY 10522, 1978, \$3.95/paper.)

"Food Dehydrator Can Help Save a Garden's Overflow", Peter Tonge. (The Christian Science Monitor, Christian Science Publishing Society, 1 Norway Street, Boston, MA 02115, August 8, 1980.) 
3-14

$\bullet$

$\bullet$ 
DRAFT

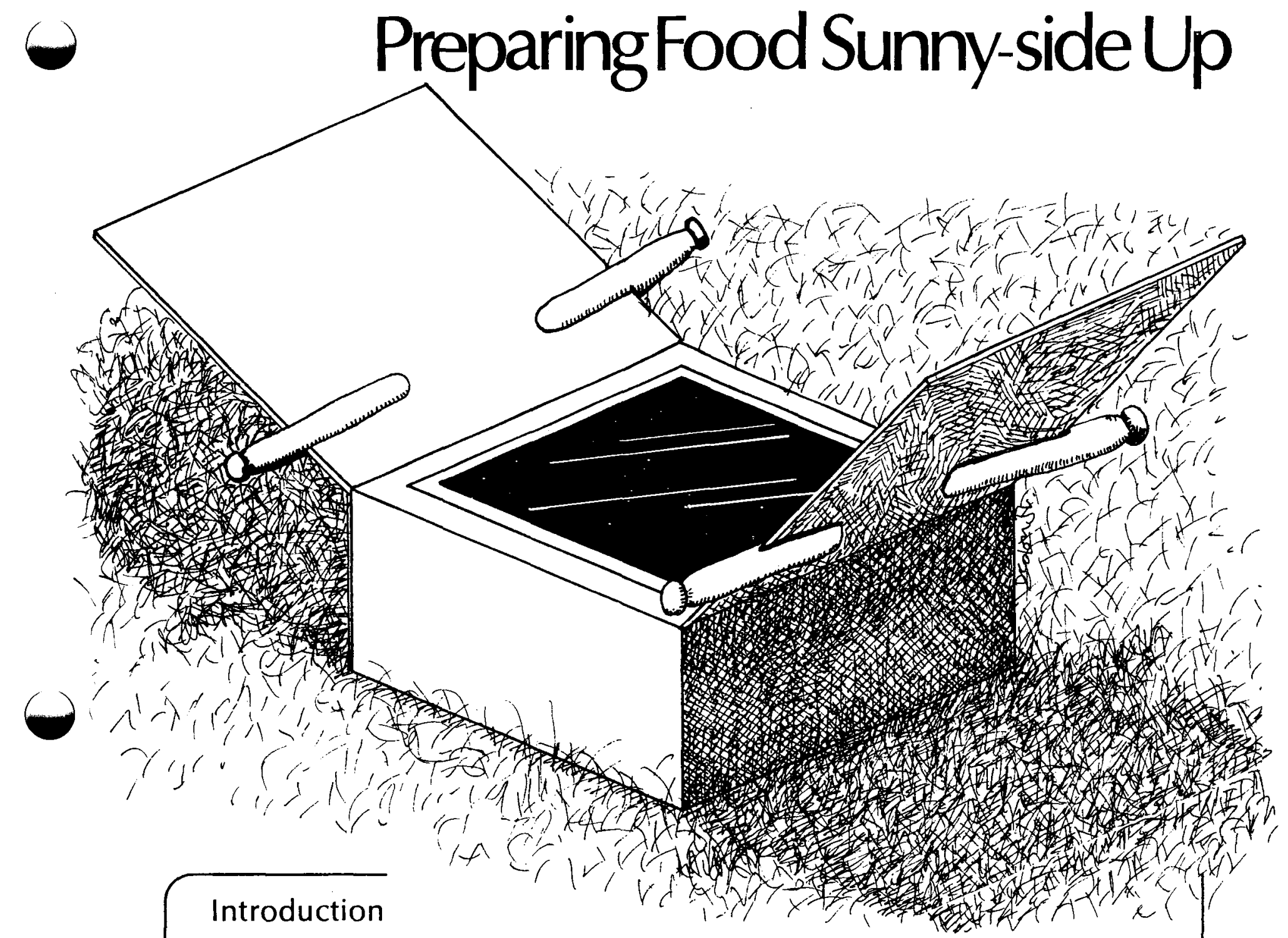

Lasagna for Thursday night supper, biueberry muffins during a winter camping trip, a chicken barbecue in July, and apple crisp in a home economics laboratory: all these have one thing in common. Besides being tasty, these dishes can be prepared solely by the use of solar energy. Since each of these foods originally developed through the energy of sunshine, a natural progression would be to complete the food preparation process with solar energy. Solar energy is available year round and at no cost to the cook who is willing to explore the possibilities of preparing food in a solar oven.

In this activity you will construct a solar oven and use it to experiment with the preparation of various foods. Do you think solar cooking will become a part of your future, not as an occasional experiment, but as an accepted cooking method in your kitchen? 


\section{Objectives}

to

At the completion of this activity, you should be able

- construct a solar oven that serves as a low-cost, portable appliance,

o determine the optimum conditions for solar cooking in terms of time of day, temperature, and sunlight,

o practice solar energy cookery by preparing various foods in a solar oven,

- compare solar cooked foods to foods cooked in a conventional oven, and

o list the advantages and disadvantages of solar cooking.

\section{Skills and Knowledge You Need}

\section{Measuring in metric units}

Folding and cutting skills

Reading recipes

Measuring ingredients

\section{Materials and Equipment}

meter stick

scissors and/or sharp knife

one roll of aluminized tape

clip-on clothespins

large piece of heavy cardboard ( $1.08 \mathrm{~m} \times 1.39 \mathrm{~m})$

strip of blanket fiberglass insulation ( $22 \mathrm{~cm} \times 1.08 \mathrm{~m}$ )

work gloves and kitchen mitts

two pieces of foil, mirror, or mylar ( $36 \mathrm{~cm} \times 36.5 \mathrm{~cm}$ each)

tempered glass $(27.5 \mathrm{~cm} \times 27.5 \mathrm{~cm})$

one oven thermometer

one can of barbecue flat black spray paint

one shiny metal pan

one dark metal pan 


\section{Procedure}

1. Using Worksheet $A$, practice making a solar oven. This practice oven will be $1 / 5$ the size of the actual solar oven.

2. Prepare the sample oven in the following manner.

a. Fold under each long side of the paper, along the folds shown in Diagram 1. After creasing the paper, open it flat again.

b. Cut the paper on each solid line, as shown in Diagram 2 .

c. Fold the paper under on each dotted line, as shown in Diagram 2 .

d. Look at the numbers printed on the sections of the oven. Fold the oven so that section 2 overlaps section 1 (see Diagram 3). Tape. Then fold the following sections in upon one another and tape:

$$
\begin{array}{rll}
3 & \text { and } & 4 \\
5 & \text { and } & 6 \\
7 & \text { and } & 8 \\
9 & \text { and } 10 \\
11 & \text { and } 12 \\
13 & \text { and } 14
\end{array}
$$

Sections 12 and 14 will extend above the sides of the oven and will help support the wings. The shape of this sample solar oven will give you an idea of the structure of the actual oven.

3. Now you are ready to begin the actual solar oven. Cut a sheet of heavy cardboard that measures $1.08 \mathrm{~m}$ $\mathrm{x} 1.39 \mathrm{~m}$. Measure and draw lines as indicated in Diagram 4. Label each section with the appropriate number from the sample oven worksheet. Be sure to label both front and back sides. Fold the cardboard on the dotted lines and cut it on the solid lines.

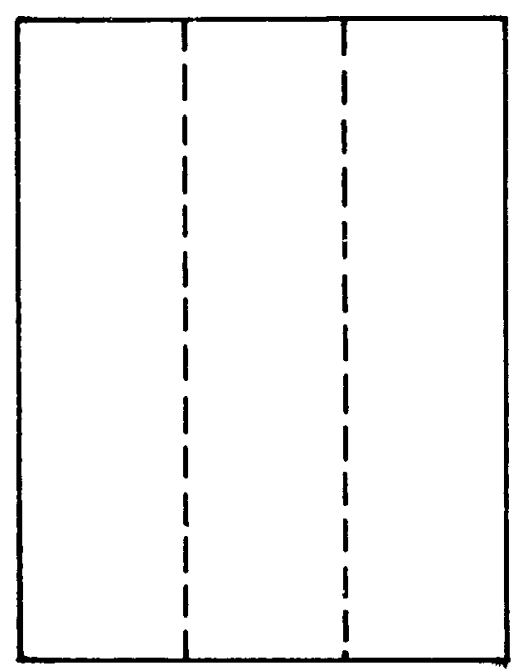

$\underline{\text { Diagram } 1}$

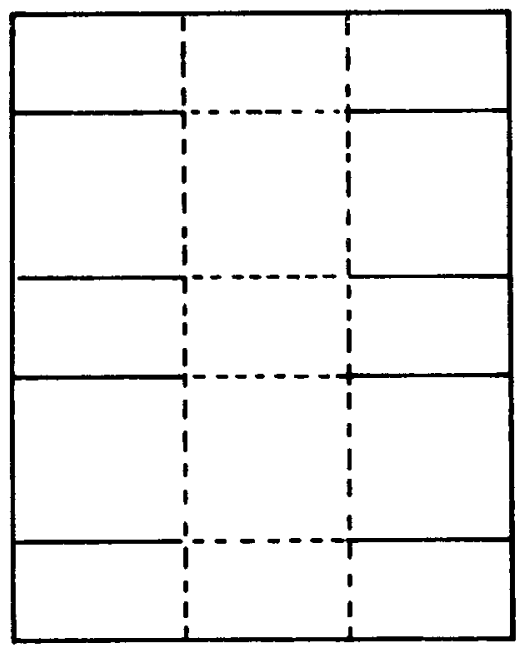

Diagram 2

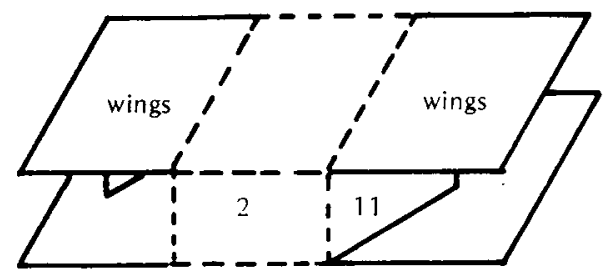

$\underline{\text { Diagram } 3}$ 
Diagram 4

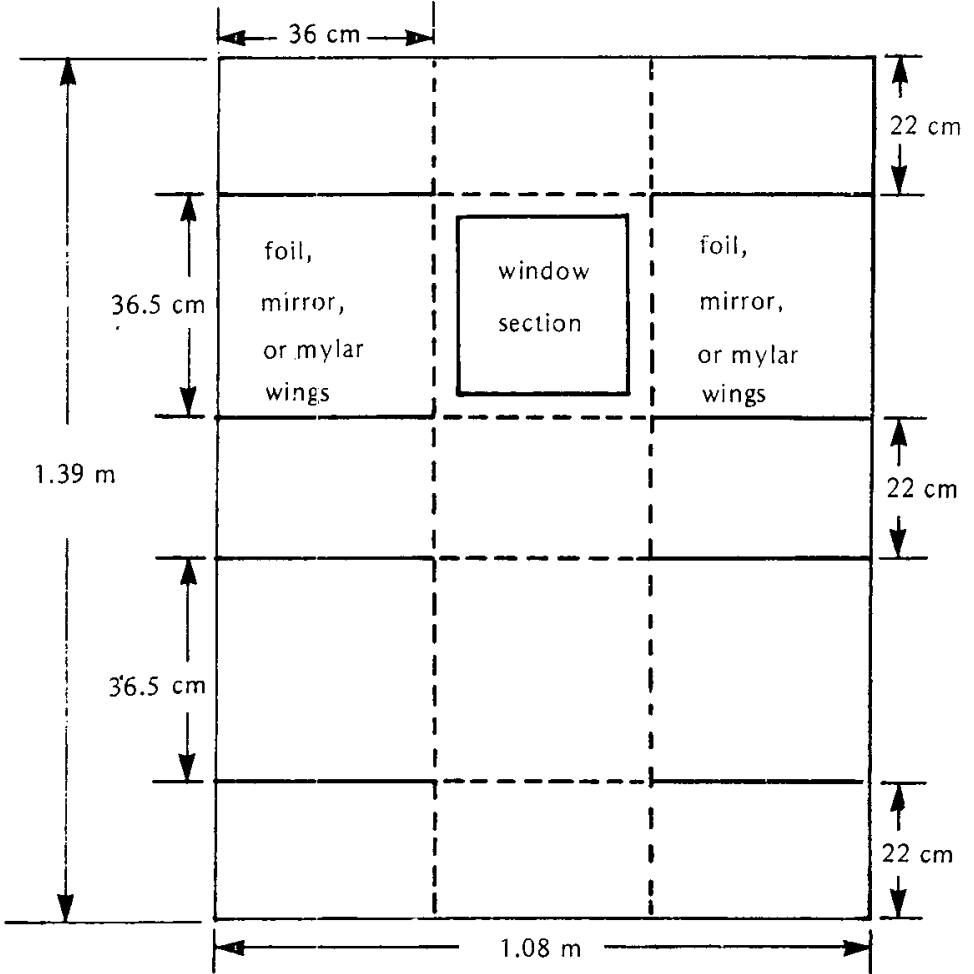

Front

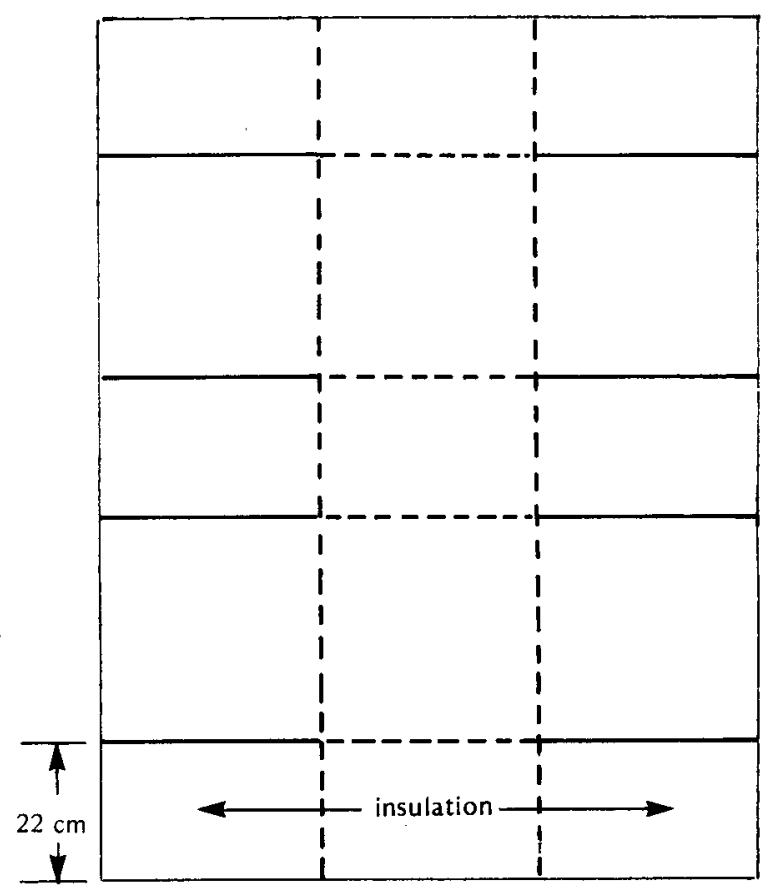

Back

4. With a sharp knife cut out the window section so that it measures $27.5 \mathrm{~cm} \times 27.5 \mathrm{~cm}$.

5. Cut a strip of fiberglass insulation to measure $22 \mathrm{~cm}$ by $1.08 \mathrm{~m}$.

Caution: Always wear gloves when handling fiberglass insulation.

6. With aluminized tape fasten the insulation to the area indicated in Diagran 4.

7. Spray sections $15,16,17,18,19$, and 20 with black spray paint.

Caution: Use the spray paint in a well-ventizated area.

8. With aluminized tape, fasten two pieces of mirror, foil, or mylar $(36.5 \mathrm{~cm} \times 36 \mathrm{~cm}$ each) to the sections indicated in Diagram 4. 
9. Fold the solar oven together in the same way you folded the sample oven.

10. Fasten sections 1 and 2,3 and 4 , and 5 and 6 together with small pieces of aluminized tape.

11. Fold section 12 to meet 11 , and 14 to meet 13 . Fasten sections 12 and 14 to the wings with clip clothespins, so that they support the wings.

12. Place aluminized tape around the edges of the tempered glass. Tape the glass in place over the window opening. Food can be placed in or taken out of the oven by removing the glass. If the temperature inside the oven becomes too high, the glass can be removed to allow air circulation.

Caution: Remove hot glass with gloves or oven mitts.

13. Place the oven thermometer inside the solar oven.

14. Face the oven's window into the sun and adjust the wings to reflect the sun's rays into the window.

Caution: Do not look directly at the oven's wings while adjusting them or cooking in the oven.

15. Heat the oven for several days to dissipate the paint fumes.

16. Follow the directions on Worksheet $B$ to prepare and compare food products, using both your new appliance and a conventional oven. Recipes for lasagna and apple crisp are given on Worksheet $\mathrm{C}$.

17. While cooking foods, test your oven at different times of day, and under different conditions of temperature and sunlight.

\section{Questions}

1. Why is the inside of the solar oven a dark color? How does this affect the cooking process?

2. At what time of day would the sclar oven be most efficient? In what season of the year would solar cooking be most efficient?

3. Were there any temperature, time of day, or sunlight conditions under which your oven did not operate? If so, what were they? 
4. Which type of cookware prepares food the most quickly with the best appearance, texture, and taste? Why?

5. What similarities did you observe in food preparation in a solar and a conventional oven? What differences?

6. What are some of the advantages of using a solar oven to cook foods? The disadvantages?

\section{Looking Back}

The solar oven can serve as an inexpensive alternative to conventional cooking methods. Solar energy is free and abundant, and can provide the temperatures needed to cook a wide variety of foods. As you experiment with different temperature and sunlight conditions at various times of day, food preparation in a solar oven becomes an interesting, enjoyable, and efficient procedure. The solar oven you've constructed can fold into a compact unit that is easy to store or transport, inexpensive to construct, and free to operate.

\section{Going Further}

The Future Homemakers of America Chapter can raise money by selling healthy breakfast foods or afterschool snacks which were prepared in a solar oven.

In an open-air shopping mall, present a display and demonstration of solar cooking. The tasty treats you prepare will be sure to draw a crowd.

Invite parents, teachers, the administration, and/or the Board of Education to a solar-prepared luncheon.

During an Open House or on a Conference Day, prepare refreshments using solar energy. 


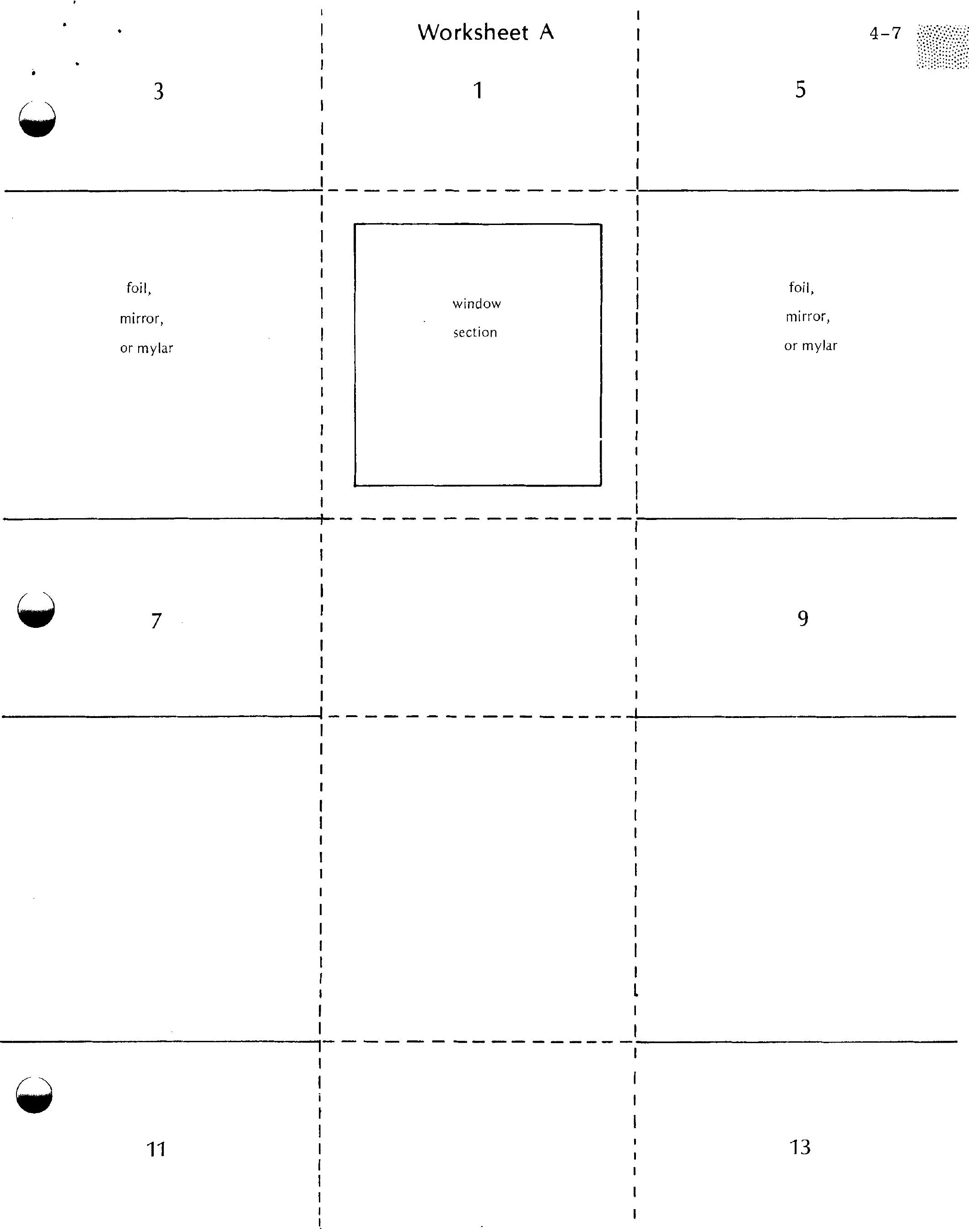




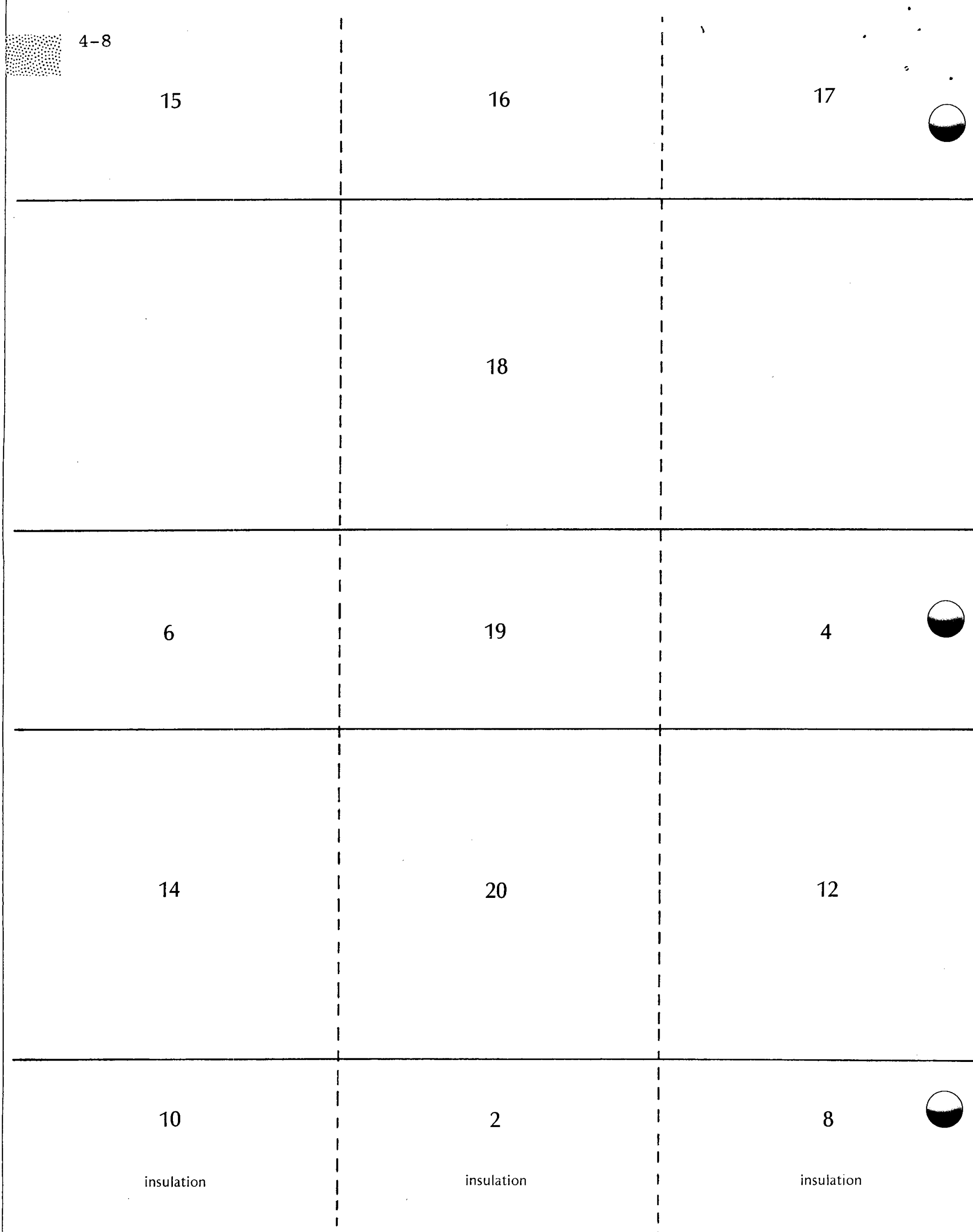




\section{Worksheet B}

\section{Food Preparation Test 1}

1. Prepare two identical food products using the same recipe. For example, use the same apple crisp recipe to prepare two separate batches. Measure ingredients accurately to insure identical products.

2. Cook one food in a conventional oven and the other food in the solar oven.

3. Record the cooking time required for both ovens.

4. Evaluate the appearance, texture, and taste of the food cooked in each oven.

5. Repeat Steps 1-4 using a variety of foods.

\section{Food Preparation Test 2}

1. Prepare two identical food products using the same recipe. For example, use the same lasagna recipe to prepare two separate batches.

2. Place one food product in a shiny metal pan and cook in the solar oven.

3. Place the other food in a dark metal pan and cook in the solar oven.

4. Record the time required to cook each food product.

5. Evaluate the appearance, texture, and taste of the foods cooked in both pieces of cookware.

6. Repeat Steps $1-5$ using a variety of foods. 


\section{Worksheet C}

\section{Apple Crisp}

$\begin{array}{rlll}5 & & \text { apples, peeled and sliced } \\ 125 & \mathrm{ml} & \text { brown sugar } & \\ 200 & \mathrm{ml} & \text { flour } \\ 115 & \mathrm{~g} & \text { butter, cut in small pieces } \\ 2.5 & \mathrm{ml} & \text { cinnamon } & \\ 2.5 \mathrm{ml} & \text { nutmeg }\end{array}$

1. Preheat oven to $190^{\circ} \mathrm{C}$.

2. Butter a shallow baking dish.

3. Spread the apples in the baking dish.

4. Combine flour, sugar, cinnamon, and nutmeg in a bowl.

5. Blend in butter until mixture becomes crumbly.

6. Spread mixture over apples.

7. Bake 45 minutes or until crust is browned.

8. Serve hot as is, or with cream or ice cream.

Makes 4-6 servings.

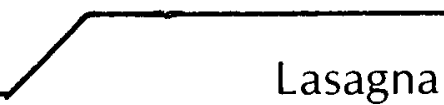

$\begin{array}{rlll}1 & \text { pkg. } & (454 \mathrm{~g}) \text { lasagna noodles } \\ 227 & \mathrm{~g} & \text { lean ground beef } \\ 1 & \mathrm{jar} & (908 \mathrm{ml}) \text { spaghetti sauce } \\ 227 & \mathrm{~g} & \text { mozzarella cheese, shredded } \\ 454 & \mathrm{~g} & \text { ricotta or cottage cheese } \\ 125 & \mathrm{ml} & \text { grated Parmesan cheese }\end{array}$

1. Cook and drain lasagna noodles according to package directions.

2. Cook ground beef. Pour off fat.

3. Add sauce; cook 15 minutes.

4. Preheat oven to $190^{\circ} \mathrm{C}$.

5. Grease a shallow, rectangular baking dish.

6. Reserve enough noodles to cover top of lasagna.

7. Dribble $250 \mathrm{ml}$ sauce over the bottom of the dish.

8. Place layers of noodles, mozzarella, and ricotta or cottage cheese over sauce.

9. Top with $375 \mathrm{ml}$ sauce and second layers of noodles, mozzarella, and ricotta or cottage cheese.

10. Add reserved noodles; pour on remaining sauce.

11. Sprinkle with Parmesan cheese.

12. Bake 30 minutes, until hot and bubbling.

Makes 8 servings. 


\section{Teacher Information \\ PreparingFood Sunny-side Up}

\section{Suggested Grade Level and Skill Area}

7-12 Home Economics

Future Homemakers of America

Food and Nutrition

Housing and Home Furnishings

Outdoor Living

Vocational classes in food service

\section{Skill Objectives}

Constructing a solar oven

Determining the direction of the sun's rays

Adjusting the solar oven to catch the sun's rays

Preparing foods according to recipe directions

Using a solar oven to cook foods

Evaluating and comparing solar cooked foods and conventionally cooked foods

\section{Content Objectives}

A solar oven is an example of an energy-efficient household appliance.

There are optimum conditions for solar cooking in terms of cookware, temperature, sunlight, time of day, and time of year. In general the solar oven will perform better under high temperatures and intense sunlight, and when using dark-colored cookware.

Solar energy cookery can be evaluated in terms of time of preparation, degree of browning, texture, and taste of the finished product.

Solar energy cookery can be compared to conventional oven cookery by using the criteria listed above.

There are both advantages and disadvantages to the use of solar energy for cooking. Advantages include low-cost, efficient, and enjoyable food preparation. The major disadvantages are that the sun doesn't always shine and that temperatures may be too low for all forms of solar cooking.

\section{Background}

As fossil fuels become scarce and expensive, people will turn to alternative sources of energy for performing everyday household tasks. One such source is solar energy for cooking. The solar oven is a usable appliance in most areas of the world during most seasons of the year. 
To understand the principle behind solar cooking, imagine leaving a parked car on a sunny day. On returning to the closed car, you find that the trapped air has become hot. The same is true in a solar oven. The rays of the sun penetrate the glass window and are absorbed and reradiated by the interior surfaces. The reradiated rays have a longer wavelength and are unable to pass back through the glass. The result is a closed space with sufficiently high temperatures to bake and cook a wide variety of foods.

Depending on the weather conditions, the solar oven will take between fifteen and thirty minutes to preheat to a temperature suitable for cooking. A solar oven can easily attain a temperature of $350^{\circ} \mathrm{F}$, but the temperature will decrease slightly when food is placed in the oven. To determine the temperature of the oven, an inexpensive oven thermometer can be placed inside.

Regulation of the temperature in a solar oven will take practice and careful watching. Since the position of the sun is always changing with respect to the solar oven, the oven must be frequently readjusted to catch the sun's rays. In the morning and in the late afternoon, the rays will be low in the sky. The same is true in winter. The optimum solar cooking conditions will occur at midday in summer. The solar oven can easily be used year round, though, if you remember to regulate the location of the oven and if you save high-temperature recipes for the months of long, intense sunshine.

With practice, you will be able to regulate the solar oven by using the door as a vent whenever excessive temperatures are reached. Skill will also be developed in aiming the solar oven to suit the needs of food preparation. For example, if a food needs to be defrosted before cooking, the solar oven can be aimed in a direction where the sun's rays will be stronger later in the day. The earlier, less direct rays will defrost the food, the stronger rays will cook it, and the less direct rays later in the day will keep the food warm.

Solar cooking has many advantages, but some of the most obvious are that solar energy:

- is an unlimited resource

- involves no cost

- is available in al1 geographic locations

- does not heat the surrounding area and is therefore suitable for cooking during hot summer months

- does not cause smoke or fire

- is available year round, under the proper conditions.

When selecting cookware for solar cooking, look for dark, lightweight materials that heat quickly. Shiny steel or aluminum pans reflect heat and decrease efficiency, as does aluminum foil. Painting the exterior of pans black will increase heat absorption. 
As you begin to cook with the solar oven, use it in the middle of the day with recipes that require low temperatures. This will guarantee success. Later you can be creative, cooking a variety of foods under many different sunlight conditions.

\section{Advance Planning}

The materials for the solar oven should be collected ahead of time by the students or teacher. Purchasing the needed materials for the oven could be a consumer project, with students learning to comparison shop for the supplies. Students should be asked to bring scrap materials in from home.

Large sheets of glass and cardboard can be cut to size before class if the equipment to cut them is not available in the classroom. The home economics and industrial arts teachers may want to work as a team on this project, as materials and equipment from both departments will be needed. Math teachers may want to teach a lesson on the measuring skills needed for this project.

The solar oven box may be constructed out of cardboard or heavier, flexible material. The cardboard oven is easier to construct, but will be less efficient and durable.

You may want to cut the fiberglass insulation yourself, both to save time and to eliminate the need for students to handle the insulation.

You may want to tape together a sample oven worksheet for students to examine before they try their own.

\section{Suggested Time Allotment}

Three periods to construct the solar oven

Two periods for food preparation and testing

One period for interpretation of data

\section{Suggested Approach}

This activity can be completed as either a class or individual project. Decide on the number of solar ovens that will be constructed. If one oven is to be constructed, this may be done as an independent study project by a pair or team of students. If more than one oven is to be completed, the class can be divided into groups. The food preparation can also be completed on an individual or class basis. If students will be working as a class, the solar ovens may be used in a traditional laboratory style.

You may want to spray paint the interior of the oven yourself to eliminate student exposure to fumes. 
If appropriate, duplicate the background information for distribution to students.

In doing the second food preparation test, try to duplicate the same conditions for each pan. Otherwise the results of the test may vary, and the advantages of the dark pan over the shiny pan won't show up.

\section{Precautions}

After the oven is completed, leave it in bright sunshine for several days until the paint fumes dissipate. You may notice a film on the glass. Continue wiping this off until the glass stays clean. This will indicate that the oven is ready for use.

Warn students not to look directly at the reflective surfaces of the oven.

Make sure all glass and mirror edges are toped to prevent cuts. Handle fiberglass only with gloves. Use spray paint only in a well-ventilated area.

\section{Points for Discussion}

Which materials in a solar oven are reflective and which are absorptive?

Describe the effect on solar cooking of the position of the sun with respect to time of day and season of the year.

Compare the energy use of a conventional and a solar oven.

What do you think is the future of solar cooking in the United States?

\section{Typical Results}

Foods prepared by either a conventional oven or a solar oven operating under optimum conditions will require equivalent cooking times.

Foods prepared in dark, lightweight cookware will cook faster than foods prepared in shiny, reflective cookware.

Optimum cooking results will occur at midday during the summer months due to the position of the sun's rays. 


\section{Evaluation}

To determine the students' ability to regulate the oven temperature through air venting and tracking of the sun, record the temperature of the interior of the solar oven during cooking.

To determine students' ability to regulate a solar oven for maximum efficiency, evaluate food products for cooking time, appearance, taste, and texture.

To analyze the students' knowledge of solar oven operation, discuss the principles behind food preparation in a solar oven.

Ask students to list the advantages and disadvantages of solar cooking.

\section{Modifications}

For better results during colder months when the sun is low in the sky, you could try redesigning the oven so that the window can be angled to catch the sun's rays, while the pans remain level.

\section{References}

Energy Conservation in the Home, Lil Clinard. (U.S. Department of Energy, Technical Information Center, P.0. Box 62, Oak Ridge, TN 37830, 1977, free.)

Roughing It Easy, Dian Thomas.

(Warner Books, 75 Rockefeller Plaza, New York, NY 10019, 1978, $\$ 2.50 /$ paper.)

The Solar Cookery Book, Beth and Dan Halacy. (Peace Press, 3828 Willat Avenue, Culver City, CA 90230, 1978, $\$ 7.95$.

Solar 2: Proceedings of the U.N. Conference on New Sources of Energy. (Cloudburst Press, 2116 Western Avenue, Seattle, WA 98121, 1978, $\$ 8.50 /$ paper.) 
4-16

8

$\ominus$ 


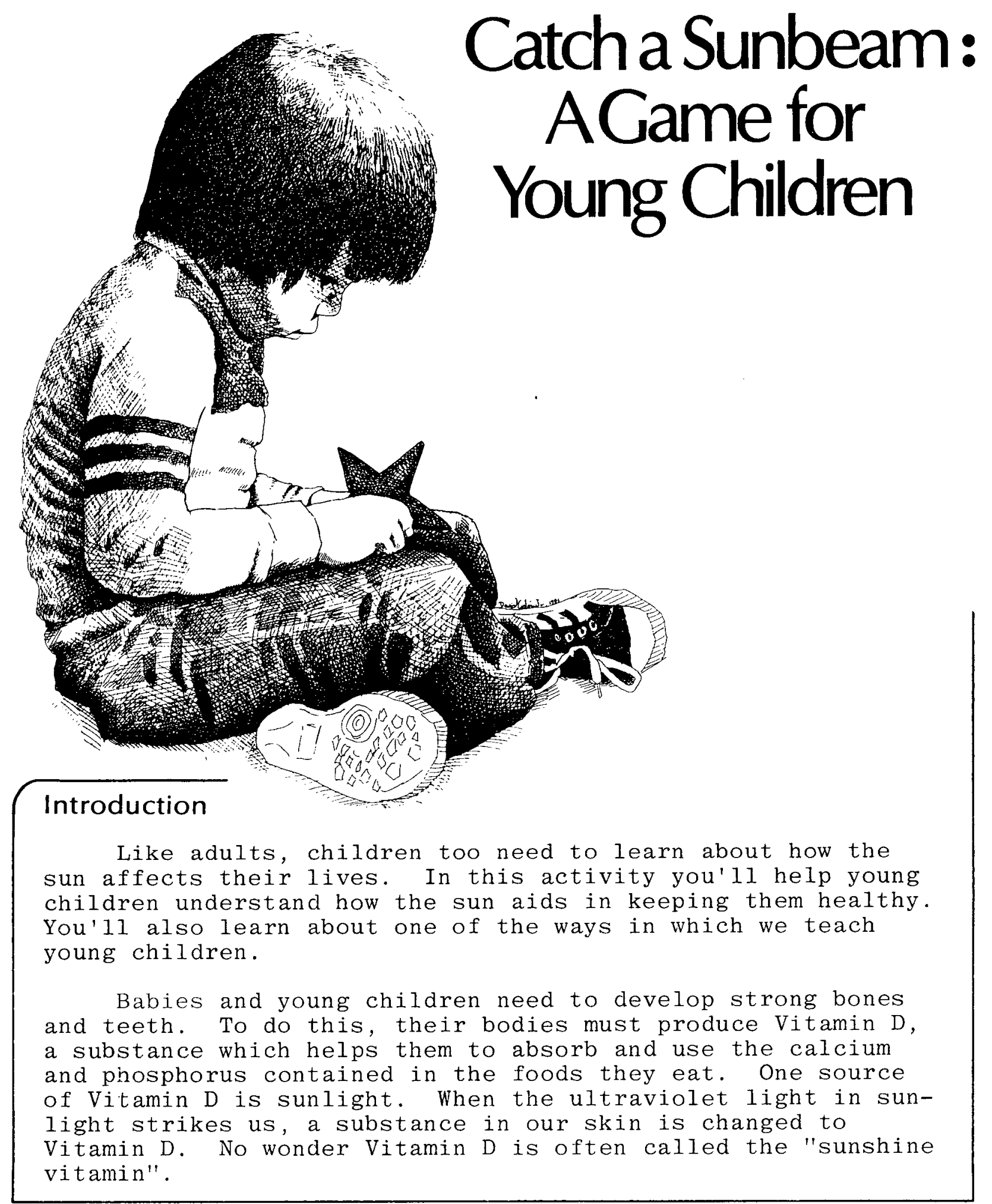




\section{Objectives}

At the completion of this activity, you should be able to

o teach young children a game called "Catch a Sunbeam",

o sew a bean bag to use in the game,

o explain to young children how sunshine helps to keep the human body healthy,

o state how the human body uses Vitamin $D$,

o recognize that sunshine is a natural source of Vitamin $D$, and

o identify Vitamin D-rich food.

\section{Skills and Knowledge You Need}

How to cut fabric

How to sew a running stitch

\section{Materials and Equipment}

2 8-inch squares of yellow felt

yellow thread

a sewing needle

scissors

dried peas, beans, lentils, or large bird seed

straight pins

magazines

cardboard or tagboard

\section{Procedure}

1. Cut out the paper pattern of the sun provided on the worksheet. Be sure to cut on the "cutting" line.

2. Place the two 8-inch squares of yellow felt together. Place the paper sun on top of the squares. At the tip of each ray of sunshine, pin the paper sun to both squares.

3. Cut out the two layers of felt by cutting around the paper pattern. 
4. Mark the "sewing" line on the top piece of felt. Remove the paper sun by tearing it off. Leave the pins in place.

5. Thread a needle with yellow thread. Knot the end.

6. Sew around the sun on the "sewing" line, using a small running stitch and leaving a one-inch opening on one ray.

7. Fill the sun bean bag with dried peas, beans, lentils, or birdseed.

8. Finish sewing the last inch of the "sewing" line. Knot securely.

9. Obtain information on Vitamin D from your teacher. Cut pictures of Vitamin D-rich foods from magazines and mount them on cardboard or tagboard.

10. Sit in a circle with all the children around the outside and the "teacher" in the center. (The teacher may be any student in the class.) The teacher should hold up a flashcard with the term "Vitamin D" written on it and explain that when sunlight strikes our skin, Vitamin $D$ is produced by our bodies. The teacher should then explain the function of Vitamin D.

11. Show examples and/or pictures of foods that contain Vitamin D. Most of the Vitamin D contained in these foods was produced when the foods were exposed to sunlight or ultraviolet light.

12. Tell the children to close their eyes and imagine that they are the "sun", sending rays out to all the other students. Ask them to explain how Vitamin D can keep our bodies healthy and to tell the sources of Vitamin D.

13. Have the children stand in a circle and listen to the directions for the game "Catch a Sunbeam". If possible stand outdoors in the sunshine or indoors near a window.

14. Choose one child to be the sun's messenger. The child should walk around the circle carrying the sun bean bag while the other children chant:

"A sunbeam, a sunbeam, Who will catch the sunbeam?"

15. The messenger should drop the sunbeam behind any child in the circle.

16. That child should pick up the sun and try to tag the messenger before he or she runs around the circle and reaches the empty space. 
17. If the messenger is tagged, he or she must take another turn. If the messenger safely returns to the space, then the child carrying the sun becomes the messenger and takes a turn.

18. The game should continue until each child has a turn.

\section{Questions}

1. What vitamin is made when sunlight touches the skin?

2. How is that vitamin produced?

3. Why is it necessary for babies and children to have the proper amounts of that vitamin?

4. What foods provide us with Vitamin D? How is Vitamin $D$ produced in these foods?

5. Why is it a good idea to teach young children through games?

\section{Looking Back}

When people are exposed to the sun, a substance in their skin is changed to Vitamin D. When milk, grains, or even bread are exposed to ultraviolet light, similar substances are also converted to Vitamin $D$. When we artificially irradiate these foods with ultraviolet light, we are said to be "fortifying" them. These foods, as well as sunshine, are our best sources of Vitamin D. Vitamin $D$ is especially important for building strong bones and teeth in young children.

Children learn through play. By playing a game in the sun, they have learned that their bodies need the sun's rays to stay healthy.

\section{Going Further}

Prepare a picnic or snack outside in the sun for the children. Choose a food or foods that are high in Vitamin D. Explain again how Vitamin D is produced.

As the children play "Catch a Sunbeam", have the messenger call out a food that is a source of Vitamin $D$ as the sun bean bag is dropped behind a player.

Take a large sheet of heavy cardboard and draw a picture of a house on the surface so that the entire sheet becomes a house. Cut out the doors and windows. Prop the cardboard against a wall. Have the children toss the sun 
bean bags through the doors and windows to collect points. This game can be played individually or in teams, and is a good way for children to gain skill in accurate throwing. The game can then lead into a discussion on the way sunshine enters a house and the benefits of passive solar design for homes. 


\section{5-6}

\section{Worksheet}

Making a Sun Beanbag

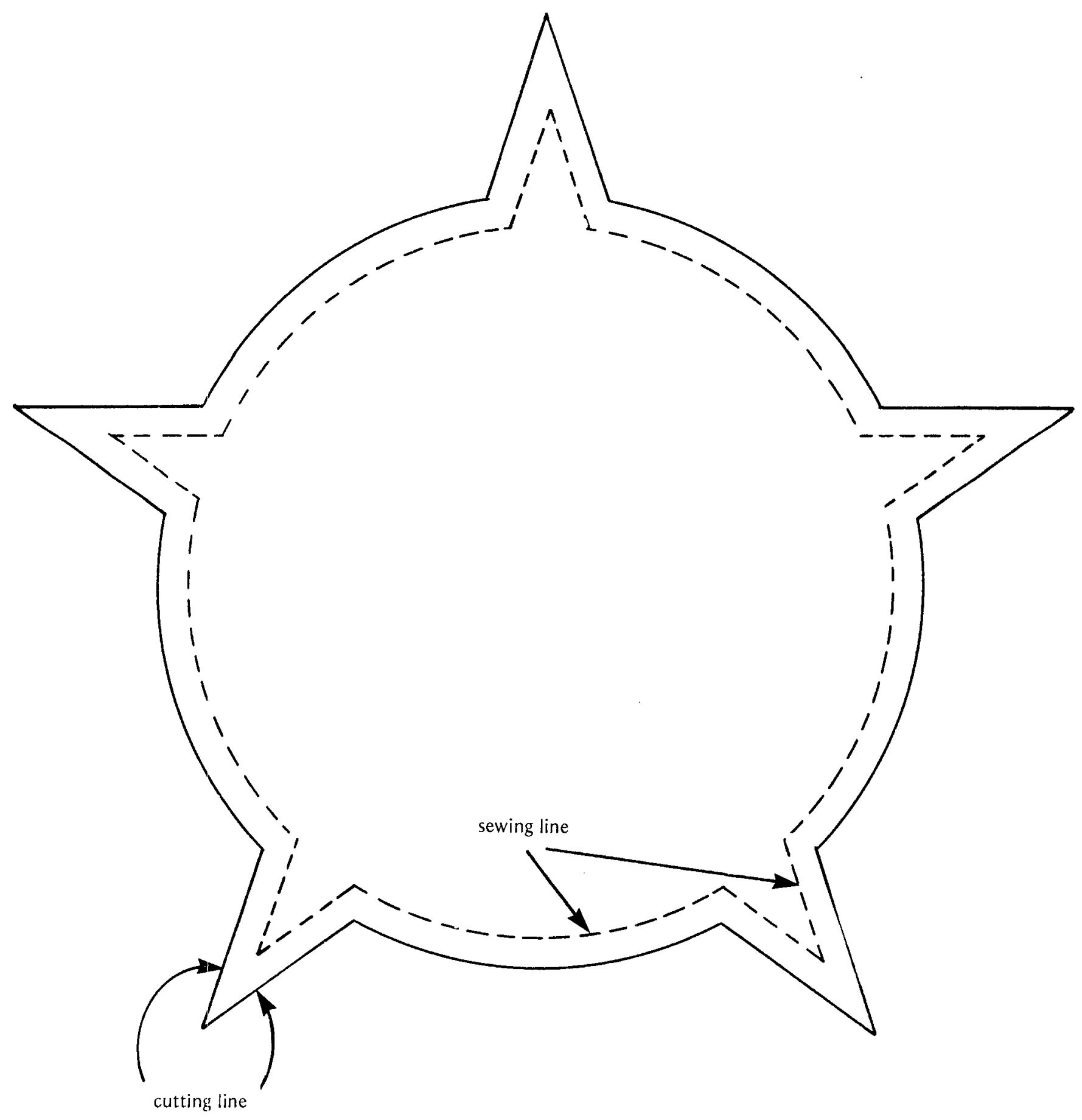


Teacher Information

\title{
Catch a Sunbeam : AGame for Young Children
}

\section{Suggested Grade Level and Skill Area}

7-12 home economics program in which students are working with young children

Future Homemakers of America

\section{Skill Objectives}

\author{
Pattern cutting \\ Fabric cutting following a pattern \\ Sewing fabrics together with a running stitch \\ Teaching young children through games
}

\section{Content Objectives}

Sunshine in the form of ultraviolet light is necessary for conversion of a substance in human skin to Vitamin $D$.

Vitamin $D$ is necessary for building strong bones and teeth in young children. It allows the body to utilize calcium and phosphorus.

Natural foods contain little Vitamin D, but do contain substances which, when exposed to ultraviolet light, are converted to Vitamin D. When these foods are irradiated artificially to produce Vitamin $D$, they are said to be fortified.

Children learn readily through the use of games that also contain instruction.

\section{Background}

Vitamin D is available to the body through two separate processes. The first process occurs when human skin is exposed to sunshine. Human skin normally contains a fat-related compound known as cholesterol, which can be converted through a complex series of chemical reactions into dehydrocholestero1. This compound is converted to Vitamin $\mathrm{D}\left(\mathrm{C}_{27} \mathrm{H}_{44} \mathrm{O}\right)$ when exposed to certain wavelengths of ultraviolet light (generally not those which cause sunburning). The most crucial factor in the production of Vitamin $D$ is not the quantity of dehydrocholesterol in the skin but the availability of the wavelengths of ultraviolet which trigger the conversion process.

Rickets is a disease in which bones do not calcify normally and teeth develop poorly calcified enamel. This disease can be prevented by proper amounts of Vitamin $D$. Vitamin $D$ allows the absorption into the bloodstream of the calcium and phosphorus contained in food and the reabsorption of phosphorus in the kidneys. Rickets is a disease of the temperate regions of the earth, where there is much cloudiness, fog, and 
air-borne dust to filter out the ultraviolet rays of the sun. Heavy clothing and window glass will also filter out ultraviolet, further reducing the natural production of Vitamin $D$ by the skin. Fortunately, rickets is becoming a rare disease, because there is a second method of obtaining Vitamin D--observing a proper diet.

Common foods contain little Vitamin D. Plants and animals, when exposed to sunlight, can also produce Vitamin $D$, but the amount in any prepared food will vary with the food's exposure to sunlight. Saltwater fish contain large amounts of Vitamin D, as do the livers (which can store Vitamin D) of cod, halibut, and sharks. Thus the importance of the famous cod-liver oil. Today many common foods are fortified with Vitamin D, by either feeding the vitamin to the animals or irradiating milk or breads with ultraviolet radiation from arc lamps.

It should be noted that both methods of obtaining Vitamin D can be overdone. Excessive exposure to sunlight can cause skin cancers in some individuals, while overdoses of Vitamin D in foods can cause nausea, loss of appetite, and headaches, as well as a loss of calcium and phosphorus by the body.

\section{Advance Planning}

Purchase supplies for the sun bean bag ahead of time.

Gather magazines from which pictures of Vitamin D-rich foods can be cut (saltwater fish, fortified milk, and bread).

\section{Suggested Time Allotment}

One period to sew sun bean bags

One period to receive Vitamin $D$ instruction and practice roles as teachers

One period to teach young children about Vitamin D and to play "Catch a Sunbeam" (15 minutes for teaching session and 20-30 minutes to play the game and provide summary for the lesson)

\section{Suggested Approach}

This activity provides an excellent opportunity for students to work with young children in a child development program. It also allows students a chance to prepare materials and perform as teachers in providing instruction to youngsters.

Perform this activity as a class project or as individual projects for interested class members. If older home economics students or FHA members are working with young children they may work on a oneto-one basis with the children, allowing them to help make the sun bean bag. In this case, the bean bag can be given to the child to take home. 
Step 4 in the procedure requires students to mark a sewing line on the fabric. They may need instruction on how to do this.

Prepare the students well for their roles as teachers. Give them instruction on Vitamin D. Allow them time to prepare the flash cards and pictures of foods rich in Vitamin D. Have them practice what they will say and do before they teach the game to the children. Allow different students to perform different sections of the game part of the activity. Emphasize the importance of their teaching roles.

\section{Precautions}

If student supplies are not provided by the school, alternatives should be sought. Two suggestions would be to

sell the bean bags as a fund raising project (Christmas decorations, toys, paper weights, door holders, draft stoppers), or

ask a local charity group to supply materials, or have students collect odds and ends from home.

If the lesson is taught outside, prepare the children for the bright sunshine by explaining how strong the sun's rays can be and by suggesting the use of sunglasses.

As children mu around the circle, be sware of hazards and hidden obstacles.

\section{Points for Discussion}

How does the body obtain Vitamin $\mathrm{D}$ during the winter or on cloudy days?

Do people with dark skin receive more or less Vitamin D from sunshine than people with light skin? Why?

What foods have you eaten this week that have provided you with Vitamin D?

What are the dangers of overexposure to sunlight or overdoses of Vitamin D?

\section{Typical Results}

The students will enjoy creating their sun bean bags, but younger students may have difficulty with motor coordination skills.

The young children will learn three or four sources of Vitamin $D$ and will understand that it helps create strong bones and teeth.

The young children will enjoy playing the game "Catch a Sunbeam" and will understand that sunshine plays a major role in their health. 


\section{Evaluation}

Observe the students as they make the sun bean bags. Check the final product for sewing skills.

Verbally quiz the young children on the sources and function of Vitamin $D$.

Analyze the students' cooperation, sharing techniques, and teaching skills when playing the game. Observe their interactions with the children.

\section{Modifications}

Students could allow the young children to sew the bean bags themselves, giving help as needed, or they could allow the young children to help them make the bean bags.

The children could search in magazines for their own pictures of the sources of Vitamin D.

\section{References}

Catch a Sunbeam, Florence Adams.

(Harcourt, Brace, Jovanovich, 757 Third Avenue, New York, NY 10017,1978 , \$7.95/paper.)

Energy from the Sun, Melvin Berger.

(Distributed by Harper \& Row Publishers, Keystone Industrial Park, Scranton, PA 18512, 1976, \$6.89.)

Human Physiology, Thomas Morrison et al.

(Holt, Reinhart and Winston, Inc., 383 Madison Ave., New York, NY 10017,1972 , \$15.96/paper.)

The Integral Urbau House, Self-Reliant Living in the City, Farallones Institute. (Distributed by Charles Scribner's Sons, Book Warehouse, Vreeland Avenue, Totowa, NJ 07512.

Introductory Nutrition, Helen Guthrie. (The C. V. Mosby Co., 11830 Westline Industrial Drive, St. Louis, MO $63141,1979, \$ 18.95$. 
DRAFT

\section{Sunny the Solar Snake}

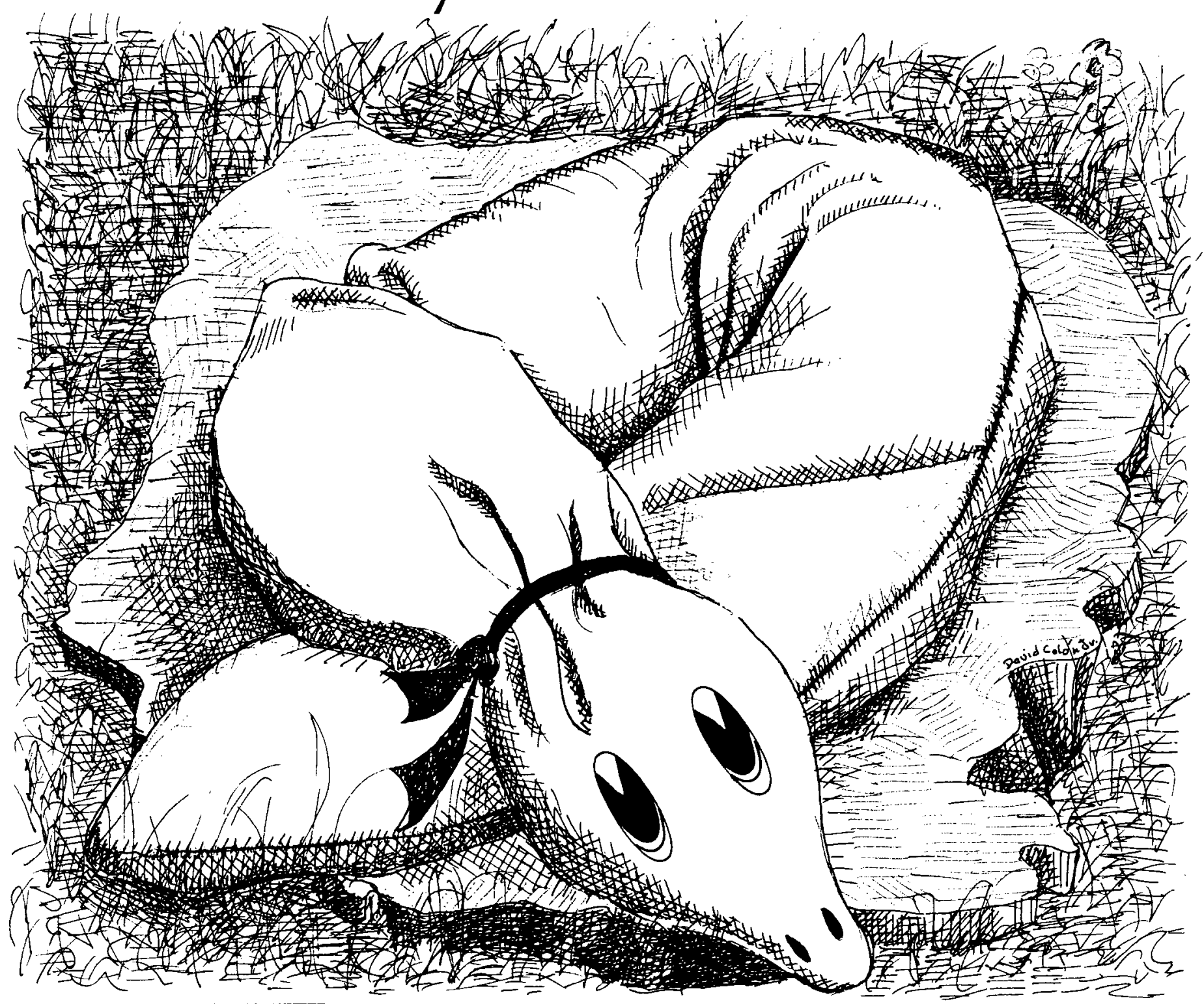

Introduction

Children are naturally curious about the world around them. The sun is a very important part of this world, for without it we could not live.

In this activity you will use a puppet draft stopper, "Sunny, the Solar Snake", to help younger students understand the importance of the sun. You will also show them ways in which the sun can help us: by heating water, by warming us, by making plants grow, by making dough rise. You will use children's natural curiosity to help them explore the ways that the sun warms and enriches human life. 


\section{Objectives}

to

At the completion of this activity, you should be able

- sew a draft stopper in the shape of a snake,

- present a skit and some simple solar energy experiments to a class of young children,

o explain the purpose and the results of each experiment to the students, and

o summarize for the students what they have learned.

\section{Skills and Knowledge You Need}

Simple sewing skills

Using a sewing machine to do simple stitching

Explaining purposes and results to young children

\section{Materials and Equipment}

one piece of colored fabric ( $1 \mathrm{~m}$ by $20 \mathrm{~cm}$ )

thread to match the fabric

straight pins

a sewing machine

scissors

sand, dried peas, beans, or lentils

rock (about $15 \mathrm{~cm}$ in diameter)

card with a large letter "S" printed on it

picture of "Sunny, the Solar Snake" sitting on a rock

\section{Procedure}

1. Fold the piece of fabric inside out and in half the long way, so that it measures $1 \mathrm{~m}$ by $10 \mathrm{~cm}$.

2. Using, straight pins, pin the edges of the long side together, as shown in Diagram 2 .

3. In the same manner, pin the edges of one end together.

4. Sew the pinned edges together, stitching $1.5 \mathrm{~cm}$ in from the edge of the fabric.
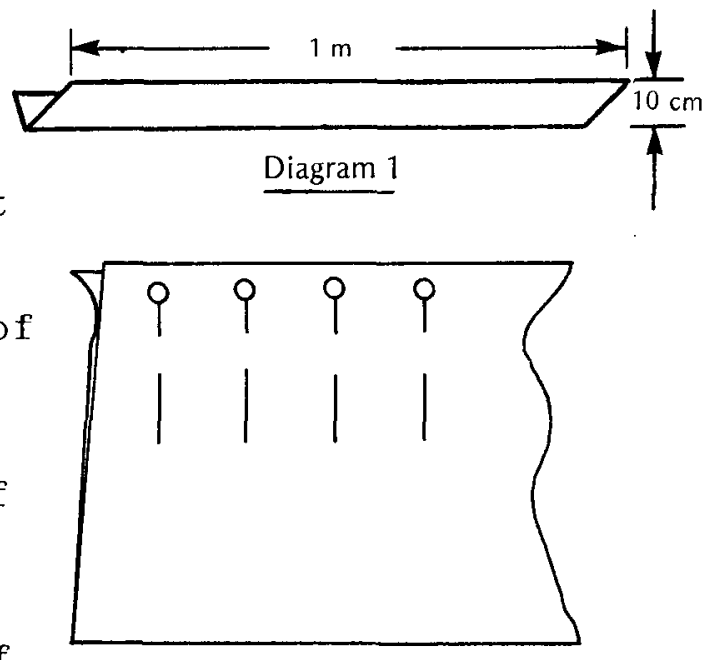

Diagram 2 
5. Trim the corners of the fabric as shown in Diagram 3 .

6. Turn the fabric tube right side out. You may want to use a ruler to help turn the fabric.

7. Fill the tube with sand, dried peas, beans, or lentils.

8. Turn the edges of the open end under and pin them.

9. Hand stitch across the open end, using an overcast stitch.

10. Decorate one end of the tube to $\underline{\text { Diagram } 3}$

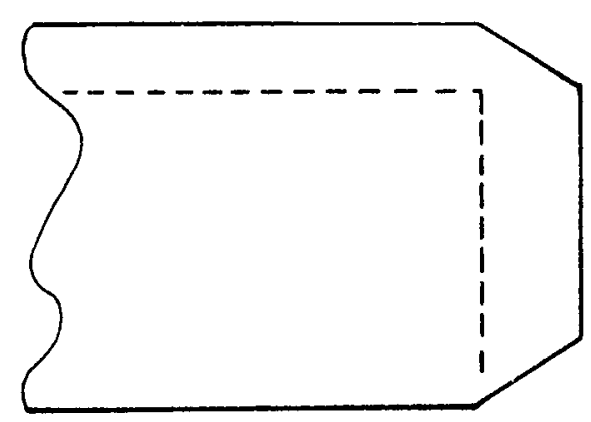
create the head of a snake. Use buttons, sequins, embroidery, fabric pieces, or drawn facial features.

11. Use the fabric snake to practice the skit, "Sunny, the Solar Snake", provided on the Worksheet.

12. Gather the materials needed for several simple experiments which show how the energy of the sun can be used. Some possible experiments are listed below.

a. Fill a black plastic bag with water. Twist-tie the top and place it in the sun for several hours. Use the warmed water to wash students' hands at the end of class.

b. Plant seeds in flower pots, orange juice cans, or $227 \mathrm{mi} \mathrm{milk}$ cartons filled first with a layer of small stones, then with potting soil. Follow the directions on the seed package. Water, then place some containers in the sun, others in a dark closet or drawer. Water regularly. Have the students observe the results. Explain the results to them.

c. Tie-dye T-shirts by arranging the fabric in several clumps and securing tightly with rubber bands. Fill a tub or sink with water and dissolve dye in the water. Soak the T-shirts in the dye. Squeeze out excess moisture, remove the rubber bands carefully with scissors, and hang on an outdoors clothesline to dry. (You may have to string a clothesline between two trees.) Explain how the drying process occurs.

d. Make bread or coffee cake according to a recipe which uses yeast. Let the dough rise in a sunny window so students can observe it. Explain how the dough rises. Bake the coffee cake or bread and serve it as a snack. 
e. Take the students outside and have them sit in a sheltered, sunny place. Let them describe how the sun makes them feel.

f. Use paper plates and sticks or straws to make sundials according to Diagram 5. Place the sundials in the sun and every hour mark the position of the stick's shadow on each plate. Explain to the young studerts how the sun seems to move through the sky and how it can be used to tell time. Allow the

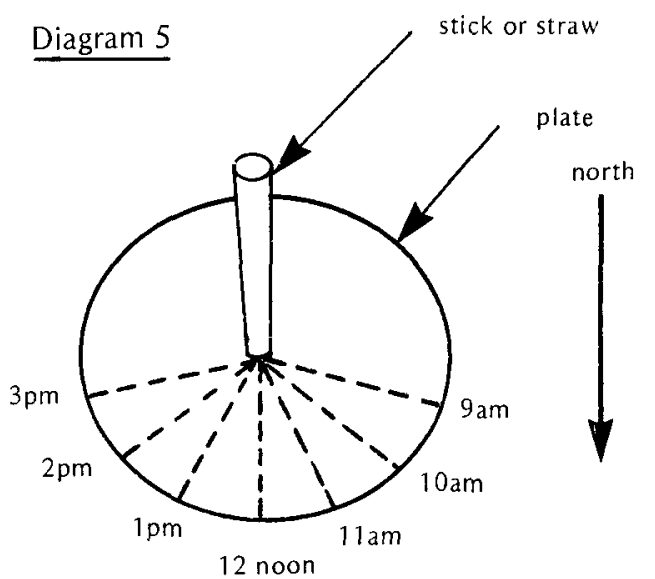
students to color the sundials and to take them home to show their parents.

13. Use "Sunny, the Solar Snake" to present the skit to a class of younger students or preschool children. Allow the young students to help you prepare the experiments. Explain the purpose of each experiment. As results from the experiments become evident, explain to the young students what happened.

14. Summarize for your young students what has been learned in this activity. Explain again the words "solar energy". Ask the students why solar energy is so important. Ask them what it would be like if there were no sun or solar energy.

15. Explain to the students that "Sunny" is really a draft stopper. If there are enough snake draft stoppers, allow each child to take one home to his/her parents.

\section{Questions}

1. Describe each experiment that was performed with the students.

2. What was the purpose of each experiment?

3. What were the results of each experiment?

4. What do you think the young students learned from this activity?

5. What kind of a follow-up lesson could you prepare for these student's?

6. How can "Sunny" be used as a draft stopper?

7. Using "Sunny" as a draft stopper is one way to conserve energy. What are some other ways? 
8. Why is it important to conserve energy?

9. Why is it important for both you and younger students to know about solar energy?

10. In what other ways could we use solar energy to help us with our everyday tasks?

\section{Looking Back}

You constructed a draft stopper to use as a prop in a skit about solar energy. This draft stopper became "Sunny, the Solar Snake", a means of exciting young children's curiosity about solar energy. In this way you were able to teach the importance of solar energy to young children.

But "Sunny" can also be used to stop drafts. By placing "Sunny" along the bottom of a door or window at home or in your classroom, the exchange of warm or cold air through the crack can be slowed down. This will help conserve energy when a room is being heated or cooled.

\section{Going Further}

Explore other ways to conserve energy beyond using a draft stopper. List as many ways of conserving energy as you can.

Prepare other simple solar energy experiments.

Dry the same clothes on a sunny day and on a cloudy day. Compare the drying times.

Melt an ice cube in sun and another in shade.

Observe evaporation of water from two smooth, dark surfaces, one in sun and one in shade.

Heat water in a coil of garden hose by laying it in the sun. Use the heated water to wash hands.

Caution: On a hot, sunny day, the water may become very hot.

Make draft stoppers for the principal's office, other classrooms, the nurse's office, and the school library.

Sell draft stoppers as holiday gifts or an FHA/HERO project. Present the draft stoppers to senior citizens as energy-saving gifts.

Write a book about solar energy for young children. Use "Sunny" as the main character.

Prepare a puppet show featuring "Sunny" and her adventures with solar energy. 


\section{Worksheet}

\section{A Skit Using "Sunny, the Solar Snake"}

Before class, heat a rock in the sun for "Sunny" to use as a prop. Arrange the young students in a circle and have the presienter sit along the edge of the circle. The rock should be on the presenter's lap.

The skit starts as "Sunny" slithers up on the rock.

Sunny: SSSS.... He110, I'm Sunny, the Solar Snake. What are your names?

Presenter: (Encourage students to say their names one at a time.)

Sunny: My name starts with the letter S. SSSS....

Presenter: (Hold up the card with the letter "S" printed on it. Encourage the students to say "S".)

Sunny: "S" is a very special letter to me because it stands for snake, sun, and Sunny, my name.

Presenter: (Hold up the picture of "Sunny" sunning on the rock.)

Sunny: You're probably wondering why my name is Sunny, the Solar Snake. Sunny and solar are both words to describe the sun, and of course you all know I'm a snake. All snakes love to lie in the sun because the sun warms them, making it possible for them to move. When I was little, I loved to lie in the sun more than any other snake my parents had ever seen. So my parents named me Sunny, the Solar Snake. (Pause.)

Have you often sat in the sun yourselves? How does it make you feel? I like lying on my rock because the sun warms it too. Would you like to feel my warm rock?

Presenter: (Pass the rock around the circle. When it returns, have "Sunny." slither up on it again.)

Sunny: Today I'm visiting you to show you how the sun's energy is helpful to living things. Sometimes the sun's energy is called solar energy. Can all of you say that?

Presenter: (Encourage the students to say "solar energy".)

Sunny: (to the presenter) Please put my rock in the sunny window. Then I'll lie there and listen to you tell us about today's experiments with solar energy.

Presenter: (Place "Sunny" and the rock on the window sill. Then explain to the students which experiments they will be performing today.) 


\title{
Teacher Information \\ Sunny the Solar Snake
}

\section{Suggested Grade Level and Skill Area}

7-12 Home Economics in which child development is taught

Child Development

Future Homemakers of America

\section{Skill Objectives}

\author{
Using simple sewing skills, including pinning and hand overcast \\ stitching \\ Decorating a draft stopper to look like a snake \\ Presenting a skit and some simple solar energy experiments to young \\ children \\ Explaining purposes and results to young children \\ Sunmarizing content
}

\section{Content Objectives}

A simple visual aid such as a puppet draft stopper can be used to stimulate children's curiosity about the world.

A skit is a simple way to convey new information to young children.

Simple solar energy experiments in which young children can participate will arouse their interest and create a positive learning environment in which to teach about solar energy.

The usefulness of solar energy can easily be demonstrated to young children by such activities as using the sun to heat water in plastic bags, make dough rise, tell time, and dry clothing. The need for solar energy in plant growth can be illustrated by growing seeds with and without sunlight.

Young children are capable of learning about the importance of solar energy.

\section{Background}

As the costs of fossil fuels continue to increase, more and more people will turn to the sun as an alternative source of energy. Today's students, both high school and elementary, will become the policy makers and consumers of tomorrow. By acquainting them with the uses of solar energy, we can help prepare them for their future roles.

Children also communicate what they've learned to their parents, and in this way we, as educators, can convey the effects of our lessons 
beyond the classroom. By teaching our students the seriousness of the energy crisis and the possibilities of alternative sources of energy, we can have an effect beyond both the classroom and today.

This activity focuses on some of the ways in which solar energy is used. It will acquaint students with the basic effects of solar energy: heating, drying, and photosynthesis. As older students teach younger ones, they will all become more appreciative of the importance of solar energy in their everyday lives. They will also learn about some simple ways in which solar energy can serve as a replacement for fossil fuels: by heating water, by drying clothes naturally, by causing dough to rise.

\section{Advance Planning}

Obtain the fabric for the draft stoppers well in advance of the activity. Assemble other needed materials and equipment.

Duplicate the worksheet for class use.

Locate any unusual materials needed for the solar energy experiments, but allow students to take over the responsibility for obtaining most of the materials.

If this activity is not being conducted as part of a child development program in which home eccnomics students normally work with young children in class, locate an elementary or preschool class for which your students can perform this activity.

\section{Suggested Time Allotment}

1 period to introduce the activity and plan the implementation of it 1-2 periods to practice the skit and prepare the experiments

1 morning or afternoon to conduct the activity

1 period to answer questions and summarize the activity

Since some of the experiments will require a longer period of time (hours to weeks) for results to become evident, either students or the teacher of the younger class should plan follow-up and summaries as needed.

\section{Suggested Approach}

Although perfect for a child development class in which home economics students normally work with young children as part of their class assignment, this activity can easily be performed in an elementary or preschool classroom. Many elementary teachers would be happy to have older students provide a lesson for their classes. 
This activity should be approached as an opportunity for home economics students to act as teachers of younger students. Each student can be assigned a part of the activity to perform. Alternatively, the home economics students can be divided into groups, and each group can prepare a different experiment to perform with a different group of younger students. Or each group can prepare the skit for a different elementary class.

Prepare the students for their roles as teachers. Emphasize the importance of what they're going to do and how they're going to do it. Give them ample time to practice the skit, prepare the experiments, and prepare for steps 14 and 15 in the procedure.

Encourage the home economics students to act naturally with younger children. Make sure they give the younger children time to respond to questions and to express their own questions, answers, and feelings.

The younger children should observe each experiment from start to finish. Plan a separate follow-up lesson for the longer experiments. If this is not possible, make sure the elementary or preschool teacher is aware of the need to demonstrate and explain these results as they occur.

\section{Precautions}

Make sure students know how to properly operate a sewing machine.

\section{Points for Discussion}

How does a draft stopper save energy?

What other projects could the class make to save energy in the home or classroom?

What are some of the ways we can use the sun to do work or provide energy?

Why is it important to start teaching children at a young age? What methods can we use to help them learn in an enjoyable way?

How can parents help their children learn? How can they help prepare their children for school? 


\section{Typical Results}

The results of the simple experiments should occur as follows:

a. The water in the black plastic bag will become warm after several hours.

b. Over several weeks, the seeds placed in sunlight will germinate and develop strong, green, healthy leaves and stems. Those seeds placed in the dark either will not germinate or will develop weak, spindly, yellow stems and leaves and will die due to lack of sunlight.

c. The T-shirts will line dry according to the type of day on which they are hung out.

d. The yeast bread or coffee cake dough will quickly double in size when placed in a warm, sunny window.

e. Students should be able to express easily how they feel in the sun.

f. Once calibrated, the paper plate sundials should be able to tell time accurately over several weeks. They should be calibrated on the hour before each day of use.

\section{Evaluation}

Observe students' skills in working with younger students, preparing and conducting the skit and experiments, and summarizing the activity.

Check the draft stoppers for evidence of sewing ability, neatness, and creative design of the snake's face.

Ask students to list simple experiments which illustratè the concepts of solar energy.

\section{Modifications}

The younger students can help make the snake draft stoppers and help design their faces.

Home economics students can encourage the parents to participate in their children's learning experiences. Have the class or an interested group of students draft a letter to the parents, explaining the solar energy activities conducted in class and encouraging the parents to conduct a similar activity at home as enrichment and reinforcement. Edit the letter and duplicate it on school stationery. Send it home with the younger students. 


\section{References}

The Best of Energy Book: Grades 1-3 and Grades 4-6,

CSU Extension Service, Denver County, and Denver Public Schools.

(Denver Co. Extension Office, 1300 East Virginia Avenue,

Denver, C0 80209, \$11.50.)

The Best Present of A11: A Reprint from Ranger Rick's Nature Magazine, Oliver Houck.

(National Wildlife Federation, 1412 Sixteenth Street, N.W. Washington, DC 20036, single copy free, additional copies

$\$ 30$ each.)

Catch a Sunbeam: A Book of Solar Study and Experiments, Florence Adams. (Harcourt Brace Jovanovich, Inc., 757 Third Avenue, New York, NY $10017,1978, \$ 7.95$.

The Day We Saw the Sun Come Up, Alice E. Goudey.

(Charles Scribner's Sons, Shipping and Service Center, Vreeland Avenue, Totowa, NJ 07512, 1961, \$8.95.)

Energy Activities with Energy Ant (Grades 1-3). (U.S. Department of Energy, Distribution, Office of Administration and Services, Washington, DC 20545, 1975, free.)

"E" the Magnificent Magician, National Science Teacher's Association. (U.S. Department of Energy, Technical Information Center, Po Box 62, Oak Ridge, TN 37830,1980 , free.)

Energy from the Sun, Melvin Berger.

(Distributed by Harper \& Row Publishers, Keystone Industrial Park, Scranton, PA 18512,1976 , \$6.89.)

Putting the Sun to Work, Jeanne Bendick. (Garrard Publishing Company, 1607 North Market Street, Champaign, IL $61820,1979, \$ 5.97$. )

Science Activities in Energy, The American Museum of Atomic Energy, Oak Ridge Associated Universities.

(U.S. Department of Energy, Technical Information Center, P.0. Box 62, Oak Ridge TN 37830, free.)

Tilly's Catch-a-Sunbeam Coloring Book, Tilly Spetang. (Environmental Action Reprint Service, Box 545, La Veta, C0 81055, $1975, \$ 1.50$. 


$$
6-12
$$




\section{DRAFT}

\section{Living with AlternativeEnergy}

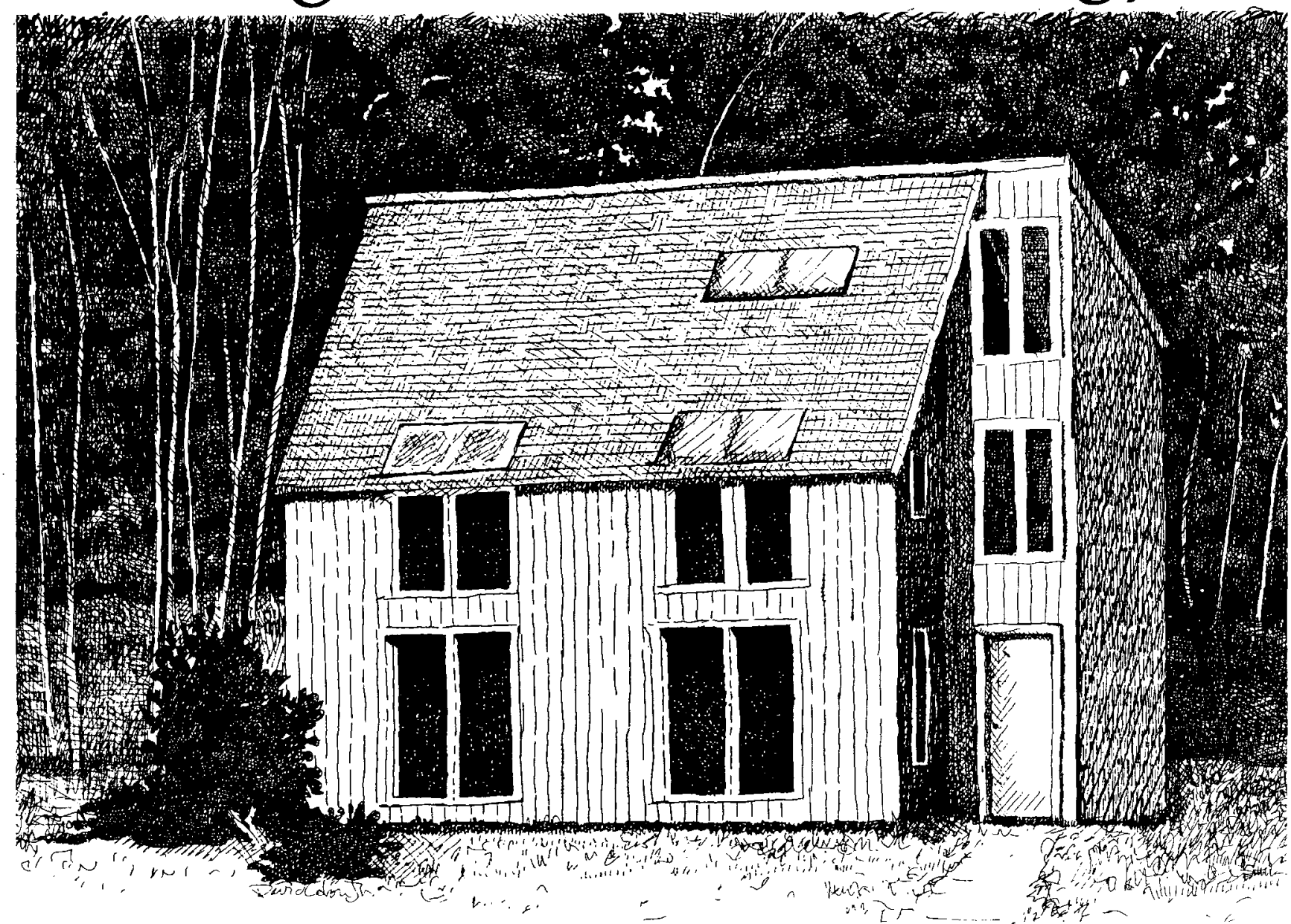

\section{Introduction}

Have you ever thought about what it would be like to live in a house that was heated or cooled by solar energy? How would your life be different if your family decided to heat your home primarily with wood? Using alternative sources of energy in your home would cause some changes in the way your family lives. These changes are often called changes in lifestyle.

In this activity you will read about families which bave different energy-consuming lifestyles. As you read each case study, think about the type of energy the family is using. Is it a renewable or nonrenewable energy resource? How has it changed the family's lifestyle? Perhaps you can imagine what it would be like for your family to live in each of the houses described in the case studies. 


\section{Objectives}

to

At the completion of this activity, you should be able

o identify the kinds of energy used to heat homes,

o determine whether each kind of energy is a renewable or nonrenewable resource,

- analyze the changes in lifestyle that each kind of energy use would require, and

- recognize the commitment needed to live in a house heated with an alternative source of energy.

\section{Skills and Knowledge You Need}

The skill of reading and discussing a case study

The knowledge that caulking is a putty-like material used to seal joints or cracks around doors and windows

The knowledge that insulation is a material that slows heat loss from a home

\section{Materials and Equipment}

a notepad and pencil for recording

\section{Procedure}

1. The teacher or another student will divide your class into three groups.

2. Appoint one person to be the recorder of your group's discussion.

3. Read and discuss each case study.

4. Answer the questions in the question section.

5. When all three groups are finished, your class should reassemble and discuss the three different lifestyles presented. 


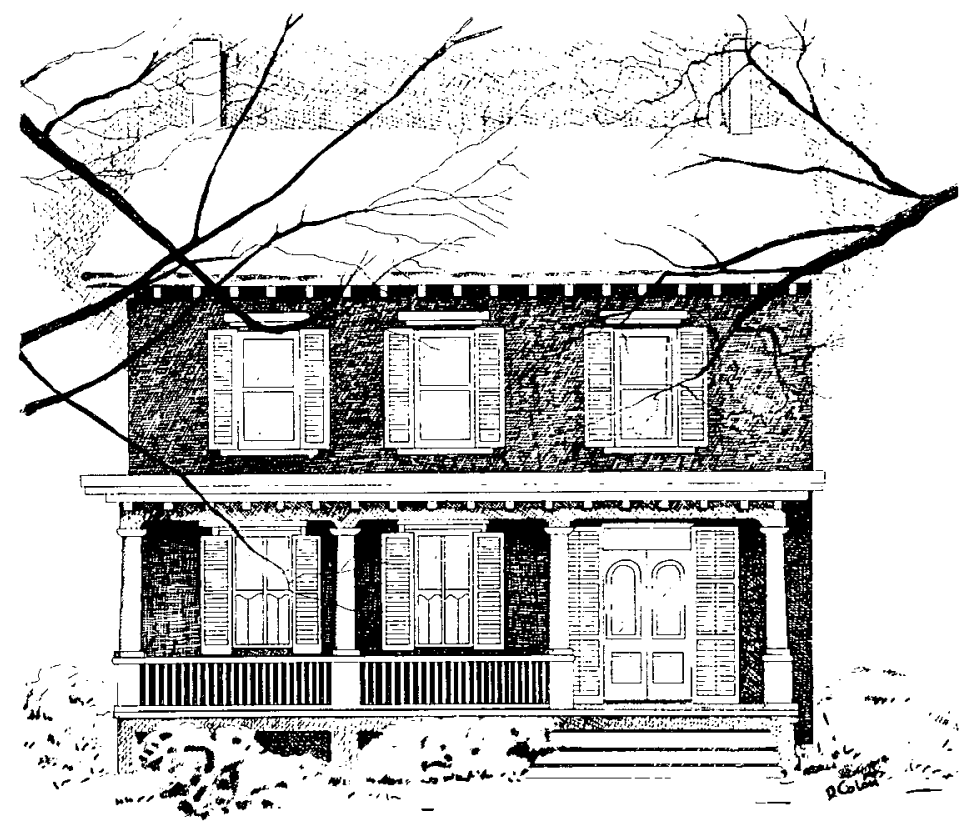

\section{Case Study 1}

The Warners moved from a large mid-western city to a small town in the country. Mr. Warner was transferred by his company to manage a factory located in the town. Mrs. Warner had worked as a technician in a medical office, but did not plan to begin work in the new location for several months, until the family was well settled. The Warners have three children of elementary school age.

The family found an older single-family dwelling in their new town. It was close to the school the children were attending and within walking distance of most community services.

The home the Warners moved into was built in the late 1930 's. It was a two-story home with a living room, dining room, kitchen, three bedrooms, and one and one half baths. One bedroom was on the first floor. The house was insulated with 3 inches of cellulose insulation in the ceiling and almost none in the side walls. All the windows and doors had wooden storm windows which were in need of caulking.

The elderly couple from whom the Warners bought the house indicated that the heating and hot water bills were not unreasonable for a house of that size. The heating system utilized a gas-fired furnace which had been converted from coal some years earlier. Water was also heated with natural gas.

The Warner family moved into the house at the end of the summer and adjusted well to their new home and community. As the weather became colder, the family noticed that the monthly heating bills were quite high. Mrs. Warner was home all day and consequently did most of the housework then. The children were in and out of the house frequently. The Warners' monthly bills were higher than they had expected and exceeded the amount they had originally budgeted for heating costs. The Warners had not realized that during the cold winter months the elderly couple had closed off the upstairs and conducted most of their daily activities on the first floor.

The Warners determined that the house needed more insulation, but this could not be installed until Mrs. Warner went to work and enough money for it could be saved. In the meantime, the farily realized that its lifestyle would have to be adjusted. 


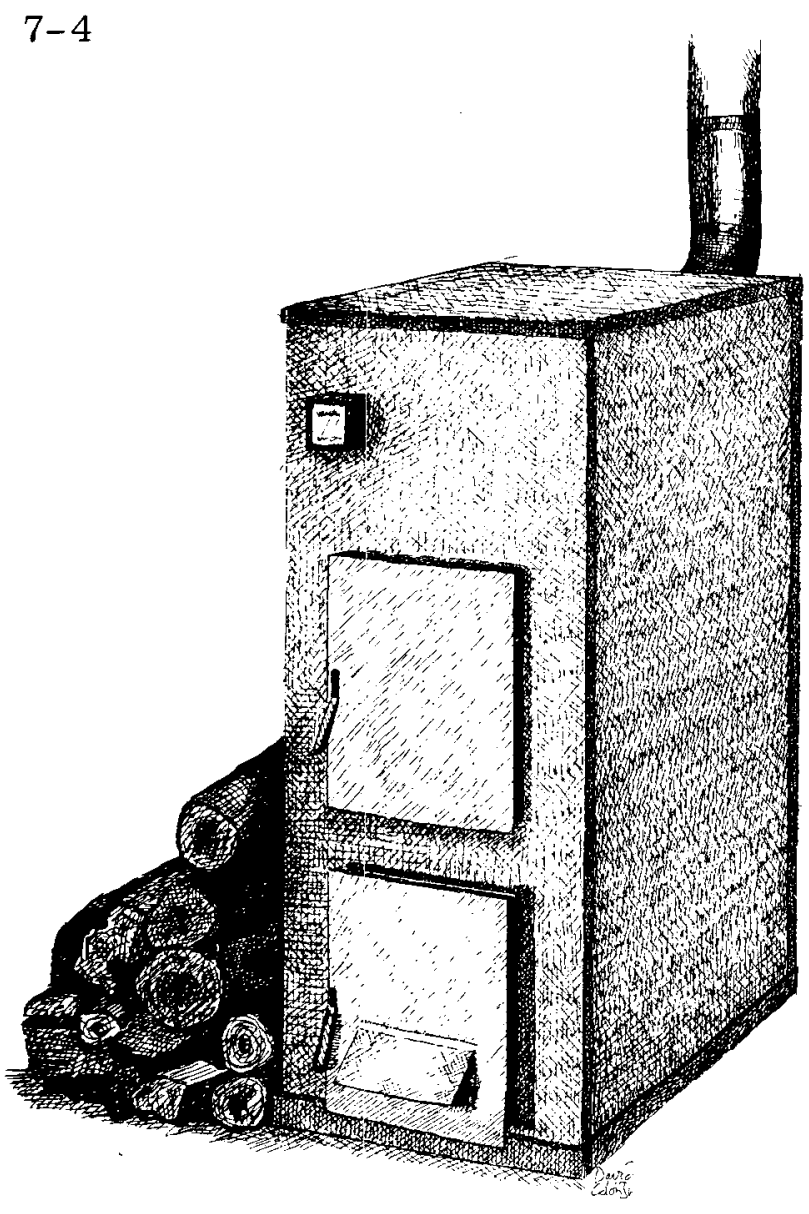

\section{Case Study 2}

The Burns family lives five miles outside of a small northern city. Ten years ago they built a ranch home for their family of six on five acres of heavily wooded land. They have four sons: Robert, age 18; Kenneth, age 16; George, age 12; and Jonathan, age 9 . Their home has been the source of much enjoyment for them. Both $\mathrm{Mr}$. and Mrs. Burns work in the city. Mr. Burns works as a building inspector and Mrs. Burns works as a manager in a local department store.

For several winters the Burns had been keeping track of their energy costs. They had noticed a $68 \%$ increase in the price of fuel oil in four years. Fuel oil was used to heat their home as well as to heat hot water for the family all year long, and with four children the need for hot water was great! With their eldest son Robert contemplating college, Mr. and Mrs. Burns were concerned about the additional financial responsibility they would soon incur.

The family decided that one way in which they could save money and energy would be to install a wood furnace in the basement. The wood furnace could be hooked to their oil-fired furnace as an auxiliary source of heat for the house. Hot water for domestic use could also be heated by the wood furnace. The family realized that they had a source of wood right in their own backyard. Since Mr. Burns had indicated a desire to start a garden, the family cut the trees down in that section of the yaid which was to be used for gardening.

The wood furnace was installed and the family worked together chopping and stacking wood. During the fall and winter, when heat was required, the family used the new wood furnace. It was necessary to feed the wood furnace three times per day: in the morning, after school, and in the evening before bed. After a period of adjustment, the Burns found their wood-heated home very comfortable and were content with their attempt to save money and conserve on the world's limited resources. 
Case Study 3

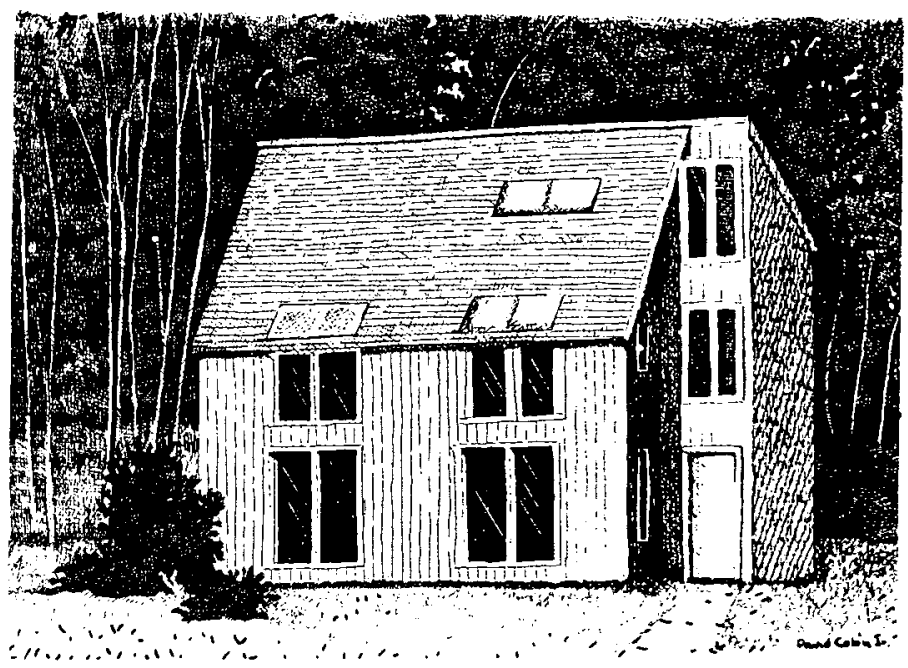

The Rogers family, which consists of father, mother, and two children (Marci, age 13. and Melanie, age 9), realized that they had outgrown their small bungalow in a southwestern city.

They looked at several larger homes for sale in their city, but decided that none of the homes they saw met their expectations. Because energy costs were rapidly increasing in their part of the country, they sought a home that was built with energy conservation in mind. The Rogers wanted a home which would be inexpensive both to heat in the winter and to cool in the summer.

After much thought, the Rogers decided that perhaps the only way they would get their energy-efficient home would be to build one. They looked at many house plans and finally decided to build a passive solar home. After consulting both an architect and an engineer about the plan, they found a general contractor who built the home for them.

The home was planned with floor-to-ceiling windows on the south side of the house and very few windows on the north side. The windows had shades which couj.d be raised or lowered in order to control the entry of the sun's rays into the house. The interior of the home was open and had spaces which could be adapted to the activities of the family. This was in marked contrast to their former home, in which each individual room had a separate purpose.

While the home was being built, the Rogers planned the interior decoration and the landscaping. They considered such factors as the type of trees and shrubs which should be planted around the house and the type of furnishings which would absorb or reflect the sun's rays.

The Rogers excitedly moved into their energy-efficient passive solar home. After several months the family members sat down one evening to discuss life in their new home. They realized that their heating costs were quite low and that the house was exceptionally comfortable. One reason for this was that they had learned to manage the house efficiently. In discussing their current home maintenance activities, they commented on the ways in which their lifestyle had changed. 


\section{Questions}

Case Study 1

1. In what ways could this family adjust its lifestyle to save energy?

2. What kind of energy is used to heat this house? Is this energy renewable or nonrenewable?

3. Considering the family's financial situation, what small structural changes, which would not be too costly, could be made to this home to make it more energy efficient?

4. What large structural changes would you suggest?

5. How will this family's energy needs change as the children get older?

6. In the future, what energy factors should this family consider when making a housing purchase?

\section{Case Study 2}

1. What changes in family lifestyle would occur as a result of heating a house with wood?

2. What heating costs did this family have after the wood furnace was installed?

3. What changes in responsibilities occurred when this family switched to wood heating?

4. What will happen when the family runs out of wood on its property?

5. Who will take care of the stove and the wood-cutting process when all of the boys have moved away from home?

6. What changes could the Burns make to the structure of their home to make it more energy efficient?

7. What kind of energy had the family been using before switching to wood?

8. What would happen if most families started using wood for home heating? 
Case Study 3

1. What kinds of activities did the Rogers have to perform to manage their house efficiently?

2. What changes in lifestyle would be necessary as a result of living in a passive solar home?

3. What might have happened to the family's heating costs if the house hadn't been managed properly?

4. What energy resources did the Rogers save by living in a passive solar home?

5. What other resolirces did the Rogers use in order to conserve energy?

\section{Looking Back}

You have had the opportunity to look at three different methods of heating a home. Each method consumed different amounts and kinds of energy. Each method also required a different family lifestyle and varying degrees of commitment by family members in order to save energy. Family members sometimes had to substitute human energy and time to conserve nonrenewable energy resources. They learned the role cooperation between family members plays in reaching family goals. Perhaps you can think of ways your family can work together to conserve nonrenewable energy resources.

\section{Going Further}

Write a case study exploring how another family might conserve energy. Perhaps you may want to write about a family using an alternative form of energy. Have the class discuss your case study.

Go along with some people who are cutting wood for use in a wood-burning stove. Observe the work involved. Ask the people why they are heating with wood.

Go to a store that sells wood-burning stoves. Ask a salesperson to explain to you how the stoves work and how much wood they require. Besides the cost of the stove, what other costs would be incurred if you switched to wood heating?

Talk to an architect who builds solar homes. How has the architect taken into consideration the change in a family's lifestyle that would result from living in a solar home? 
$7-8$

•

$\bullet$ 


\title{
Living with Alternative Energy
}

\section{Suggested Grade Level and Skill Area}

\author{
11-12 Home Economics (Housing or Family Life) \\ Future Homemakers of Americá
}

\section{Skill Objectives}

\author{
Discussing case studies as a small group \\ Identifying different energy lifestyles \\ Identifying ways in which energy resources can be saved
}

\section{Content Objectives}

Homes may be heated with renewable or nonrenewable sources of energy.

Alternative sources of energy for home heating include wood and solar.

Heating with an alternative source of energy requires a commitment by family members and a change in family lifestyle.

By increasing family cooperation and allowing the family to work together toward a common goal, heating with an alternative source of energy may actually increase the quality of family life.

\section{Background}

As the reality of the scarcity and escalating cost of nonrenewable resources becomes more apparent, more families will look to alternative forms of energy to heat and cool their homes. To a certain extent this means that their lifestyles will change. To conserve energy certain tasks that were formerly unnecessary will become the responsibility of family members. Thus, it appears there will be a substitution of human energy (which is renewable) for nonhuman energy. Some families may not want to exert human energy to conserve energy resources and may even be willing to pay the ever-increasing price for convenience. This is a decision each family will have to make.

Famiiies considering ways to conserve energy will have to recognize that some changes in the way they live may be necessary. There are many examples of this. Families that live in poorly insulated houses may find that it is economical to shut off certain portions of their homes and confine their activities to other portions. Turning off lights, turning down the heat, shutting the water off while shaving, fixing and caulking storm windows, weatherstripping, driving less, preparing oven meals, washing laundry in cold water, and eating fewer processed foods are examples of some changes in lifestyle. 
Other changes may have more impact on the ways in which families function. Using a wood-burning stove may mean extra time will have to be spent cutting, splitting, stacking, and preparing wood. The fire will have to be loaded periodically throughout the day. Soot may require extra cleaning by family members. At times the house nay seem too warm or too cold. These are all examples of changes in lifestyle. Some families have not considered these changes before making the decision to purchase a wood-burning stove. For others, purchasing a stove is a way to become more self-sufficient. These families are satisfied knowing that they are not dependent on oil, natural gas, and electric companies for energy. They enjoy the exercise of preparing wood for burning. They feel content sitting together around a warm stove on a cold winter's night.

For those who live in a passive or active solar home, there are also changes in lifestyle. Opening and closing draperies or shutters to allow the sun in or to block the sun out is a very important job. The schedule for activities such as showering or bathing and washing clothes or dishes may not always be convenient. Planning for periods when the sun does not. shine can change the way a family lives. Despite these changes, many families have found living in a solar home an exhilarating experience. They feel free from dependence on outside sources of energy. They feel they have more control over their own activities. They are satisfied in knowing that they are conserving the world's finite resources while saving money too.

\section{Advance Planning}

Review the background information to prepare for class discussion.

Duplicate case studies for distribution to students.

\section{Suggested Time Allotment}

One to two class periods

\section{Suggested Approach}

Discuss the background information, introducing students to the idea that lifestyle changes do occur as a result of increasing energy costs and shortages of supply. Adaptations by families can be very creative, with each person in the family sharing some responsibility for a conservation behavior.

Explain the way the activity will be carried out. Students will form three groups and discuss the case studies.

At the conclusion of the group discussions, the class will reassemble and discuss the case studies. The teacher should stress the importance of conservation behaviors as a means of saving energy and the responsibility each student has in achieving an energy-conserving. lifestyle.

Smaller groups (6-8 students) may work more efficiently. 


\section{Precautions}

Be careful not to insert value judgments into the discussion.

\section{Points for Discussion}

How could each case study situation be used to improve the relationships between family members?

How could families lower their energy consumption?

Human energy may have to be substituted for nonhuman energy in order to save valuable resources. What effect could this have on the amount of time family members spend doing household tasks? How will it affect the homemaker's time?

What do you think it would be like to live in a solar home? A home heated with wood?

\section{Typical Results}

With leadership from the teacher, students should understand that the lifestyles of families/people will change when they use alternative forms of energy.

\section{Evaluation}

Observe students' skill in carrying out the assignment: discussing, recording the discussion, and interacting.

Have students write an essay on living in a home that uses an alternative form of energy. What would it be like? How would they adjust? Would they like it?

\section{Modifications}

Have students write their own case studies for discussion.

Invite a person who lives in a solar home or uses a wood-burning stove to discuss changes in lifestyle with the class. 


\section{References}

Rays of Hope: Transition to a Post-Petroleum World, Denis Hayes. (W. W. Norton \& Co., Inc., 500 Fifth Avenue, New York, NY 10036, 1977 , \$3.95/paper.)

"Changing Family Lifestyles: Adapting to the Energy Crisis", T. Cornille, K. Kransky, R. Pestle. (Journal of Home Economics, American Home Economics Association, 2010 Massachusetts Avenue, N.W., Washington, DC 20036, Winter, 1979, pp. 36-37.).

"Changing Our Energy Behavior", Janice M. Hogan. (Journal of Home Economics, American Home Economics Association, 2010 Massachusetts Avenue, N.W., Washington, DC 20036, May, 1978, pp. 18-21.)

"The Energy Crisis and the Family", Beatrice Paolucci and Janice M. Hogan. (Journal of Home Economics, American Home Economics Association, 2010 Massachusetts Avenue, N.W., Washington, DC 20036, December, 1973, pp. 12-15.)

"Energy Decisions and Quality Living", Beatrice Paolucci. (Journal of Home Economics, American Home Economics Association, 2010 Massachusetts Avenue, N.W., Washington, DC 20036, Winter, 1978, pp. 22-23.)

"A Solar-Heated House", Suzanne B. Badenhop and Arthur F. Badenhop. (Journal of Home Economics, American Home Economics Association, 2010 Massachusetts Avenue, N.W., Washington, DC 20036, May, 1978, pp. 26-28.)

"Solar One", Honor Fairman. (Journal of Home Economics, American Home Economics Association, 2010 Massachusetts Avenue, N.W., Washington, DC 20036, December, 1973, pp. 27-33.) 
DRAFT

Buying SolarWithout Getting Burned

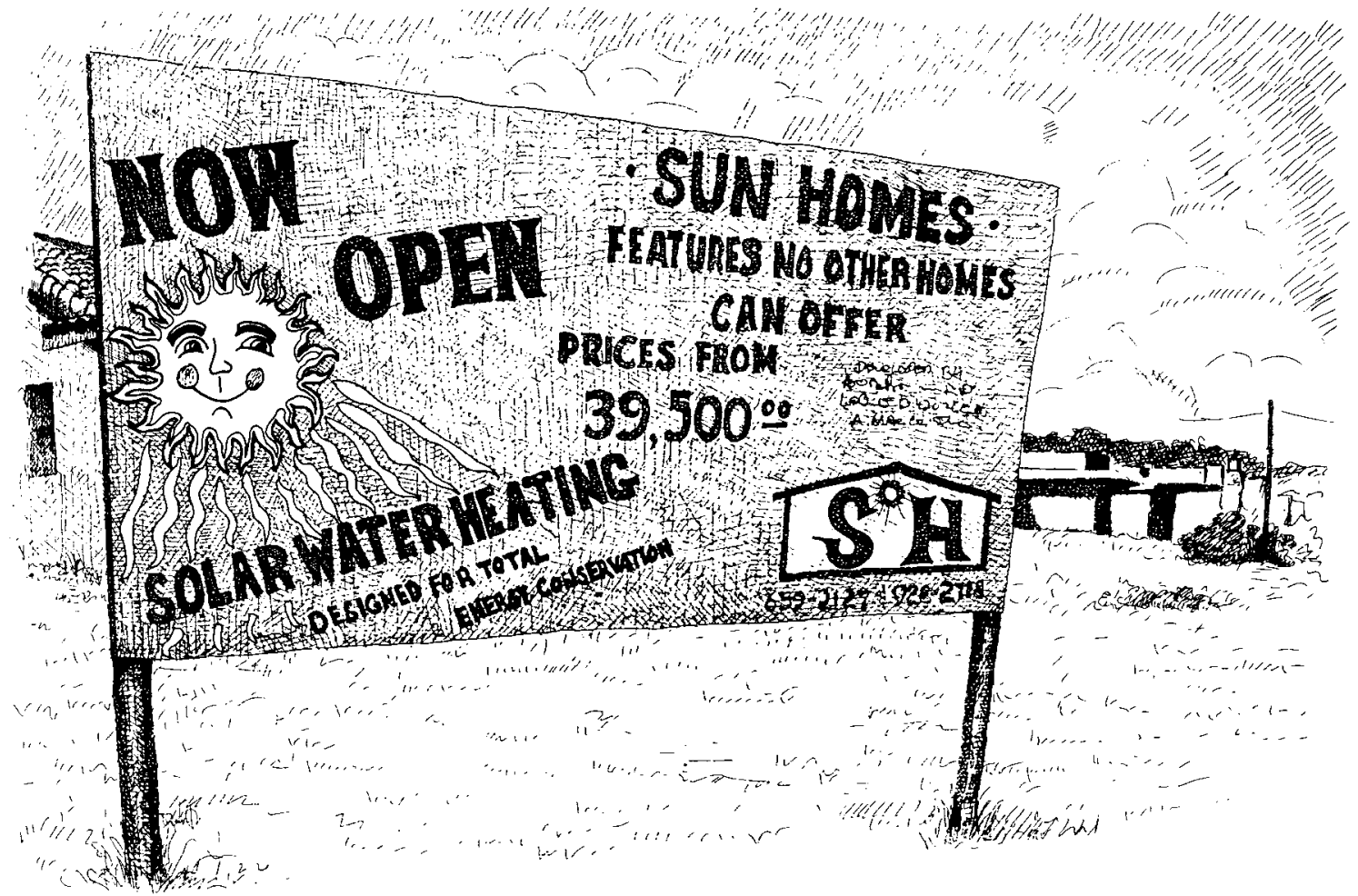

\section{Introduction}

Have you ever seen a newspaper quote similar to this one?

"Over the last few months the suburb of Pine Plains has seen a stream of visitors: builders, prospective homeowners, solar enthusiasts, and solar critics. Their goal was a house with a solar water heating system recently constructed as a demonstration project. On display was the solar collector array with all-copper plumbing, a sophisticated control system, and a 120 galion water storage unit. The tour was impressive.... but the system had stopped working shortly after it was installed."

Solar energy does work, but it takes careful thought and planning before the purchase. For many families, solar water heating can provide between 75 and 100 percent of their hot water needs. In this activity, you will learn how to wisely purchase solar water heating equipment.

What factors should you consider before purchasing a solar hot water system? They include

whether the solar system will save money over time,

what kind of system to buy,

from whom to buy it, and

how the buyer is protected by a warranty or guarantee. 


\section{Objectives}

At the completion of this activity, you should be able to

o research a topic related to the purchase of solar water heating equipment,

o identify the kinds of information you need to gather and consider before deciding to make a purchase,

o analyze data to determine the important factors in a wise purchase of solar water heating equipment, and

o provide other consumers with information about purchasing solar equipment.

\section{Skills and Knowledge You Need}

How to conduct interviews

How to do library research using periodicals and reference materials

How to write letters requesting information

How to work in a small group

How to compile your research and present it to a group

\section{Materials and Equipment}

access to a library in your school or community

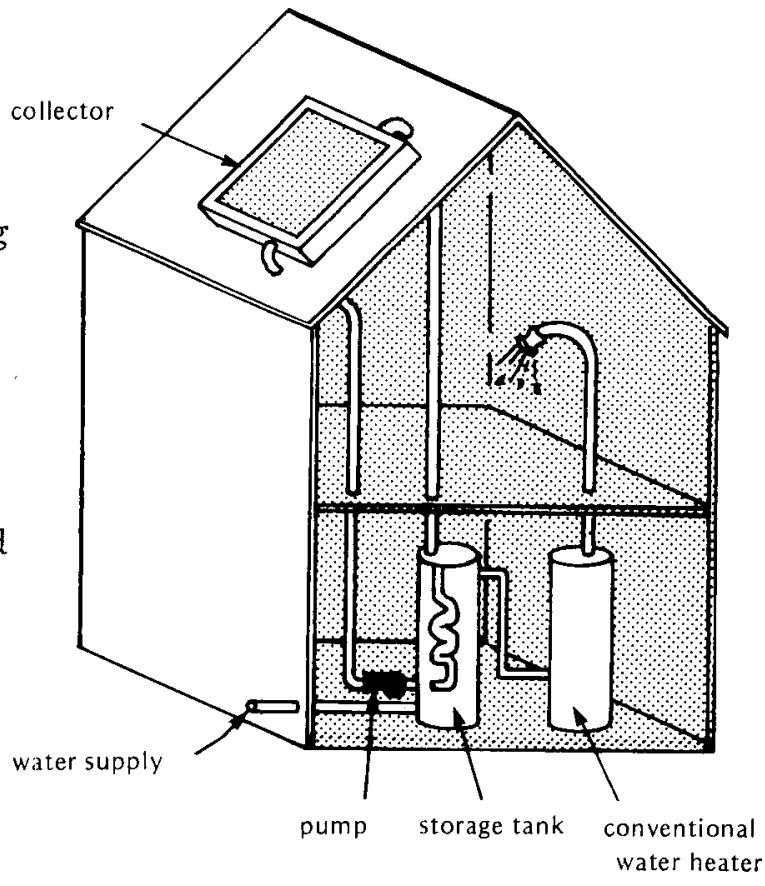

addresses of places where solar information can be obtained (your teacher can supply these)

Diagram

addresses of local solar contractors and dealers

\section{Procedure}

1. Divide your class into four groups. Each group will investigate one aspect of purchasing solar hot water equipment.

2. Select a leader who will organize the group's findings.

3. Four data tables are provided. Each begins with a question to investigate. Select one data table to complete. 
4. Investigate your question by contacting or researching three sources for information. Suggested sources are

local solar water heating dealers and contractors, solar manufacturers' catalogs and brochures, libraries, state and federal energy offices, solar information centers, and solar energy publications and pamphlets.

a. Write to, interview, or research each source to obtain the information requested in the data table.

b. Complete the data table by filling in the appropriate spaces with the data your group has collected.

5. Allow your group leader to organize and report your group's findings orally to the class.

6. Using all the data the class collected, combine the information into a one-page summary of the factors that should be considered when purchasing a solar hot water system.

7. Edit and type the summary. Distribute the summary to others by either

a arranging and duplicating a pamphlet, or

b. submitting the summary for publication in a school or community newspaper.

\section{Questions}

1. Where did you find information on solar consumerism?

2. What information did you find on your group's question?

3. What important information about purchasing solar hot water systems did the other groups gather?

4. What are the most important factors to consider in a wise purchase of a solar water heating system?

5. How will the information you and your classmates compiled on solar energy be useful to someone who is shopping for a solar water heater?

6. How might you make this information available to the citizens in your community? 


\section{Looking Back}

By now you know what information should be gathered and considered before deciding on the purchase of a solar hot water system for your home. Solar heated water can provide as much a.s 20 percent of your home's total energy consumption. Heating water with the sun saves precious fossil fuel resources for future generations while providing a clean, safe source of energy for today. Would you consider purchasing a solar hot water system for your home?

\section{Going Further}

Research the solar income tax credits available to homeowners through the state and federal governments.

Investigate the possibility of getting a bank or other lending institution to mortgage a new solar-heated home.

Talk to a real estate agent about whether a solar energy system will raise the resale value of a home in your community.

Talk to an insurance agent about insuring a home with a solar water heating system on it. How will it affect the premiums paid?

Research the estimated rate of fuel energy inflation over the life of a solar water heating system. By how many years will this inflation rate reduce the payback period for a solar water heating system?

Interview-a homeowner who has installed a solar space or water heating system. Find out how well the system is operating and how well the homeowner likes it. 
Question: Will solar water heating save money in my region of the United States?

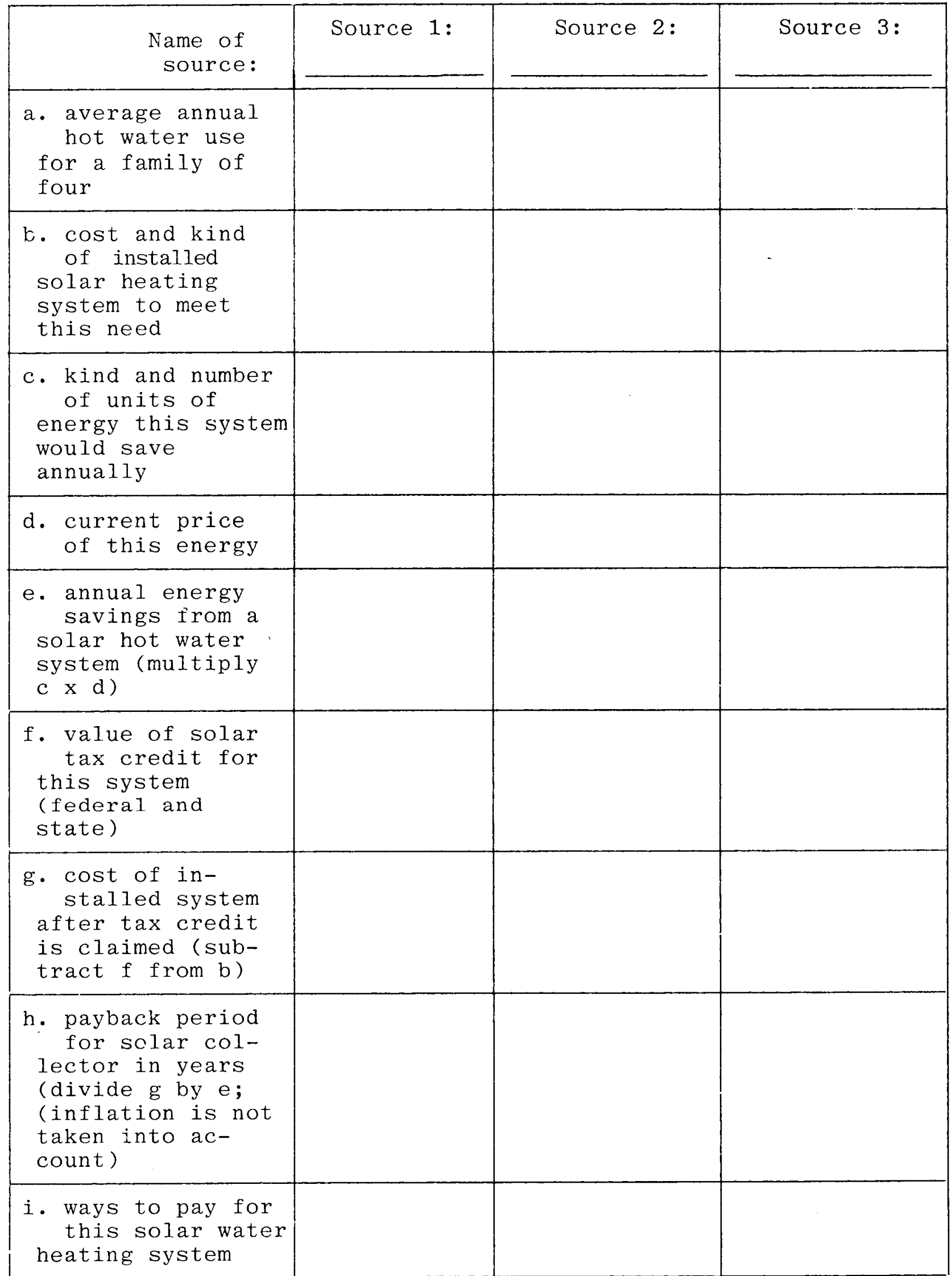




\section{Data Table 2}

Question: How do I select a reputable person to install a solar water heating system?

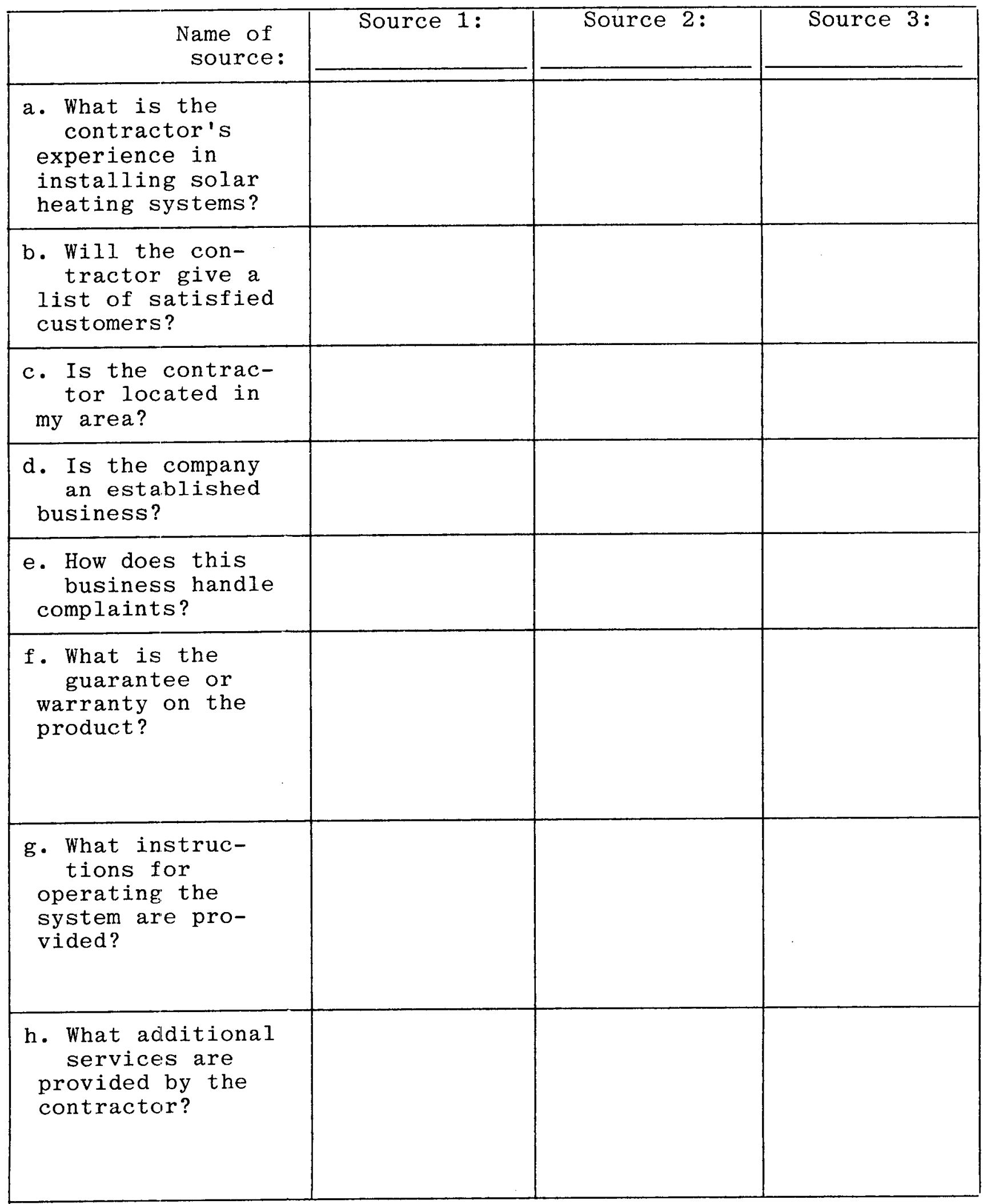




\section{Data Table 3}

Question: How do I select an appropriate solar hot water heating system?

\begin{tabular}{|c|c|c|c|}
\hline $\begin{array}{l}\text { Name of } \\
\text { source: }\end{array}$ & Source 1: & Source 2: & Source 3: \\
\hline $\begin{array}{l}\text { a. What is the cost } \\
\text { of a solar water } \\
\text { heating system for } \\
\text { a family of four? }\end{array}$ & & & \\
\hline $\begin{array}{l}\text { b. What is the ef- } \\
\text { ficiency of the } \\
\text { solar collector? }\end{array}$ & & & \\
\hline $\begin{array}{l}\text { c. What percent of } \\
\text { hot water needs } \\
\text { will this system } \\
\text { provide? }\end{array}$ & & & \\
\hline $\begin{array}{l}\text { d. What are the } \\
\text { material and } \\
\text { quality standards } \\
\text { of the solar } \\
\text { system? }\end{array}$ & & & \\
\hline $\begin{array}{l}\text { e. What monitoring } \\
\text { devices and } \\
\text { safeguards are } \\
\text { provided to in- } \\
\text { sure, proper } \\
\text { operation? }\end{array}$ & & & \\
\hline $\begin{array}{l}\text { f. What is in- } \\
\text { volved in rou- } \\
\text { tine maintenance? }\end{array}$ & & & \\
\hline $\begin{array}{l}\text { g. What is the } \\
\text { life expectancy } \\
\text { of the collector? }\end{array}$ & & & \\
\hline
\end{tabular}




\section{Data Table 4}

Questions: What are the conditions of the contract and guarantee or warranty? How am I protected as a consumer?

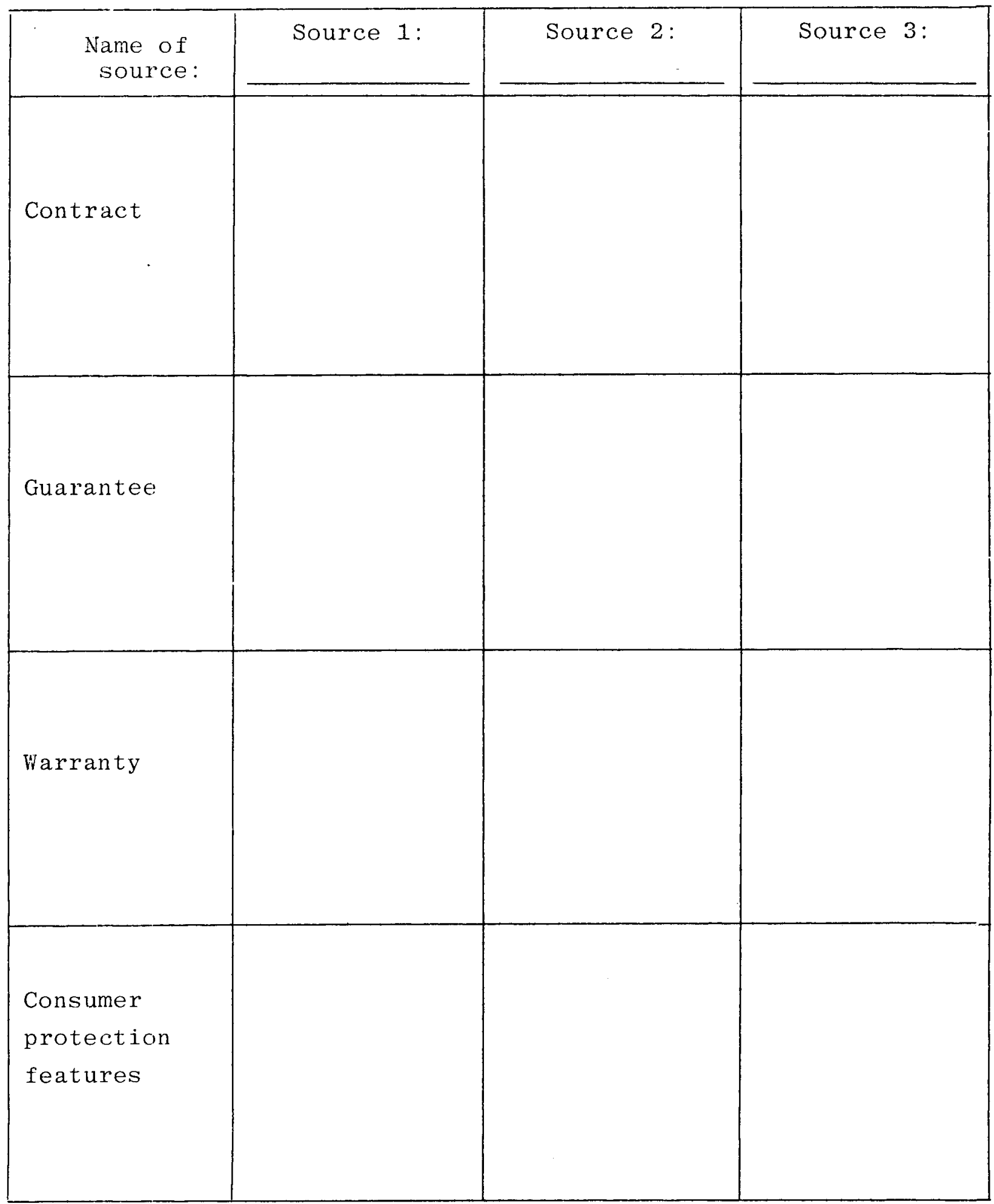




\title{
Buying SolarWithout Getting Burned
}

\section{Suggested Grade Level and Skill Area}

11-12 Home Economics

Consumer Economics

Housing and Home Furnishings

Future Homemakers of America

\section{Skill Objectives}

\author{
Researching and gathering data \\ Identifying sources of consumer information on solar hot water \\ systems \\ Compiling and then summarizing data \\ Analyzing data for consumer decision makirg
}

\section{Content Objectives}

Consumer purchase of a solar water heating system should be a planned decision based on the factual information gathered.

Factors to consider in purchasing solar water heating equipment should include whether the system will save the consumer money over time, which contractor to purchase the system from, which system will best meet the consumer's needs, and what kind of warranty or guarantee the contractor provides.

There are many sources of consumer information on purchasing solar hot water systems.

Other consumers can be provided easily with decision-making information on solar water heating.

\section{Background}

Choosing the correct solar water heating equipment for the home is no guessing game. It takes thought and considerable planning. There are many factors to consider: the type and model of system, the contractor, the warranty, the durability of the system, and the ease of maintenance and repair.

There are also several obstacles to the informed purchase of solar equipment. The consumer must overcome his own lack of knowledge and experience about solar energy, as well as that of many contractors and installers. Some manufacturers may build inferior products. Deliberate fraud and misrepresentation may occur. 
Knowledgeable solar consumerism will include cost considerations. Will solar water heating equipment save consumers money? Although this is a difficult question to answer because of the many variables involved, solar water heating systems are, in general, less expensive than conventional fuel systems when calculated over the life of the system. Exceptions may include sections of the country that experience a high percentage of overcast and cloudy weather. In determining the economy of a solar water heating system, the consumer should consider the tradeoffs between the installed cost of the system, the means of financing (cash, mortgage, loan), the solar tax credits, and the savings over the life of the system from not using conventional fuels. Don't forget to include fuel inflation rates; the more fuel prices rise, the shorter the payback period for a solar system.

Choosing a reputable solar dealer or contractor is an important consumer decision, too. Consumers should check with several contractors and assess their track records. The contractor should be experienced in solar energy systems and should be able to take care of the entire installation, from giving an accurate installation estimate to routine maintenance and repair. The contractor should provide an adequate guarantee or warranty.

The selection of an appropriate solar water heating system for any home is a complicated decision. Not only are there many brands of systems from both large and small manufacturers, hut there are separate solar components for sale that can be assembled by the owner. The selection depends on the reputation of the manufacturer, the skills of the consumer, the time the consumer has available, and the price and efficiency of the system. A relatively inexpensive system can have a low efficiency compared to a more expensive one. In general, the best selection would be a system that delivers the most heat per dollar after the other considerations have been taken into account. For many consumers, an experienced dealer or installer is the person most qualified to help them gather information and judge efficiency.

What happens if a part of a solar hot water system is improperly installed or malfunctions? In this case, the contract and warranty are important. The contract spells out the conditions, of installation: a description of the work to be done, the price, the dates work will begin and end. The warranty is the express commitment of the manufacturer and installer to stand behind the equipment and installation. Most warranties are limited and should be read through carefully.

Once the solar water heater is installed, the consumer should understand how to operate it and how to perform regular maintenance. Does the system use recirculating liquid? If so, how often should it be checked? Should the collectors be kept clean? How should this be accomplished? Whom should the consumer contact if the system malfunctions?

Although there are many factors to consider before purchasing a solar water heating system, the potential savings over the fifteen to twenty year life of the system more than justify the time required to become an informed consumer. In this activity students should learn much about becoming wise solar consumers. 


\section{Advance Planning}

Well before the activity is planned, write for resource materials for student research. In many cases students can do this writing for you as part of their regular coursework. Just make sure no one organization receives more than one request from the class. A list of resources is given at the end of the activity, and a more complete list appears in the teacher's guide.

Check the availability of magazines such as Popular Science, Consumer Reports, Changing Times, U.S. News and Wor1d Report, Solar Age, New Shelter, and the Hudson Home Guides. You may want your school library to subscribe to these magazines or you may be able to gather back issues from friends. Students also may be able to contribute back issues from home.

Coordinate the use of library facilities and equipment with the school librarian, who may want to review library procedures with the class.

Prepare a list of local solar contractors and dealers for students to contact. Inform the contractors and dealers of the activity ahead of time and let them know what questions to expect from students.

Organize pamphlets, catalogs, and brochures as they arrive.

Prepare a class lesson on the fundamentals of solar water heating. One highly recommended source is Hot Water from the Sun. (See references.)

\section{Suggested Time Allotment}

Although time will vary depending on the amount of research done by the class, 2 weeks should be sufficient for data collection.

2 - 3 days for compiling and presenting information to the class

1 - 2 weeks for summarizing and preparing the summary for distribution (not all class time)

\section{Suggested Approach}

Before starting the activity, devote a class period to the fundamentals of solar water heating, including types of systems, solar terms, and names of system components. Check the references for sources of this information.

Discuss with students how they should go about obtaining the needed information. Review letter-writing, interviewing, and telephoning procedures. Discuss using the Readers' Guide and doing library research. Remind students that they are representing the school 
when making outside contacts on this assignment, and that they should be courteous and tactful. Remind them to identify themselves and their purpose.

This activity can be divided into class and extra-class assignments. Provide additional in-class work for groups which finish early.

Allow sufficient class time for organization and oral presentation of group reports.

Duplicate copies of the group findings for each group to work from in preparing its summary. Select two or three students to combine the summaries into one, and to edit and type the final copy. The class can then decide how to distribute the summary, and a few additional students can implement this decision by completing any necessary arrangements.

Invite a consumer advocate and a solar contractor or dealer to speak to the class about solar consumerism.

Plan a field trip to a solar home.

\section{Precautions}

Be sure to make adequate plans with the school librarian before sending students to do class research.

Contact in advance of the activity any persons the students will be interviewing. Let them know the purpose of the activity and the questions the students will be asking.

obtain permission from your principal or department head before starting this activity, since it involves contact with the outside community. If students leave school grounds during the school day to conduct interviews, make sure you have parental permission.

\section{Points for Discussion}

Why is it necessary to know about solar energy and solar heating systems before investing in a particular system?

What results could occur when a consumer does not take the time to investigate solar heating systems, but purchases the first system he/she inspects?

Will a solar hot water system work in your community? Why or why not?

Are there solar collectors on homes in your community? How well do they function? 


\section{Typical Results}

Students will find a wide variety of products available for solar water heating. Quality, materials, construction, installation, efficiency, and warranties will vary significantly. Except in extremely cloudy sections of the country, students should find solar water heating cost effective over time.

\section{Evaluation}

Observe students' participation in their respective groups.

Evaluate groups on the basis of the extent of their research and the sumaries they prepare.

Group members should be able to discuss the major points of their topic.

Ask students to list the factors they should consider in the wise purchase of a solar hot water system.

Ask students to list their reasons for either choosing or not choosing to purchase a solar water heating system.

\section{Modifications}

Have students manage a "solar consumerism" display at parent-teacher night or present their summary to a community group.

\section{References}

Buying Solar, Joe Dawson.

(Superintendent of Documents, U.S. Government Printing Office, Washington, D.C. 20402, 1976, \$1.85.)

California Solar Information Packet

(California Energy Commission Publication Unit M.S. 50,

1111 Howe Avenue, Sacramento, CA 95825, free.)

The Home Energy Guide, Rothchild and Tenney.

(Ballantine Books, 400 Hahn Road, Westminster, MD 21157, 1978, $\$ 1.95 /$ paper.)

Homeowner's Guide to Solar Heating and Cooling, W.M. Foster.

(TAB Books, Inc., B1ue Ridge Summit, PA 17214, 1976, \$4.95/ paper.)

Hot Water from the Sun, U.S. Department of Housing and Urban Development.

(Superintendent of Documents, U.S. Government Printing Office, Washington, D.C. 20402, 1979, free.) 
How to Buy Solar Heating Without Getting Burnt, M. We11 and I. Spetgang. (Rodale Press, 33 East Minor Street, Emmaus, PA 18049, 1978, $\$ 6.95 /$ paper.)

Installation Guidelines for Solar DHW Systems in One-and Two-Family Dwellings, Franklin Research Center.

(Superintendent of Documents, U.S. Government Printing Office, Washington, D.C. 20402, 1980, write for price.)

I've Got a Question about Using Solar Energy.

(U.S. Department of Energy, Technical Information Center, P.0. Box 62, Oak Ridge, TN 37830, free.)

Solar Energy and Your Home, U.S. Department of Housing and Urban Development.

(Superintendent of Documents, U.S. Government Printing office, Washington, D.C. 20402, 1977, write for price.)

Solar Hot Water and Your Home, U.S. Department of Housing and Urban Development.

(Superintendent of Documents, U.S. Government Printing office, Washington, D.C. 20402, 1979, write for price.)

"Don't Get Burned by Solar Ripoffs", Stuart Diamond. (Popular Mechanics, P.0. Box 10064, Des Moines, IA 50350, June 1980.)

"New Danger: Solar Ripoffs", Frank K. Coffee. (Mechanix Illustrated, 1515 Broadway, New York, NY 10036, February 1978, pp. 70, 132.)

"Solarizing? Here are Guidelines for Getting a Square Dea1", David Dvorkin.

(Science Digest, 250 West 55th Street, New York, NY 10019, January 1980, pp. 73-75, single copy from Sales Dept.)

\section{Resource Agencies}

Center for Renewable Resources, 1028 Connecticut Avenue, N.W., Suite 1100, Washington, DC 20036.

Consumer Action Now, 355 Lexington Avenue, 16th Floor, New York, NY 10017.

The Mid-American Solar Energy Center, Alpha Business Center, 8140 26th Avenue South, Minneapolis, MN 55420.

National Solar Heating and Cooling Information Center, P.0. Box 1607, Rockville, MD 20850. 
Northeast Solar Energy Center, 470 Atlantic Avenue, Boston, MA 02110.

Solar Energy Research Institute, 1536 Cole Boulevard, Golden, Co 80401.

Solar Lobby, 1028 Connecticut Avenue, N.W., Suite 1100, Washington, DC 20036 .

Southern Solar Energy Center, 61 Perimeter Park, Atlanta, GA 30341.

U.S. Department of Energy, Technical Information Center, P.0. Box 62, Oak Ridge, TN 37830 .

Western Solar Utilization Network, Pioneer Park Building, Suite 800 , 715 SW Morrison, Portland, OR 97205.

Your local Cooperative Extension Office.

Your state energy office. 


$$
8-16
$$

。

$\bullet$ 



\section{Objectives}

to

At the completion of this activity, you should be able

- explain how the body produces, loses, and conserves heat,

o determine how different kinds of clothing function to keep the body warm, cool, or dry,

o select outfits that will be appropriate for different kinds of activities under fluctuating temperature conditions, and

- construct a poster illustrating how one outfit can be appropriate for changing temperatures.

\section{Skills and Knowledge You Need}

Discussing a topic

Reading a thermometer

Constructing a poster

\section{Materials and Equipment}

a window with a sunny exposure

several fans

extension cords

various types of clothing

two Celsius thermometers

poster paper and markers

catalogs and magazines showing clothing

\section{Procedure}

1. For the next school day, plan to bring clothing to school so you can dress like someone who is going

Insert one of the following suggestions or your own idea in the space above.

swimming

skiing

mountain

climbing

dancing

to bed ice-skating

bowling

horseback riding

golfing

to a party

roller skating to a football game

to play basketball

sailing

camping

to school in January

to school in June 
2. Make a list of the clothing you will bring to class.

3. On the next school day, dress in or bring to class the outfit you've planned.

4. Divide your class into two groups: One group should sit by a sunny window or heater. The other group should sit away from the window or heater, and should have a fan directed towards them.

5. Take a temperature reading at each group's location. By how much do the temperatures vary?

6. With your group, make a list of the reasons why people wear certain kinds of clothing.

7. After 5 or 10 minutes, switch group positions.

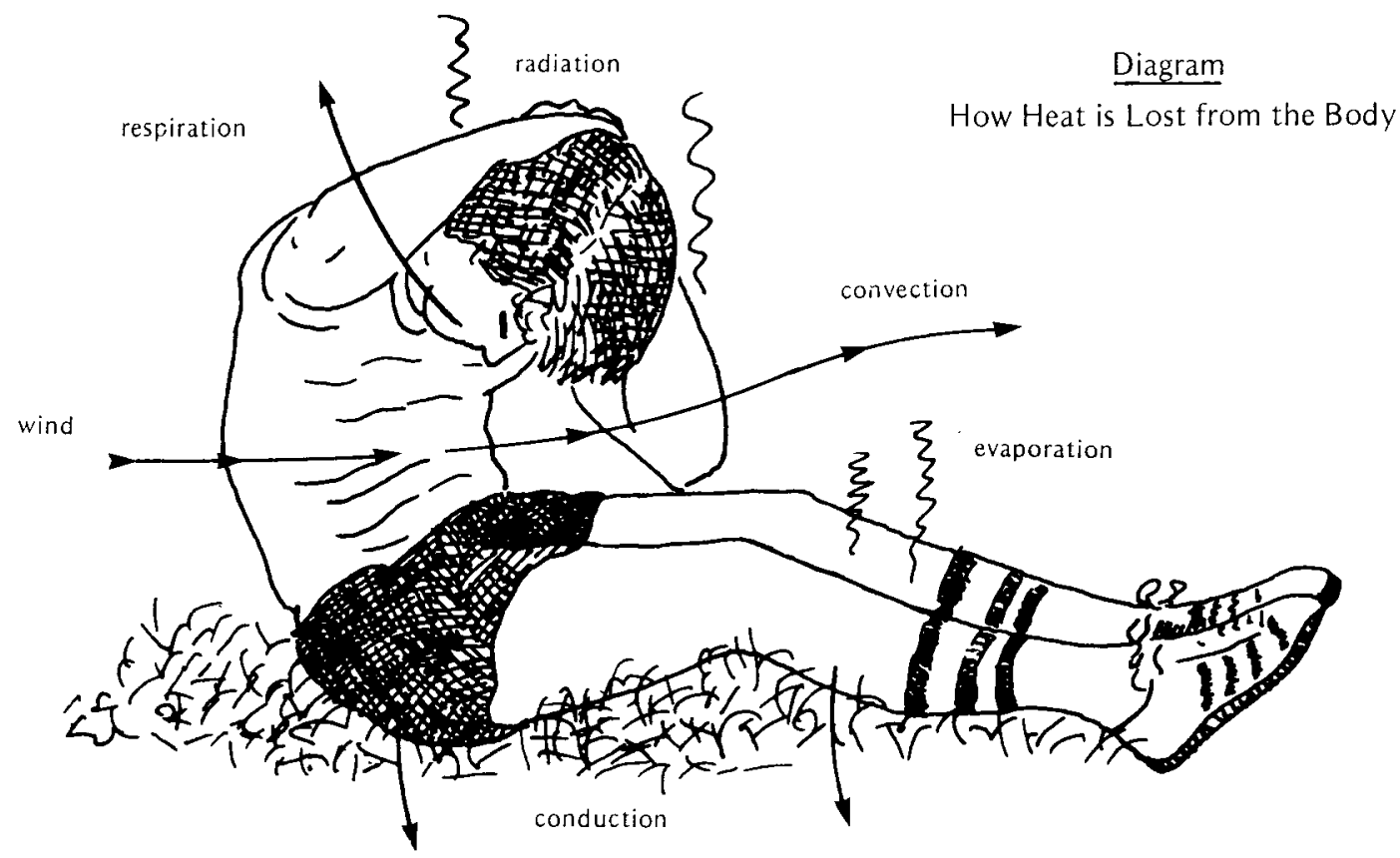

8. Discuss the ways the body maintains an even temperature. Make sure you include

what is happening to your body when you feel warm, what is happening to your body when you feel cold, ways you can increase body heat production, ways you can decrease body heat loss, conduction, convection, and radiation of body heat, evaporation of body moisture, and ways the body conserves body heat.

9. Move your chairs to form a large circle. According to clothing, sit in order from those who should be coolest to those who should be warmest. 
10. Discuss how clothing affects the temperature of the body. Make sure you include

how clothing insulates,

how clothing "air conditions",

how clothing keeps you dry,

kinds of clothing and fabrics which are good insulators,

kinds of clothing and fabrics which are good "air conditioners",

kinds of clothing and fabrics which are good at keeping you dry,

the role of air spaces and fibers in fabric, what happens when fabrics retain water vapor, how clothing color affects body temperature, how fabrics and which kinds of fabrics "breathe" or "wick" moisture away, and

the causes of hypothermia.

11. Starting with whichever of you feels coolest, explain why your outfit keeps you warm or cool.

12. Pretend that on the next school day you will be moving continually from warm locations to cold locations, both indoors and out. Study the table below on layering and then discuss how you could dress to meet these changing temperature conditions.

\section{Table}

\section{Layering Clothes for Changing Temperatures}

Choose the layers which are appropriate for the anticipated indoor and outdoor temperatures.

Layer 1: long underwear (dual-layered or soft wool)

heavy wool socks

Layer 2: light shirt or sweater

light skirt or pants

Layer 3: wool shirt or sweater

wool skirt or pants

leather shoes or boots

Layer 4: insulated vest

Layer 5: wind-proof coveralls

knitted wool gloves or mittens

wool hat

Layer 6: insulated hooded parka

fur-lined boots

insulated mittens 
13. On the next school day, come to school dressed for these changing temperatures. Arrange a class fashion show. Model your outfit for the class, explaining the types of fabrics you chose, why you chose them, and how the clothes will help you adjust to changing temperatures. If your outfit is particularly adapted to one kind of activity, explain how it functions for that activity.

14. Use catalogs and magazines to select outfits that would be appropriate for each of the activities listed in Step 1 , and that would also be comfortable under changing temperature conditions. Cut out one outfit you selected and use it to make a poster which illustrates its special qualities for temperature fluctuations.

\section{Questions}

1. What clothing did you bring to class on the first day? Why did you choose this clothing?

2. How did it feel sitting next to the sunny window or heater? How did your clothing affect this feeling?

3. How did it feel sitting in the shade with a fan blowing on you? How did your clothing affect this feeling?

4. For what reasons do people dress in particular ways?

5. What kinds of clothing and fabrics are good insulators? Good air conditioners?

6. What is the best way to dress for changing temperatures?

\section{Looking Back}

In a broad sense, all clothing selections are dressing for solar energy, for without the energy received from the sun the earth's temperature would be $-240^{\circ} \mathrm{C}$ ! No matter what activity you engage in., whether inside or out, the presence or absence of the sun's warming rays modifies the surrounding air temperature. Even the cooling effect of the wind is caused by the sun.

You've learned how to dress for the varying temperature conditions caused by solar energy both indoors and out. You've found that layering your clothing can provide comfort over a large range of temperature conditions. 


\section{Going Further}

Research the "wicking" effects of several types of fabrics. Hang different fabrics above containers of water so that the bottoms of the fabrics are in the water. Examine the fabrics after 30 or 40 minutes. What were the results?

Examine samples of different kinds of fabrics and fibers. Determine which ones would be good for insulating, for air conditioning, for waterproofing, and for layering.

Investigate the new fabrics which keep you dry during outdoor sports activities. Try recreational outfitters' catalogs or write to fabric manufacturers for information.

From what you've learned in this activity, develop a presentation on selecting clothing for living with solar energy. Select a group which would benefit from hearing this presentation. Possibilities might include elementary school children, fellow students, senior citizens, a ski club, or a scout troop.

Use your posters to make a bulletin board or display.

Write an article on clothing selection for solar energy for your school or local newspaper.

Put on a "Dressing for Solar Energy" fashion show for other classes, your parents, or a community group. 
 \\ Living with SolarEnergy: Clothing's Role
}

\section{Suggested Grade Level and Skill Area}

\author{
7-12 Home Economics \\ Clothing: Construction and Selection \\ Clothing: Textiles \\ Family Life: Lifestyle Changes and Effects on Families \\ Family Life: Health and Safety \\ Future Homemakers of America
}

\section{Skill Objectives}

Discussing appropriate clothing selection for living with solar energy and energy conservation

Selecting appropriate clothing for fluctuating temperature conditions

Constructing a poster illustrating proper clothing selection for various activities

\section{Content Objectives}

As energy use patterns change, more and more families will heat their homes with solar and other alternative forms of energy. Energy conservation will become more important and homes will be cooler in winter and warmer in summer.

The choice of clothing affects the rate of body heat loss.

Selecting appropriate clothing for living with solar energy, both indoors and out, includes layering fabrics for added warmth and "peeling" layers for cooling down.

\section{Background}

There are many reasons why people wear different kinds of clothing: adornment, self-expression, group identity, and modesty are only a few. But clothing is also important for protection and survival, and for adapting to the indoor temperature fluctuations which are becoming more common as we turn to energy conservation and alternative forms of energy.

The human body must maintain a constant body temperature of $37^{\circ} \mathrm{C}$. Heat loss from the body depends on the temperature of the body and the type of clothing worn. When body heat loss is greater than body heat production, we feel uncomfortably cold. When body heat loss is less than body heat production, we feel uncomfortably warm.

Balancing body heat loss with body heat production can be achieved in several ways. When we are cold, we can raise the body's rate of metabolism by taking in more food, especially carbohydrates, or by increasing muscular activity by such things as rubbing our hands or 
stamping our feet. We can also add more clothing to slow down the rate of heat loss from the body. The body itself will conserve heat by constricting blood vessels at the surface of the skin, reducing heat loss and routing the blood supply through the vital organs deep inside the body.

When we are warm, we want to increase the rate of heat loss from the body. The body normally loses heat in several ways: through conduction, in which the body makes contact with a cooler object, such as when we sit on the cold or damp ground or hold an ice cube in summer; through convection, in which heat is carried away from the body through the movement of air currents, either natural convection currents such as drafts or artificial ones such as fanning oneself; and through radiation, in which the body normally gives off heat waves in all directions. The body also increases heat loss through breathing and perspiring, processes in which heat is lost through the evaporation of body moisture.

Clothing can affect the rate of body heat 1oss. It can act as an insulator for the body by trapping additional layers of still air, or it can act as an air conditioner, allowing the body to cool itself by the evaporation of perspiration. Clothing can also act to keep the body dry, both from weather conditions and perspiration.

clothing fabric is a mixture of fiber and air. The air, not the fiber, is the insulator. When fibers are woven or knitted into fabric, additional air spaces are created. Dressing to keep warm means wearing open weaves and knits that trap a lot of air. Fishnet, thermal knits, and kinky-napped and hairy-textured fabrics are better than smooth, tightly knit fabrics such as gabardine, which have few air spaces. Down and the new insulating fabrics also trap air. By layering clothing we create additional dead air spaces between each layer, thus increasing the insulating effect.

In dressing to keep warm, we should try to avoid sweating. Water vapor in clothing reduces the insulating properties of the fabric. Damp clothing continually adds moisture to the skin. Heat is drawn from the body to evaporate this moisture, resulting in uncontrolled heat loss.

Dressing to keep cool involves selecting clothing that permits air circulation and the evaporation of moisture. Less clothing should be worn, with more openings at neck, wrists, waist, and ankles for air circulation. Light colored clothing will reflect heat, keeping the body cooler.

For keeping cool during warm weather or for keeping dry during outdoor sports activities, it is important to wear fabrics that "breathe". These fabrics allow hot, moist air to pass through the fabric and evaporate from the outer surface. Cotton and wool are especially good fabrics for this, while synthetics are not. "Breathing" takes place through the air spaces between fibers. "Wicking" occurs when the moisture actually moves through the fiber to the surface of the fabric. New synthetic fibers, such as polypropylene, have recently been developed to wick moisture away; these fibers produce fabrics especially useful for winter sports. 


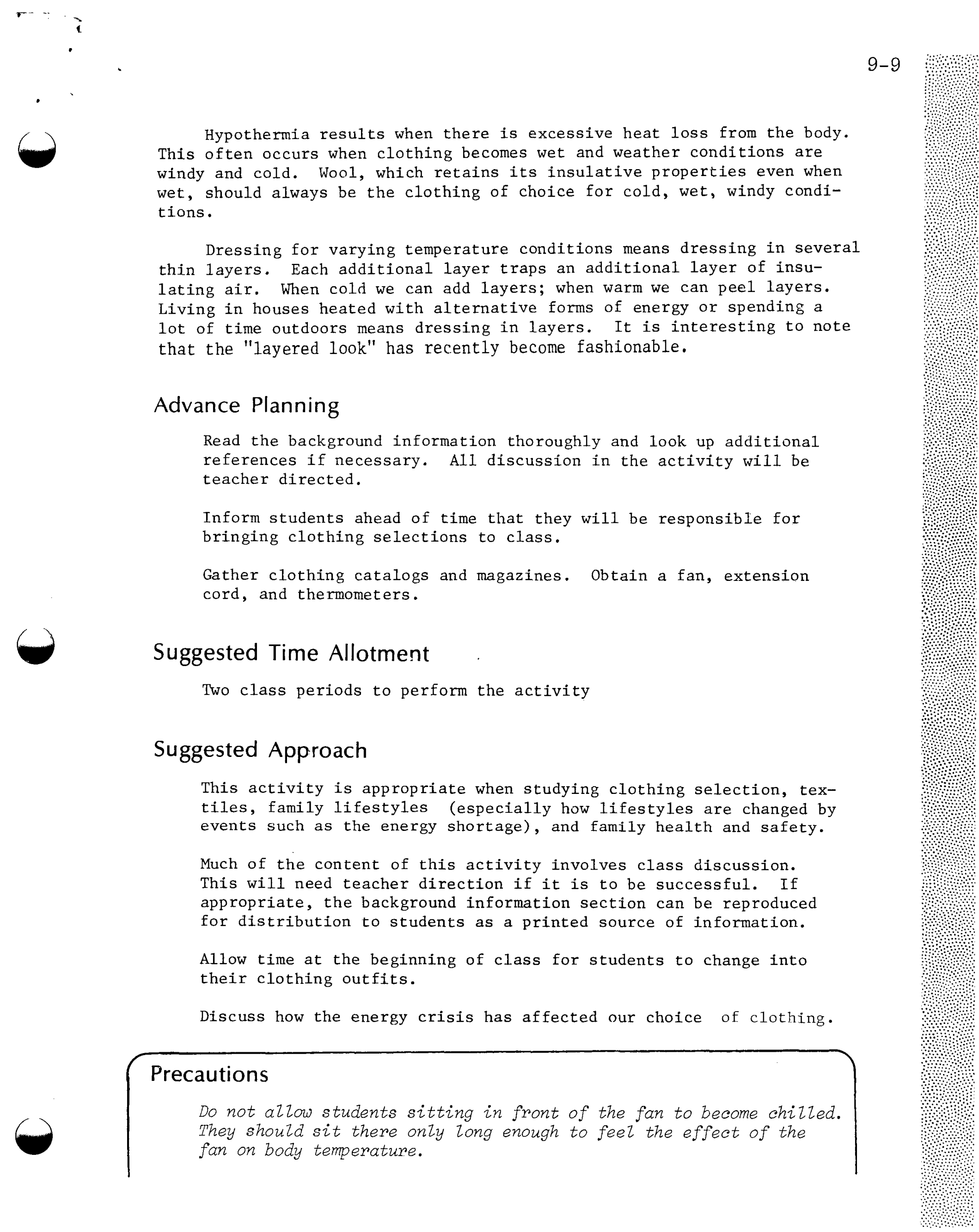


Students may have difficulty getting clothing for the activity. Possible solutions are to have the teacher collect extra clothing, to have students select roles which utilize clothing they already own (for example, a skier could select a role requiring winter clothing), or to allow extra time for students to locate clothing.

\section{Points for Discussion}

What activities requiring specific clothing are affected by the sun? How are they affected?

How does solar energy affect body heat?

\section{Typical Results}

Students will be more aware of the effect their clothing has on body heat. They will be able to select appropriate clothing for various temperatures, environments, activities, and occasions.

\section{Evaluation}

Observe students' participation in the discussion and activities.

Evaluate students' posters to determine how well they selected an appropriate outfit for changing temperatures.

Ask students to list ways they can dress appropriately for solar energy and energy conservation.

\section{References}

Energize Your Career Wardrobe, Cooperative Extension. (Mailing Room, 7 Research Park, Cornell University, Ithaca, NY 14853, write for price.)

How to Keep Warm and Keep Your Fashion Cool, Jean McLean. (N.Y. State College of Human Ecology, Cooperative Extension, Ithaca, NY 14853, write for price.)

"Clothes for the Cold", Annie Proulx. (Country Journal, Country Journal Publishing Co., Inc., 205 Main Street, Brattleboro, VT 05301, December, 1980.)

"Teaching Resource Conservation in Home Economics", Hazel Taylor Spitze.

(Illinois Teacher of Home Economics, University of Illinois at Urbana-Champaign, Division of Home Economics Education, 351 Education Building, Urbana, IL 61801, Vo1. 21, No. 3, pp. 106-112, Jan./Feb. 1978.)

"Winter Warmth--Wearing It Thin", Wayne Merry. (The Backpacker, c/o Wm. Kemsley, 65 Adams Street, Bedford Hil1s, NY 10507, Vo1. 9, Issue 2, p. 22, Feb./March, 1981.) 


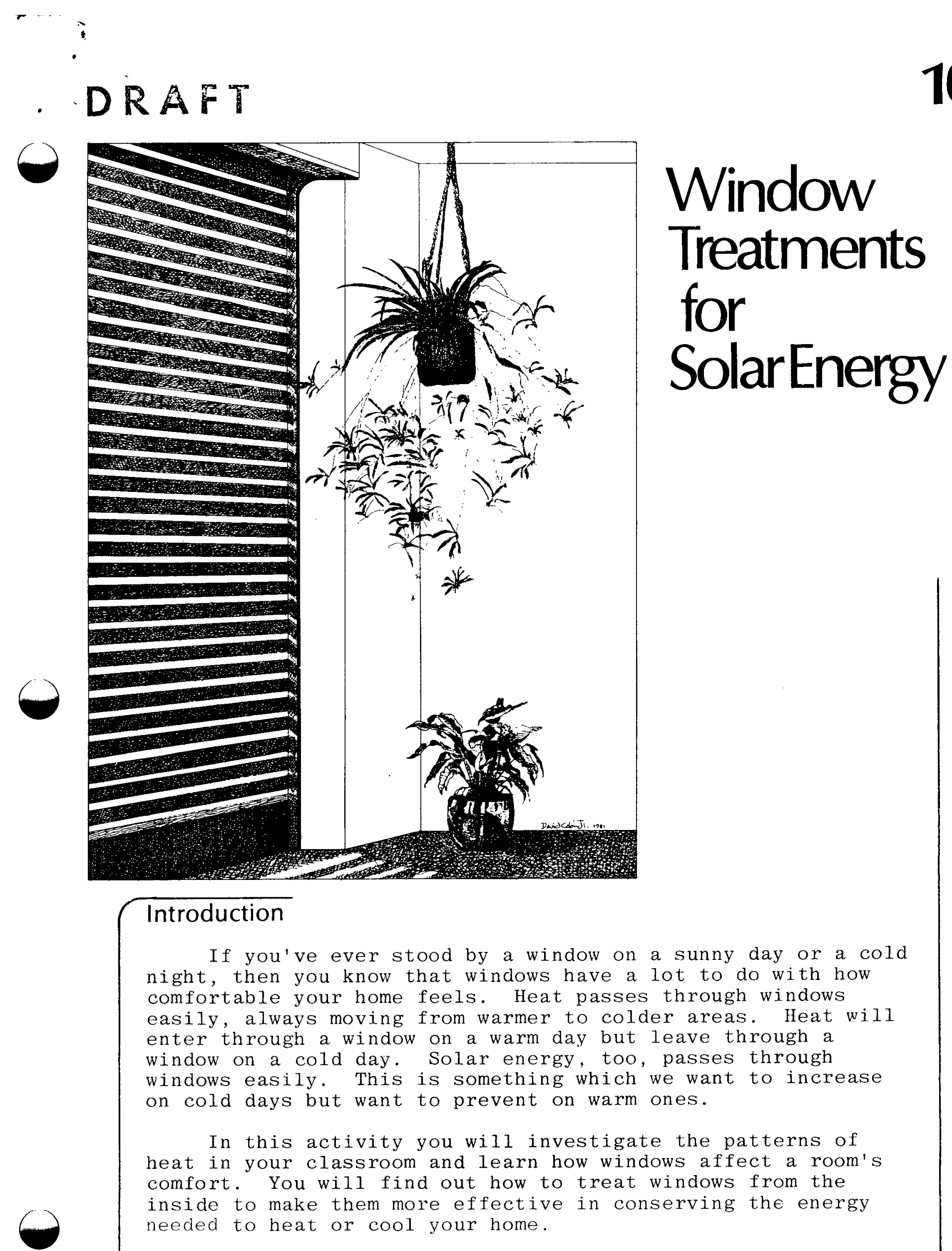




\section{Objectives}

to

At the completion of this activity, you should be able

o determine the areas in a room which are warmest and coldest and explain why,

- determine the places where air infiltration occurs in a room and explain why,

o Iist the functions of windows,

o list the kinds of energy-saving window treatments and explain the need for them,

o research energy-saving window treatments in current books and magazines, and

o recommend energy-saving window treatments for various situations, listing their advantages and disadvantages.

\section{Skills and Knowledge You Need}

Reading a thermometer

Recording and graphing data

Researching information in current books and magazines

Taking notes

\section{Materials and Equipment}

Iamp with uncovered light bulb

six Celsius thermometers

string and masking tape

colored pencils

a sheet of plastic, paper, or tissue $(15 \mathrm{~cm} \times 15 \mathrm{~cm})$

a pencil

a fan

current books, pamphlets, and magazines containing window treatment information

index cards 


\section{Procedure}

\section{Part 1. Collecting Data}

1. Turn on the lamp. Cup your hands near the bulio. Answer Question 1 by describing what you feel.

Caution: Do not touch the burb. It may be very hot.

If possible, stand next to a sunny window. Add to Question 1 by describing what you feel now.

2. Suspend six thermometers around the classroom. Three thermometers should be placed 1 meter from the ceiling and three 1 meter above the floor. Make sure at least one thermometer is in front of a window. Record the position of each thermometer in Data Table 1 on Worksheet A.

For example, Thermometer 2 's position might be "on the back wall, 1 meter above the floor". Also record the outside weather conditions; for example, a partly cloudy day with a temperature of $5^{\circ} \mathrm{C}$.

3. Divide the class into six groups. Each group should select a thermometer to read. Every minute for 20 minutes read the temperature of your group's thermometer. Record the thermometer readings of all the groups in Data Table 2 .

4. Graph the temperature data from each thermometer on the graph provided (Worksheet B). Use different colored pencils for each set of data. Be sure to make a key for the graph.

5. Take a sheet of paper, plastic, or tissue and tape one edge to a pencil. Hold this "infiltration meter" in various positions around the edges of several closed windows, either in the classroom or at home. Answer Question 2 by describing your results.

6. Hold your "infiltration meter" $15 \mathrm{~cm}$ in front of the fan. Then hold it $15 \mathrm{~cm}$ behind the fan. Use the results from these two activities to answer Questions Diagram 1 3 and 4 . 
Part 2. Researching Window Coverings

7. As a class, make a list of the functions of windows. List as many reasons as you can for why we have windows in our homes.

8. Define radiation, conduction, and convection.

9. Discuss how and when heat is lost or gained through a window. Be sure to include in your discussion such factors as

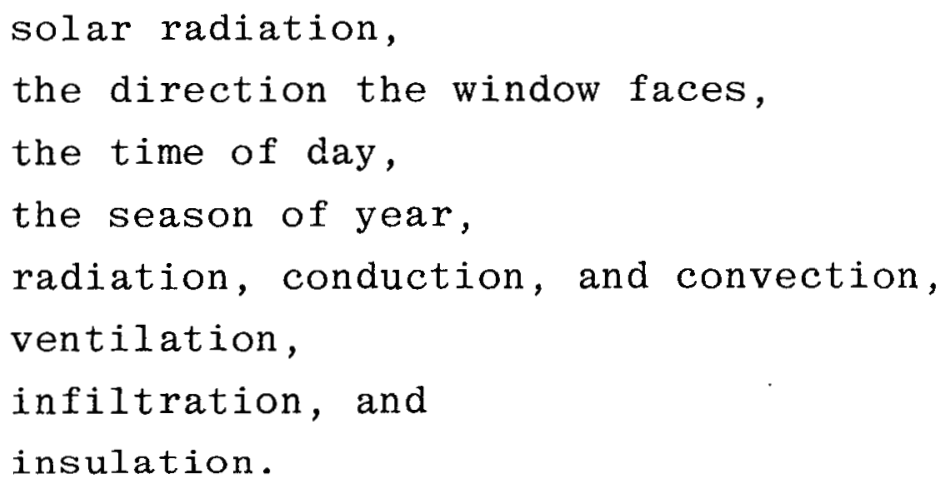

10. Using the Reading Activity provided, as well as current books, pamphlets, and magazines, research the kinds of window coverings which can be used to admit more sunlight when needed to help heat the house, to admit less sunlight when needed to help cool the house, and to reduce heat loss from windows at night or during cloudy periods. Use index cards to list and take notes on the kinds of window treatments available for solar energy and energy conservation.

11. Read the three case studies provided on Worksheet $\mathrm{C}$.

12. Use your notes and the Reading Activity to recommend a window treatment for each case study situation. Explain why you chose each window treatment.

13. As a class, discuss the advantages and disadvantages of the window treatments recommended for each activity.

\section{Questions}

1. What did you feel when you placed your hands near the light bulb? When you stood next to the sunny window?

2. What happened when you held the "infiltration meter" at different positions around windows?

3. What happened when you held the "infiltration meter" in front of the fan? In back of the fan? 
4. What caused the results you obtained when holding the "infiltration meter" around windows?

5. Describe the results you obtained from graphing room temperatures. Where was the room warmest? Coldest?

6. How did the temperatures in front of the window compare with those in other parts of the room? Why?

7. What are the functions of windows?

8. What is window heat loss? How and when does it occur?

9. What is window heat gain? How and when does it occur?

10. List as many energy-saving window treatments as you can.

11. What window treatment did you recommend for each case study? Why?

12. What are the advantages of the window treatment you recommended for each activity? The disadvantages?

\section{Looking Back}

You have learned how heat is lost or gained through windows. As energy becomes more expensive, controlling this heat exchange will become more important. One way to conserve energy is through window treatments. During cold weather, these treatments can be opened to allow sunlight in or closed to keep heat in. During warm weather, these treatments can serve an opposite function. They can be closed to keep sunlight and heat out or opened to allow cooling breezes in. When these window treatments are sealed at the edges to reduce air infiltration, they are even more effective.

Each window is unique. When selecting a window treatment, you should choose the kind of treatment which best meets your needs and tastes and best solves the window's problems. There are many kinds to choose from: draperies, shades, shutters, panels, and interior storm windows. Each varies in cost, attractiveness, effectiveness, and ease of use. The choice is up to you.

\section{Going Further}

Investigate the windows in your own home. What kinds of window treatments are being used now? What kinds of 
treatments would you recommend to increase energy savings? Design, construct, and install a new treatment in your own home.

Plan a window treatment to save energy in your classroom. As a class or FHA/HERO project, raise money to construct and install this treatment.

Investigate commercial window treatments which are designed to save energy. Compare their costs, R-values, effectiveness in reducing heat loss or heat gain, ease of installation and use, attractiveness, and durability.

Use your research to write a pamphlet or news article on window treatments for solar energy and energy conservation. Duplicate the pamphlet for distribution to community groups or submit the news article to school and community newspapers. 


\section{Changes in Room Temperatures}

Data Table 1

Outside Weather Conditions:

Thermometer Positions

\begin{tabular}{|c|l|}
\hline$\frac{\text { Thermometer }}{1}$ & Position \\
\hline 2 & \\
\hline 3 & \\
\hline 4 & \\
\hline 5 & \\
\hline 6 & \\
\hline
\end{tabular}

\section{Data Table 2}

\section{Room Temperatures over Time \\ Temperature $\left({ }^{\circ} \mathrm{C}\right)$}

\begin{tabular}{|c|c|c|c|c|c|c|}
\hline $\begin{array}{c}\text { Time } \\
\text { minutes) }\end{array}$ & $\begin{array}{c}\text { Ther- } \\
\text { mometer } \\
1\end{array}$ & $\begin{array}{c}\text { Ther- } \\
\text { mometer } \\
2\end{array}$ & $\begin{array}{c}\text { Ther- } \\
\text { mometer } \\
3\end{array}$ & $\begin{array}{c}\text { Ther- } \\
\text { mometer } \\
4\end{array}$ & $\begin{array}{c}\text { Ther- } \\
\text { mometer } \\
5\end{array}$ & $\begin{array}{c}\text { Ther- } \\
\text { mometer } \\
6\end{array}$ \\
\hline 1 & & & & & & \\
\hline 2 & & & & & & \\
\hline 3 & & & & & & \\
\hline 4 & & & & & & \\
\hline 5 & & & & & & \\
\hline 6 & & & & & & \\
\hline 7 & & & & & & \\
\hline 8 & & & & & & \\
\hline 9 & & & & & & \\
\hline 10 & & & & & & \\
\hline 11 & & & & & & \\
\hline 12 & & & & & & \\
\hline 13 & & & & & & \\
\hline 14 & & & & & & \\
\hline 15 & & & & & & \\
\hline 16 & & & & & & \\
\hline 17 & & & & & & \\
\hline 18 & & & & & & \\
\hline 19 & & & & & & \\
\hline 20 & & & & & & \\
\hline
\end{tabular}


m 10-8

Worksheet B

Changes in Room Temperatures over Time

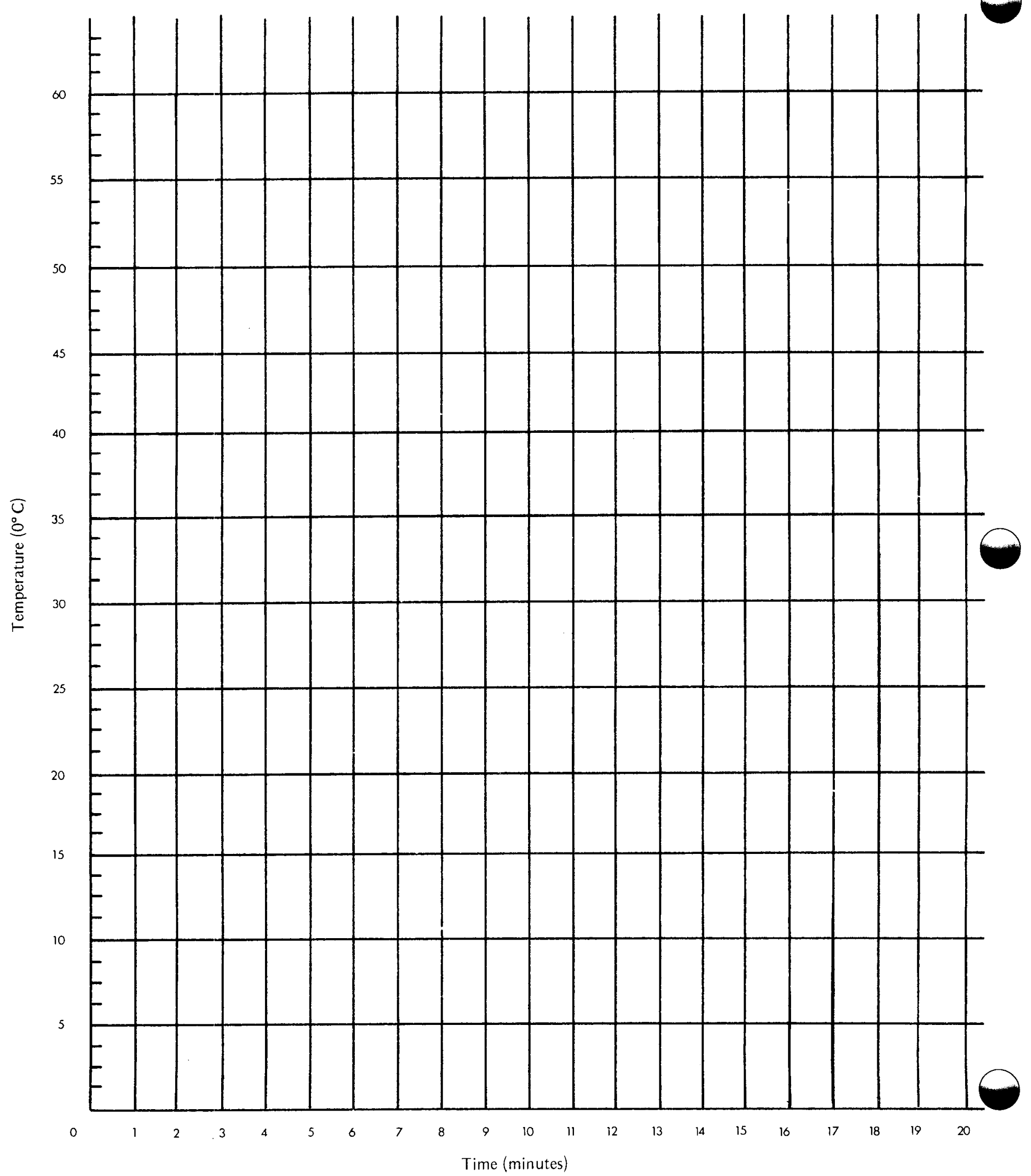




\section{Worksheet C}

\section{Case Study 1}

For the winter months, Sue and John will be living in an apartment in New England. The apartment's living room has only one window area, a set of south-facing patio doors which lead to a small balcony. The doors are not tightly fitted and air leaks in around the edges. For now, Sue and John have a light-weight pair of draw draperies covering the window area, but they want the room to remain comfortable during the coldest winter days. Because they are on a limited budget, this newlymarried couple does not have much money to spend on window coverings. What window treatment would you recommend for this couple's living room?

\section{Case Study 2}

Jim has just moved into a college dorm in a southwestern town. His corner room has two windows, one facing south and the other west. Although the room is air conditioned, the heat from the sunlight entering the windows makes the room very uncomfortable by late afternoon. Jim would like to select a covering for his windows that will be attractive, but will also help to keep the room cool. What window treatment do you recommend for Jim's dormitory room?

\section{Case Study 3}

Karen and David have lived in their story-anda-half Cape Cod home for over twenty years. Since their children are now grown and have recently moved away from home, the two bedrooms and bath on the second floor are unused during the winter months.

Winters are cold in the northern plains states where David and Karen live, and they are trying to reduce their home heating bills. They have closed off the second floor. Even though the upstairs windows have storm windows and weatherstripping, a large amount of heat is still being lost directly through the glass. David wants to find a type of window treatment which will reduce this heat loss. What kind of treatment do you recommend? 


\author{
Worksheet D \\ Reading Activity \\ Interior Window Treatments
}

Draperies

One common window treatment is the use of draperies. When drawn during cold weather or at night, draperies can reduce heat loss from a warm room. They can also be opened when the sun is striking the windows to take advantage of its heating effect. During warm weather draperies can be closed to help keep the room cool.

Conventional draperies, though, will not prevent much heat exchange through a window. The reason i.s simple. Draperies stand away from the window, leaving a space between drapery and window. In winter, for example, the air in this space is cooled by the cold window, drops toward the floor, and is replaced by warm air at the top. (See Diagram 2.) This continuous action creates a convection current, reducing room temperature near the window. In fact, a conventional drapery reduces heat loss from a room by only $10 \%$. $\underline{\text { Diagram } 2}$ Conventional Draperies

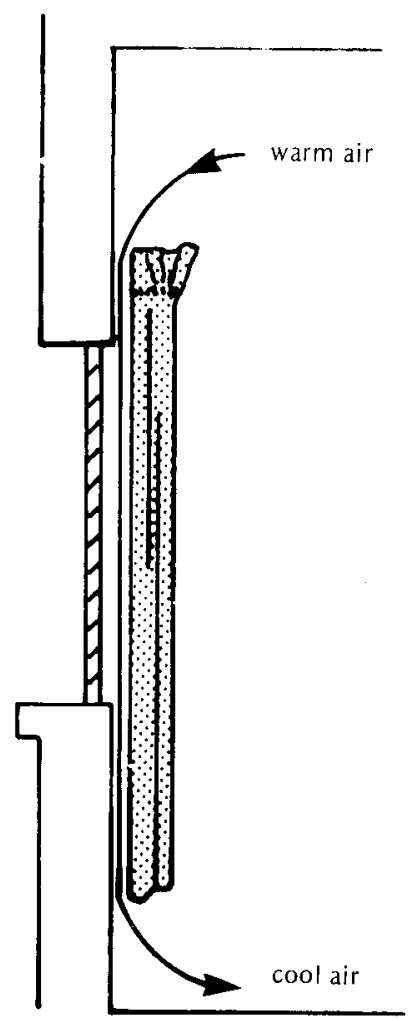

To prevent this convection current from being set up, draperies

Diagram 3 Insulating Draperies

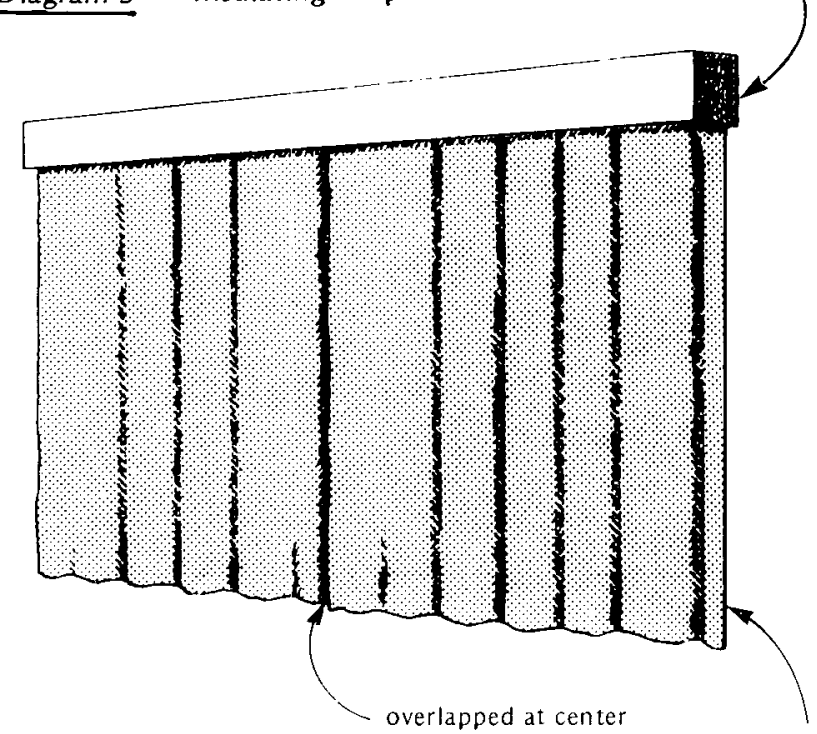
should be fitted at the top or bottom. Most simply, this can be done by letting the draperies fall onto the windowsill or floor. For maximum effectiveness, the draperies should also be fitted at the top (with a cornice or by placing the drapery against the ceiling), sealed at both sides, and overlapped at the center. (See Diagram 3.) This kind of drapery can reduce heat loss as much as 25\%. Thermal draperies, with two layers separated by an air space, will reduce this heat loss even further. 
Diagram 4 Roller Shades, Summer Use

Roller Shades

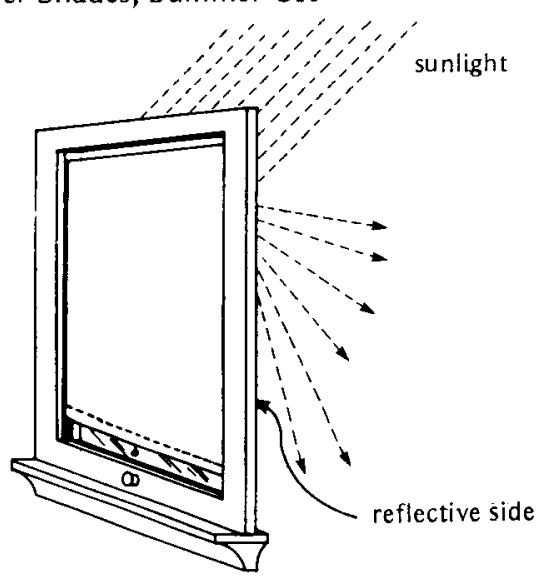

Diagram 5 Roller Shades, Winter Use

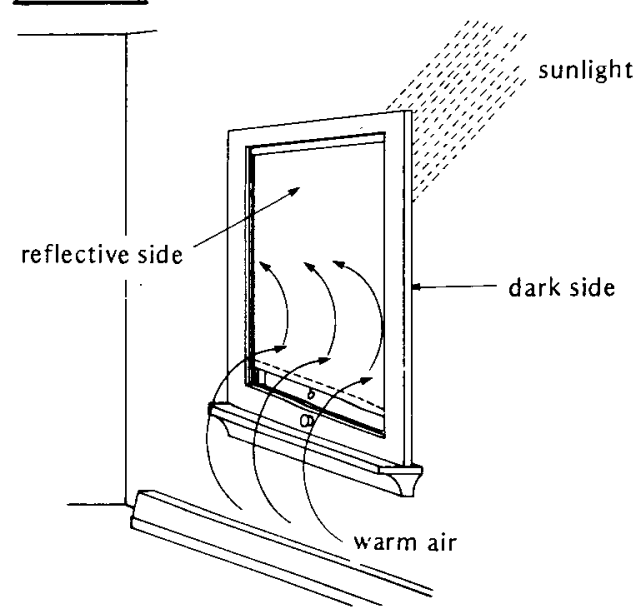

This most common form of window shade is an effective energy saver when properly installed and used. The shade blocks air flow and forms an insulating layer of air between the shade and the window. A roller shade reduces heat exchange by as much as $28 \%$. By adding side tracks, tape, or closures to seal the shade to the window frame, heat exchange can be reduced by $45 \%$. If the shade is made of or covered by a reflective material, this heat exchange can be reduced even further.

For greatest efficiency, a shade should be reversible, reflective on one side and dark-colored on the other side. The reflective material should always face the warmer side - outward in summer and inward in winter -- while the dark-colored material should face out in winter to act as a solar collector (absorbing sunlight and converting it to heat). (See Diagrams 4 and 5.)

In summer, shades should be lowered on sunlit windows to reduce solar heating. In winter, shades on the south side of a house should be raised during the day to increase solar heating, then lowered at night to reduce heat loss.

Diagram 6 Insulating Interior Shutters

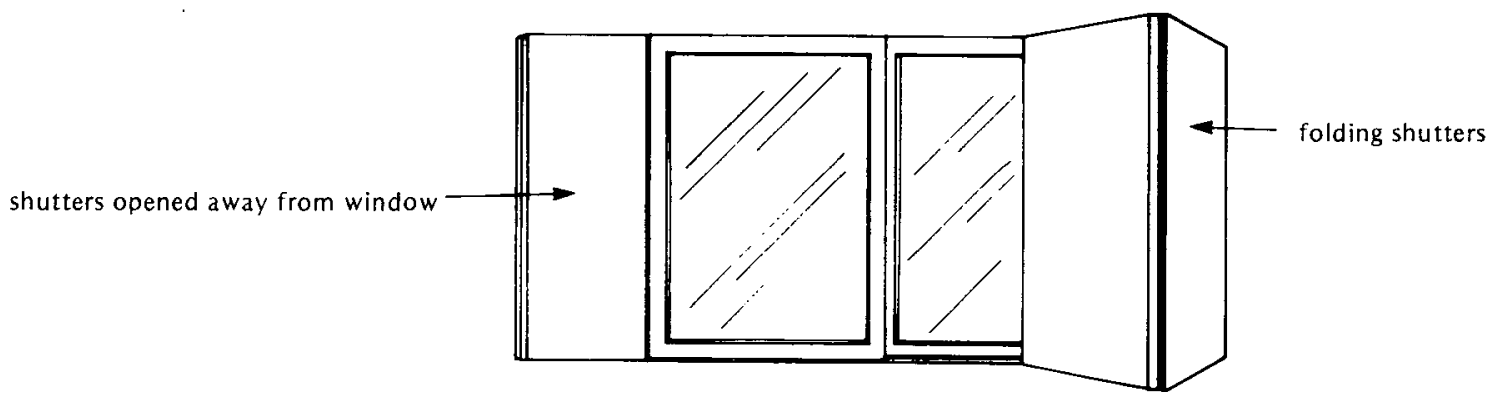

Insulating Shutters

Insulating shutters are a very expensive form of window treatment, but may reduce heat exchange by as much as $80 \%$. They consist primarily of insulation, plywood or wood panels, a vapor barrier, and a decorative covering. Insulating shutters should fit tightly to the frame on all sides to prevent convection currents and to trap an insulating layer of air between the shutter and the window. 
Insulating Panels

Insulating panels, or pop-in shutters, are normally made of rigid insulation. They are inexpensive, whether you buy a kit or make your own. These panels can be popped into the windows as needed, but require storage space when not in use. They can be covered with decorative fabric to make them more attractive. Insulating panels are made so that their edges seal tightly against the window frame. Seals can be made of magnetic tape or velcro strips. This type of window treatment can reduce heat exchange by as much as $85 \%$.

\section{Interior Plastic Storm Windows}

A simple and inexpensive way to reduce heat exchange is the interior storm window. It can be made of polyethelene (like clear garbage bags) or rigid plastic. This window treatment can remain in place all winter and will reduce heat loss by as much as $50 \%$. Flexible plastic can be easily and quickly taped to the window frames. Rigid plastic storm windows must be mounted in the same nanner as insulating panels.
Diagram 7 Insulating Panels

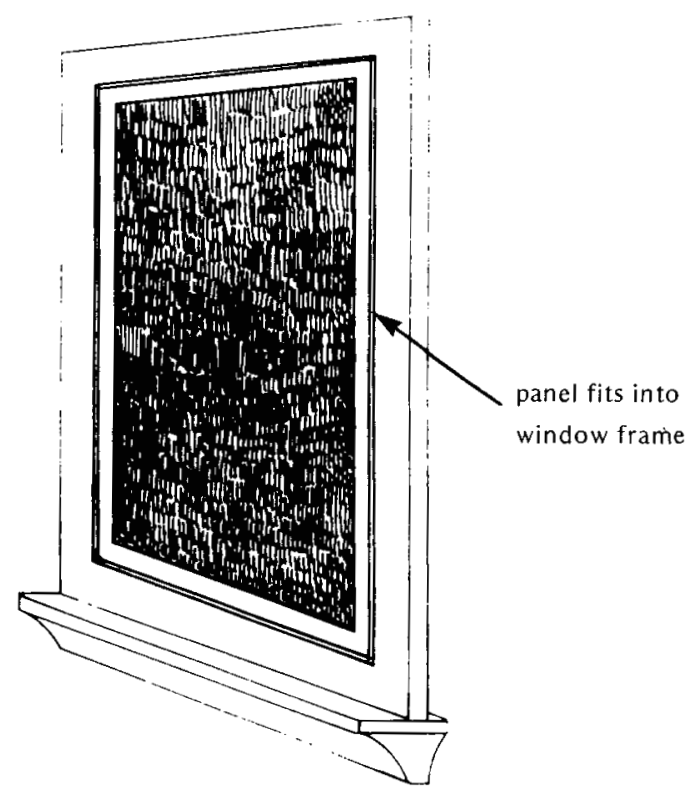

Diagram 8 Plastic Interior Storm Windows

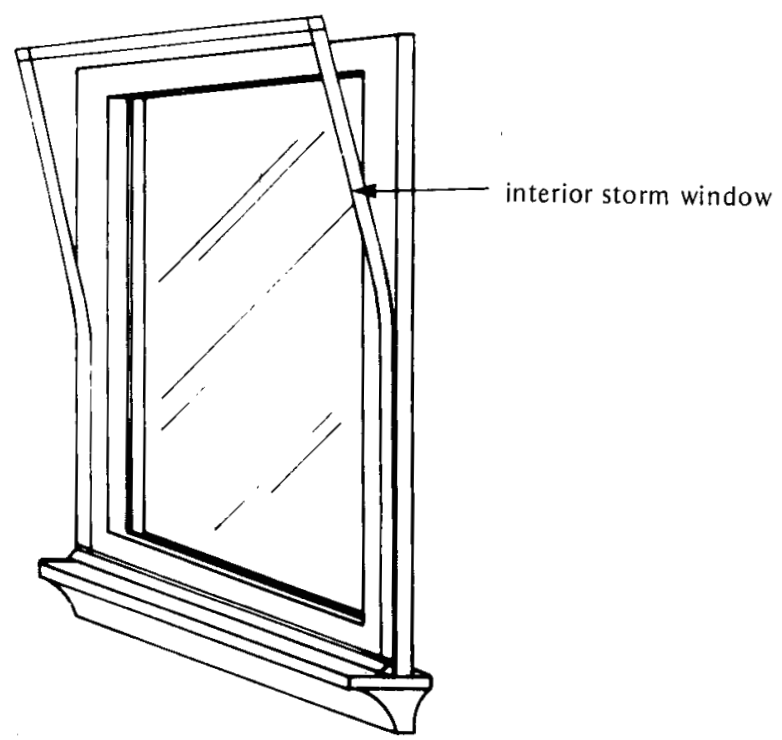




\title{
Teacher Information
}

Window Treatments for SolarEnergy

\section{Suggested Grade Level and Skill Area}

\author{
9-12 Home Economics \\ Housing and Furnishings \\ Consumer Education \\ Clothing Construction: Nonwearable Projects \\ Future Homemakers of America
}

\section{Skill Objectives}

Recording, graphing, and interpreting data

Building and using an infiltration meter

Researching and taking notes

Analyzing window needs and recommending window treatments to meet these needs

Determining advantages and disadvantages of particular window treatments

\section{Content Objectives}

Windows transmit solar energy. They can be used during cold weather to provide heat if solar energy penetrates them, but during warm weather the penetration of solar energy should be eliminated in order to prevent excessive heat gain.

Windows also transmit heat energy. During cold weather, heat should be prevented from escaping through them, but, in warm weather, heat should be prevented from entering through them.

Window treatments that reduce heat loss or heat gain and also reduce air infiltration can save energy. These treatments vary in cost, effectiveness, durability, ease of installation and use, and attractiveness.

Energy-saving window treatments include draperies, shades, shutters, panels, and interior storm windows. Different windows require different treatinents, depending on their size, shape, orientation, and placement. The factors of personal taste and expense also determine the choice of window treatments.

Every window treatment has advantages and disadvantages. 


\section{Background}

Windows provide light, ventilation, and a view of the area outside. They also transmit solar and heat energy. As the price of energy increases, we will be forced to seek methods of maximizing solar gain and minimizing heat loss during cold weather, and of minimizing solar and heat gain in warm weather, in order to conserve the energy needed to heat and cool our homes.

Windows on the south side are of great value as heat collectors, but only on cold, sunny days. At night they lose heat, and during warm weather they can cause a room to overheat. Windows facing in other directions experience a net heat loss on cold days and a net heat gain when outside temperatures are warmer than inside temperatures. Windows can transmit 20 times more heat than an insulated wall of the same size.

Heat is transmitted through windows in several ways. Radiation occurs when heat is transferred from one object to another through space. On cold nights, heat is radiated from your body to the cold window. Conduction occurs when heat passes through an object. Glass is a good heat conductor and transmits heat from the warmer air touching it. Convection occurs when heat is transferred by the movement of air. Warm air touching cold window glass, for example, conducts heat to the glass, becomes cooler and more dense, and drops toward the floor. Warm air replaces it from above, and a current is set up. A convection current can transfer substantial amounts of heat. Infiltration occurs when air leaks through windows and doors around the glass and frame. Infiltration produces drafts and can be eliminated by caulking, weatherstripping, and air-tight insulation.

Insulating window treatments will reduce unwanted heat exchange. As long as they can be removed or opened on the south side to permit solar gain when needed, they are an effective means of reducing energy costs and conserving fossil fuels.

\section{Advance Planning}

Duplicate a11 necessary worksheets.

Obtain copies of magazines, pamphlets, and books containing information on window treatments. Arrange with the school librarian to use magazines and The Reader's Guide to Periodical Literature. Check the references listed at the end of this activity and obtain materials from them. Rodale's New Shelter, Hudson Home Magazine, Solar Age, Blair and Ketchum's Country Journal, your cooperative extension agent, and state energy office are excellent sources of articles and information.

Obtain inexpensive thermometers, a fan, and a lamp.

If desired, suspend the thermometers in the classroom in advance of the activity.

Prepare a lesson on heat loss and gain through windows and prepare to lead discussion in step 9. 


\section{Suggested Time Allotment}

1 period to collect data

1 period to graph and analyze data

2 to 3 periods to conduct research

1 period to complete case studies

1 period to summarize and discuss

\section{Suggested Approach}

The discussion in this activity will need much teacher direction. Prepare for leading class discussion.

With junior high students you may want to perform on1y the "Collecting Data" section of this activity, then discuss window treatments in general as means of controlling solar gain and heat exchange.

If possible, collect temperature data in front of a window which receives direct sunlight during the class period. Conducting the activity on a partly cloudy day will provide the most dramatic results. Repeating the activity on sunny or cloudy days or in different seasons will also emphasize the dual role of windows in heat loss and solar gain. Extrapolate results to other weather conditions and times of day.

Seek out resource people in your community who are knowledgeable about window treatments. These may include homemakers, store managers, building suppliers, cooperative extension agents, and interior decorators. Ask them to share their information with class members.

\section{Points for Discussion}

For maximum effectiveness in heating, how can window treatments be used to manage solar gain?

What are some exterior window treatments which would conserve energy?

What are the factors which determine the treatment for any window?

What kinds of treatments could be prepared for classroom windows? For windows in your home? 


\section{Typical Results}

The graphs should show that the classroom will be warmest at the window when sunlight is penetrating it; will be coolest at the window on cloudy, cold days; and will be warmer as height above the floor increases.

\section{Evaluation}

Observe students' participation in class discussion.

Check data tables and graphs for completeness and accuracy.

Check notes for completeness.

Ask students to list kinds of insulating window treatments and to explain the need for them.

Give students a new case study and ask them to recommend a window treatment, listing the advantages and disadvantages of their choice.

\section{References}

Al1 Through the House, Thomas Blandy and Denis Lamoureux.

(McGraw-Hill, 1221 Avenue of the Americas, New York, NY 10020, $1980, \$ 7.95 /$ paper.)

Energy Savers Catalog.

(Publications International, Ltd., 3841 West Oakton Street, Skokie, IL $60076,1977, \$ 6.95 /$ paper.)

Energy Saving Window Treatments, Regina Rector. (Cooperative Extension Programs, Cornell University, Martha Van Rensselaer Hall, Ithaca, NY 14853, write for price.)

547 Easy Ways to Save Energy in Your Home, Roger Albright. (Garden Way Associates, Charlotte, VT 05445, 1978, \$4.95/paper.)

Passive Solar Energy Book, Edward Mazria.

(Rodale Press, 33 East Minor Street, Emmaus, PA 18049, 1979. $\$ 12.95 /$ paper.)

Window Design Strategies to Conserve Energy: NBS Building Science Series 104, Robert S. Hastings.

(Superintendent of Documents, U.S. Government Printing Office, Washington, DC 20234, 1977, write for price.)

"Insulating Shutters and Shades", Larry Gay.

(Blair and Ketchum's Country Journal, 205 Main Street, Brattleboro, VT 05301, January, 1981, pp. 60-65.)

"The Least Expensive Solution", Wayne Shick. (Rodale's New Shelter, 33 East Minor Street, Emmaus, PA 18049, october, 1980 , np. 34-35.) 
"A Mini-Catalog of Products", Roger Rawlings. (Rodale's New Shelter, 33 East Minor Street, Emmaus, PA 18049, October, 1980, pp. 36-39.)

"The New Look in Window Blinds". (Hudson Home Magazine, Hudson Publishing Co., 289 South San Antonio Road, Los Altos, CA 94022, November, 1980, pp. 98-101.)

"New Wrinkles in Window Insulation", William Langdon. (Solar Age, Solar Vision, Inc., Church Hill, Harrisville, NH 03450, August, 1979, pp. 20-23.)

"A Shade and A Shutter: Insulating Window Covers You Can Make". (Solar Age, Solar Vision, Inc., Church Hill, Harrisville, NH 03450, August, 1979, pp. 24-30.)

"A Shade You Pull Down".

(Rodale's New Shelter, 33 East Minor Street, Emmaus, PA 18049, October, 1980, p. 30.)

"A Shutter You Pop In", Roger Rawlings.

(Rodale's New Shelter, 33 East Minor Street, Emmaus, PA 18049, October, 1980, pp. 31-33.)

"The Trouble with Windows (And What to Do)", Michael LaFavore. (Rodale's New Shelter, 33 East Minor Street, Emmaus, PA 18049, October, 1980, pp. 27-29.) 


\section{$10-18$}

$\ominus$ 

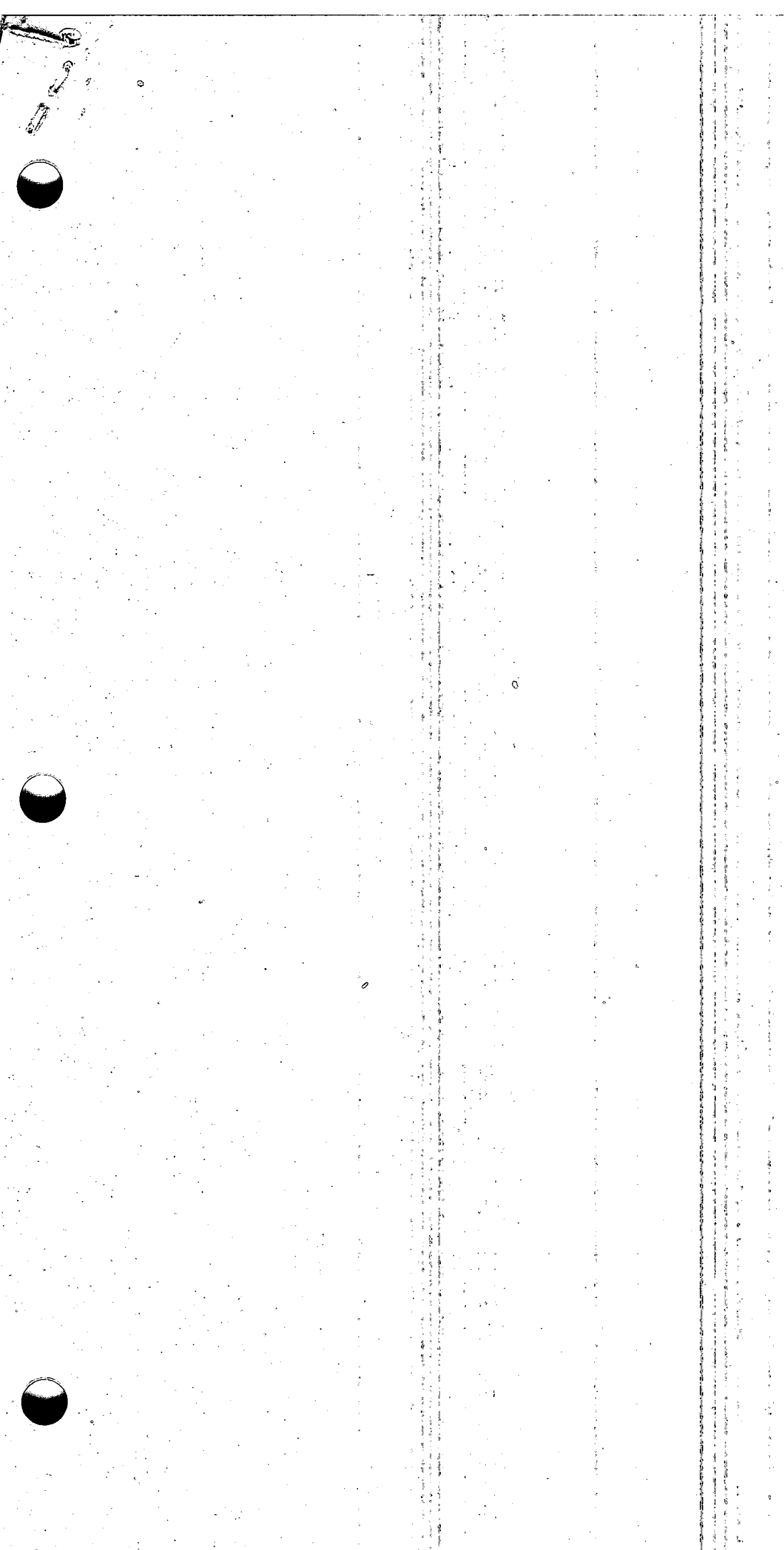


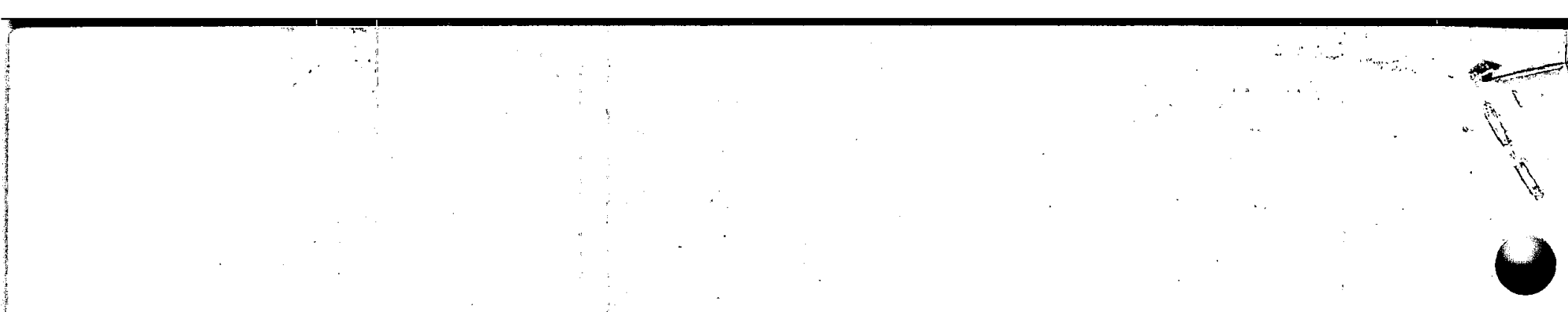

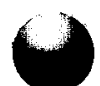

